\title{
Runehamar Tunnel Fire Tests
}

Haukur Ingason Anders Lönnermark Ying Zhen Li

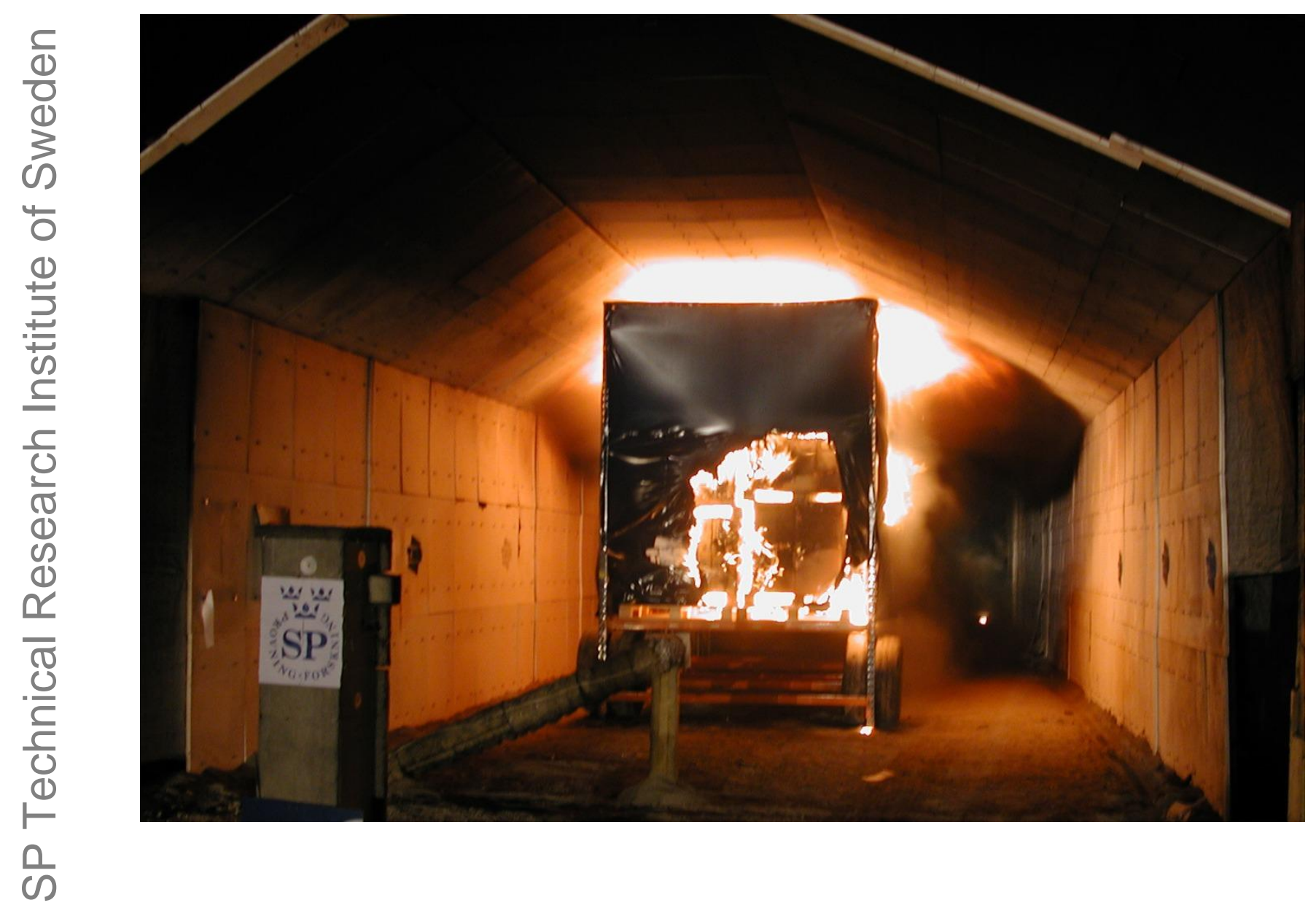




\section{Runehamar Tunnel Fire Tests}

Haukur Ingason

Anders Lönnermark

Ying Zhen Li 


\begin{abstract}
Five large-scale fire tests, including one pool fire test and four HGV mock-up fire tests, were carried out in the Runehamar tunnel in Norway in year 2003. Detailed information about these tests is presented. In addition, previous work on these tests and new analyses are presented in this report. Heat release rate, fire growth rate, gas temperature, flame length, radiation, fire spread, gas production, ventilation, backside wall temperature, pulsation, backlayering and visibility are investigated thoroughly. Simple theoretical models are developed to estimate and predict these parameters. The correlations developed can be used by engineers working on fire safety in tunnels.
\end{abstract}

Key words: large-scale, tunnel fire, heat release rate, gas temperature, heat flux

SP Sveriges Tekniska Forskningsinstitut

SP Technical Research Institute of Sweden

SP Report 2011:55

ISBN 978-91-86622-85-5

ISSN 0284-5172

Borås 2011 


\section{Nomenclature}

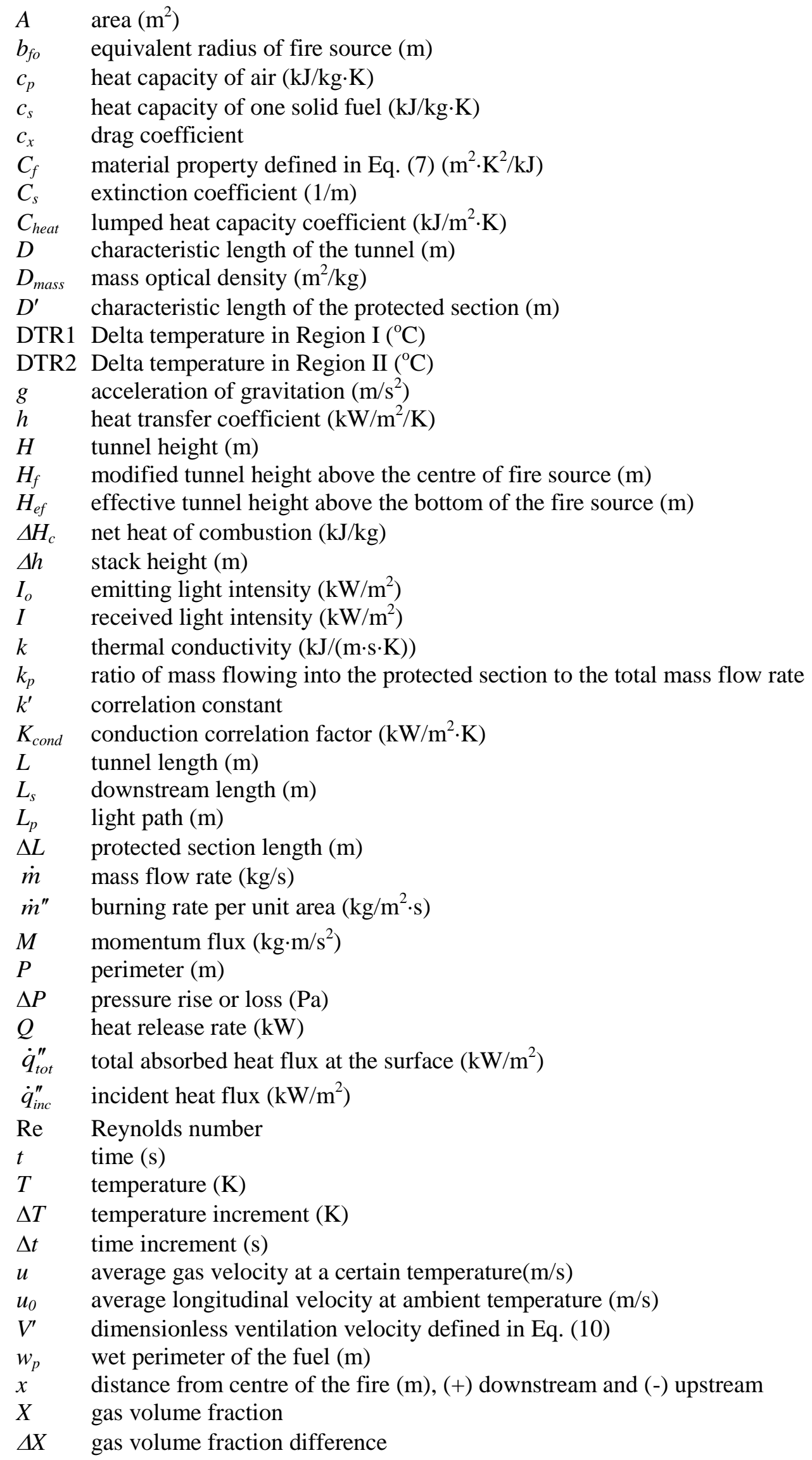


$V_{i s} \quad$ visibility (m)

Greek symbols

$\rho$ density $\left(\mathrm{kg} / \mathrm{m}^{3}\right)$

$\lambda \quad$ friction coefficient of the tunnel

$\lambda^{\prime} \quad$ friction coefficient of the protected section

$\xi \quad$ local friction coefficient

$\Delta_{o} \quad$ wall roughness (m)

$\theta \quad$ slope (\%)

$\varepsilon \quad$ emissivity

$\sigma \quad$ Stefan-Boltzmann constant $\left(\mathrm{kW} / \mathrm{m}^{2} \cdot \mathrm{K}^{4}\right)$

Sup and subscripts

0 ambient condition

avg average

$c \quad$ convective heat or ceiling

$\mathrm{CO}_{2}$ carbon dioxide

e exit

$f \quad$ fuel or flame

fan mobile fan

fr friction loss

$g$ gas

HGV Heavy Goods Vehicle

$i \quad$ ith time step or ith material

ig ignition

in inlet

$j \quad$ jth section

$k \quad$ kth species

$m$ mean

max maximum

$o \quad$ outside

$o b \quad$ obstruction

$\mathrm{O}_{2} \quad$ oxygen

$p \quad$ protected section

$P T$ plate thermometer

$s \quad$ solid fuel

$t \quad$ tunnel

$T \quad$ thermal stack

$w \quad$ wall surface or wind

$\infty \quad$ surrounding the surface

$\eta_{t} \quad$ efficiency of the fan inside the tunnel

$\eta_{o} \quad$ efficiency of the fan outside the tunnel 


\section{Contents}

$\begin{array}{ll}\text { Abstract } & 3\end{array}$

$\begin{array}{lr}\text { Nomenclature } & 4\end{array}$

1 Introduction $\quad 10$

$2 \quad$ Experimental procedure $\quad 11$

$\begin{array}{lll}2.1 & \text { The mobile fan units } & 11\end{array}$

2.2 The HGV trailer mock-up 11

$\begin{array}{lll}2.3 & \text { The fire protection system } & 13\end{array}$

$2.4 \quad$ Flow obstructions 14

$\begin{array}{lll}2.5 & \text { Measurements } & 15\end{array}$

$\begin{array}{lll}2.6 & \text { Meteorological conditions } & 17\end{array}$

$3 \quad$ A short summary of test results $\quad 18$

$\begin{array}{lll}3.1 & \text { Heat release rate } & 18\end{array}$

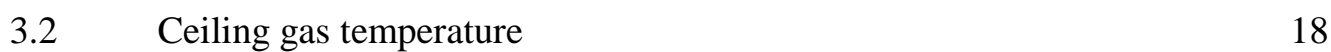

$\begin{array}{ll}3.3 & \text { Data measured at the measurement station }\end{array}$

$\begin{array}{lll}3.4 & 19\end{array}$

3.5 Fire spread to the targets 19

3.6 Backside temperature of fire protection boards 19

$\begin{array}{lll}3.7 & \text { Backlayering } & 19\end{array}$

$4 \quad$ Discussion of results $\quad 22$

4.1 Heat release rate 22

$\begin{array}{lll}4.2 & \text { Fire Growth rate } & 24\end{array}$

4.3 Gas temperature 25

$\begin{array}{lll}4.4 & \text { Flame length } & 28\end{array}$

$\begin{array}{lll}4.5 & \text { Radiation } & 30\end{array}$

4.6 Fire spread 33

$\begin{array}{lll}4.7 & \text { Gas production } & 35\end{array}$

$\begin{array}{lll}4.8 & \text { Ventilation } & 37\end{array}$

4.9 Backside wall temperatures 41

4.10 Pulsation $\quad 45$

4.11 Backlayering $\quad 46$

$\begin{array}{lll}4.12 & \text { Visibility } & 47\end{array}$

5 Conclusions $\quad 5$

Appendix A Test Results - Runehamar test T0 54

Appendix B Test Results - Runehamar test T1 60

$\begin{array}{lll}\text { Appendix C } & \text { Test Results - Runehamar test T2 } & 68\end{array}$

Appendix D Test Results - Runehamar test T3 75

$\begin{array}{lll}\text { Appendix E } & \text { Test Results - Runehamar test T4 } 83\end{array}$ 


\section{Preface}

The tests were funded by a consortium consisting of the Swedish Road Administration, the Swedish Rail Administration, the Swedish Rescue Services Agency, the Swedish Fire Research Board and the European Commission through the UPTUN project.

The technicians at SP: Joel Blom, Michael Magnusson, Lars Gustavsson, Markus Lönnmark, and Ari Palo-Oja are acknowledged for their invaluable help during planning and performance of the tests. Jari Antinlouma is acknowledged for his excellent work video documenting the tests series.

The personnel at TNO and SINTEF are gratefully acknowledged for their cooperation in performing the large-scale tunnel tests in Runehamar tunnel together with Promat International, Gerco, B I G Innovative, Composite Media, and the Norwegian Road Administration. 


\section{Summary}

Five large-scale fire tests, including one pool fire tests (T0) and four HGV mock-up fire tests (T1-T4), were carried out in the Runehamar tunnel in Norway in 2003. Detailed information about these tests is presented. Both previous work on these tests and new analyses are presented. Simple and robust theoretical models are developed to estimate and predict heat release rate, fire growth rate, gas temperature, flame length, radiation, fire spread, gas production, ventilation, backside wall temperature, pulsation and backlayering.

The Runehamar tunnel fire tests have significantly improved our knowledge of fire dynamics in large tunnel fires. A typical commodity found in HGVs trailers could produce a rapidly growing fire producing a peak heat release rate of $200 \mathrm{MW}$. Further, the measured maximum excess gas temperatures beneath the ceiling were approximately $1350{ }^{\circ} \mathrm{C}$. A maximum flame length up to about 100 meters ignited fuel ("targets") placed over $70 \mathrm{~m}$ downstream at the floor level.

Heat release rates were estimated using oxygen consumption method based on measured data in the measurement station $458 \mathrm{~m}$ downstream of the fire and the transport time was also corrected. A simple method to estimate the maximum heat release rate was also proposed since the maximum heat release rate in a well ventilated tunnel fire can be directly proportional to the burning rate per unit fuel area, heat of combustion and the total fuel areas, provided the fuel is fully involved in the fire.

A theoretical approach to model the fire growth rate in a ventilated tunnel fire was proposed. The relationship between the flame spread rate and fire growth rate was correlated since the longitudinal flame spread dominates the fire spread in a ventilated tunnel fire. The thermal inertia, heat of combustion, wet diameter and mass burning rate per unit area of the fuel play important roles in the fire growth rate and the ventilation velocity is proportional to the fire growth rate.

Maximum ceiling gas temperatures in the tests were investigated and it shows a very rapid increase after ignition. A robust equation for the maximum ceiling gas temperature was proposed which correlate all the important parameters, including heat release rate, ventilation, tunnel geometry and fuel geometry, with the maximum ceiling gas temperature. It can be used to estimate the maximum ceiling gas temperature under a given condition and help to choose the right temperature-time curve to use in structural analysis of tunnel walls. Another robust equation for ceiling gas temperature distribution along a longitudinally ventilated tunnel was also proposed to estimate the ceiling gas temperature at any given place.

The flame length was investigated and it was found that the data of flame lengths from EUREKA program were much lower than the others. An equation based on traditional ceiling jets theory and a dimensionless equation were proposed. The effect of velocity on the flame length was found to be weak.

The incident heat flux at the ceiling in a large tunnel fire was found to be a blackbody with approximately unit emissivity. It was also shown that a simple equation can be used to calculate the incident heat flux provided the gas temperature is known. This equation for the incident heat fluxes is useful for fire resistance tests. The incident heat flux at the floor level was found to be slightly lower than at the ceiling.

The fire spread to the neighboring vehicle, simulating by wood and plastic targets was tested and investigated. It was found that an average temperature of approximately $500{ }^{\circ} \mathrm{C}$ seems to give the best correlation with the fire spread. The investigation of the ceiling gas 
temperatures above the targets show the existence of a critical ceiling gas temperature while the target is just ignited. A critical gas temperature beneath the ceiling, $700{ }^{\circ} \mathrm{C}$ for wood materials placed at floor level and $490{ }^{\circ} \mathrm{C}$ for plastic materials placed at floor level, is found to be responsible for fire spread to the fuels placed on the floor. The critical ceiling gas temperature could be much lower if the materials were placed at a higher level. According to previous study [16-18], a critical gas temperature beneath the ceiling of $600{ }^{\circ} \mathrm{C}$ was found for fire spread to the wood cribs with their top surfaces at $75 \%$ of the tunnel height from floor level.

Carbon dioxide production is found to be directly proportional to the heat release rate, while $\mathrm{CO}$ production is dependent on not only heat release rate, but also fuel type and combustion conditions. The average concentration of $\mathrm{CO}$ was in a range of $400 \mathrm{ppm}$ to $2500 \mathrm{ppm}$. Most of the $\mathrm{CO}$ was produced at the beginning of each test.

In order to describe the reduction in the longitudinal airflow velocity during the tests due to the fire and hot gases resistances, a theoretical model was developed and validated using the large-scale tests data. Two methods for calculating the characteristic temperature related to the thermal expansion and stack effect are presented and analyzed. The longitudinal ventilation velocity during a large tunnel fire can be estimated well using Equation (20) with aid of Equation (21). The average temperature at the middle point between the fire source and the downstream exit according to Equation (21) is appropriate to consider as the characteristic temperature of the downstream section.

A simple theoretical model for thermal conduction is used to compare with the tests data. The numerical results of backside wall temperature in test T0 correlates very well with the experimental data, but was much higher than tests data in $\mathrm{T} 1$. The main reason for this discrepancy was probably the uncertainty in the thermal properties of the Promatect $T$ board material at high temperatures. The simple calculation method appears appropriate to predict the temperature in the tunnel structures provided that the thermal properties are known.

Pulsations (oscillation) of the main airflow were observed during the tests with fires that exceeded $125 \mathrm{MW}-135 \mathrm{MW}$. Two different periods of the pulsations were registered, short periods of about $4 \mathrm{~s}$ and longer periods of approximately $18 \mathrm{~s}$. It has been shown with simple acoustic calculations that the oscillation periods (4 $\mathrm{s}$ and $18 \mathrm{~s}$, respectively) are properties of the system.

The maximum backlayering length in tests $\mathrm{T} 1$ to $\mathrm{T} 4$ were approximately $100 \mathrm{~m}$, independent of the fact that the corresponding heat release rate ranges from $66 \mathrm{MW}$ to $202 \mathrm{MW}$. This confirms that in a large tunnel fire, the backlayering length is nearly independent of the heat release rate and only dependent on the ventilation velocity.

The mass optical density is much higher and approximately a constant of around $400 \mathrm{~m}^{2} / \mathrm{kg}$ in Test 0 where the diesel produces a large amount of soot. In other tests using commodities as the fuels, the mass optical density lie in a range of 10 to $138 \mathrm{~m}^{2} / \mathrm{kg}$, and it is higher at the early stage and then decreases to a lower level when the fire gets fully developed. These values for HGV mock-up tests correlate well with the data from Eureka 499 tests for trucks. Note that the value of mass optical density is mainly dependent on the fuel type. Assuming that the flow is fully mixed in the tunnel, i.e. the well stratification disappears after a certain distance from the fire, the visibility downstream of a tunnel fire can be easily calculated using Eq. (30). 


\section{Introduction}

In the recent years, the interest for fire safety issues in tunnels has increased dramatically owing to numerous catastrophic tunnel fires, e.g. the fire accident in the Mont Blanc tunnel between France and Italy which resulted in 39 deaths (1999), and the fire in the St.

Gotthard tunnel in Switzerland which caused 11 deaths (2001). In these fires the cargo in heavy goods vehicle (HGV) trailers played a major role in the catastrophic outcome. The main reason is that the HGV trailers contain a very high fire load and the fire can easily spread with the assistance of the ventilation. In the period leading up to the Runehamar tests it was, therefore, clear that large scale fire tests, simulating a HGV fire, were needed to fully understand the mechanisms of the fire dynamics in a catastrophic tunnel fire.

Therefore, five large-scale fire tests were carried out in the Runehamar tunnel in Norway in year 2003. The Runehamar tunnel fire tests were initiated, planned and performed by the SP Technical Research Institute of Sweden (Former SP Swedish National Testing and Research Institute). The magnitude of the tests required the development of a Consortium working together. Therefore, a cooperation was initiated with TNO in the Netherlands and SINTEF in Norway. Further, several industrial partners were included in the Consortium to provide equipment and expertise. Promat International and GERCO installed the thermal protection of the tunnel over a distance of $75 \mathrm{~m}$. Two mobile fans were provided the project through B I G Innovative.

The Runehamar tunnel fire tests have significantly improved our knowledge of fire dynamics in large tunnel fires. They show that a typical loaded truck (HGV) can produce a rapidly growing fire up to $200 \mathrm{MW}$. The measured maximum excess gas temperatures beneath the ceiling were about $1350{ }^{\circ} \mathrm{C}$. A maximum flame length about 100 meters ignited the fuels placed at the floor level over $70 \mathrm{~m}$ downstream.

These tests have previously been presented and discussed in various publications [1-10]. In previous publications on the Runehamar large-scale tests the focus has been on the measurements of heat release rates [1-2], gas temperatures in the ceiling [3-4], fire spread and flame lengths [5-6] obtained in these tests, pulsations of the tunnel flow in two of the tests [7-8], heat fluxes [4,9] and humidity and toxicity in these tests [10]. These papers are referred to frequently and widely used by practicing engineers and scientists. However, until now there has not been a comprehensive test report with all test data available. In addition, some of these papers give preliminary data compiled shortly after finishing these tests. These preliminary data has been reanalysed and some corrections to initial analyses are provided in this report. The report will also make it easier for those who need additional data to make a further analysis of the tests and to better understand how they were performed.

This report meets these needs by giving all the detailed information about the tests and a more complete analysis of all the results. The report also gives a summary of the articles that have been written since the performance of the tests in year 2003. 


\section{Experimental procedure}

The Runehamar tunnel is situated about $5 \mathrm{~km}$ from Andalsnes, $40 \mathrm{~km}$ south of Molde in Norway and is a two-way asphalted road tunnel that was taken out of use in the late 1980s. It is approximately $1600 \mathrm{~m}$ long, $6 \mathrm{~m}$ high and $9 \mathrm{~m}$ wide with a cross-section of about 47 $\mathrm{m}^{2}$. The tunnel has an average uphill slope of $0.5 \%$ up to about $500 \mathrm{~m}$ from the east portal (where the fans were located) to the west portal, followed by a $200 \mathrm{~m}$ long plateau and then a 900 long downhill section with an average slope of $1 \%$ towards the west portal. The fire was mainly located about $1037 \mathrm{~m}$ from the east portal, i.e. on the downhill section of the tunnel. This location turned out to be particularly interesting as this small slope created a large pressure resistance for the mobile fans.

\subsection{The mobile fan units}

The longitudinal flow inside the tunnel was created using two mobile fan units (Mobile Ventilation Unit - MVU 125/100 courtesy of B I G Innovative in Germany). One fan was positioned approximately $12 \mathrm{~m}$ outside the east tunnel entrance (see Figure 2.1) and the other was positioned about $50-60 \mathrm{~m}$ inside the tunnel. The diameter of each fan was $1.25 \mathrm{~m}$ with six impeller blades and the engine was $75 \mathrm{Kw}$ (100 HP) providing about 2600 $\mathrm{N}$ axial thrust at $2000 \mathrm{RPM}$. The primary air flow rate of each fan was $47.2 \mathrm{~m}^{3} / \mathrm{s}(170000$ $\mathrm{m}^{3} / \mathrm{h}$ ). The centreline longitudinal velocity $50 \mathrm{~m}$ upstream of the fire source prior to ignition was in the range of $2.9-3.4 \mathrm{~m} / \mathrm{s}$. At the measurement station $458 \mathrm{~m}$ from the fire the centreline velocity ranged from $2.8 \mathrm{~m} / \mathrm{s}$ to $3 \mathrm{~m} / \mathrm{s}$ prior to ignition. After ignition and when the fire was at its peak conditions the centreline velocity was reduced down to about $2.4 \mathrm{~m} / \mathrm{s}$ to $2.5 \mathrm{~m} / \mathrm{s}$ due to the flow resistance of the fire and the thermal stack effects. The centre of the fire was located $563 \mathrm{~m}$ from west entrance and the airflow direction in the tunnel was from east to west.

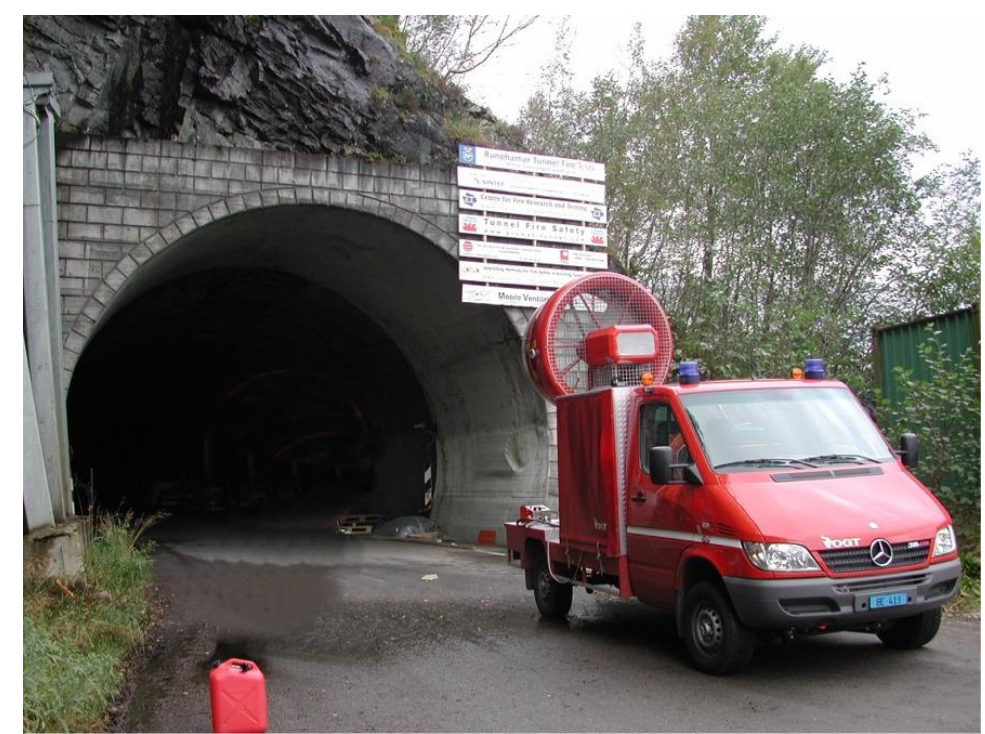

Figure 2.1 Mobile fan units placed at the east entrance to create a longitudinal flow inside the tunnel. One was placed just outside the entrance (in photo) and one was placed about 60 inside the entrance.

\subsection{The HGV trailer mock-up}

The commodities were placed on particleboards on a rack storage system to simulate a HGV measuring $10450 \mathrm{~mm}$ by $2900 \mathrm{~mm}$. The total height was $4500 \mathrm{~mm}$ and a $0.5 \mathrm{~mm}$ thick polyester tarpaulin covered the cargo. The height of the platform floor was $1100 \mathrm{~mm}$ above the road surface. At a distance of $15 \mathrm{~m}$ from the downstream end of the test commodity there was a target consisting of one pallet row of the same test commodity as 
used in test in question. The upstream side of the target was covered with a polyester tarpaulin. In Table 2.1, more thorough information about the commodity used in each test is provided.

The centre of the fire was in tests T0-T2 located $1037 \mathrm{~m}$ from the east portal, i.e. on the downhill section of the tunnel. However, the fire source was moved $2 \mathrm{~m}$ upstream in T3 and further $5 \mathrm{~m}$ in $\mathrm{T} 4$ due to safety reasons.

Before the mock-up tests, a pool fire test (T0) was carried out. This test was carried out to check the instrumentation and calibrate the measurements of the heat release rate measurements. The fire source consisted of diesel loaded in a pan with a diameter of 2.27 $\mathrm{m}$. The total volume of the fuel was $200 \mathrm{~L}$, see Figure 2.2. No data or information about this test has been published previously.

Table 2.1 Description of the fire load used in the large-scale test series.

\begin{tabular}{|c|c|c|c|c|c|}
\hline $\begin{array}{l}\text { Test } \\
\text { no }\end{array}$ & $\begin{array}{l}\text { Description of the fire load } \\
\text { (target not included) }\end{array}$ & Target & $\begin{array}{l}\text { Total } \\
\text { weight } \\
\text { (kg) }\end{array}$ & $\begin{array}{l}\text { Theoretical } \\
\text { calorific } \\
\text { energy } \\
(\mathrm{GJ})\end{array}$ & $\begin{array}{l}\text { Maximum } \\
\text { HRR } \\
\text { (MW) }\end{array}$ \\
\hline T0 & $\begin{array}{l}\text { 200 L Diesel in a pool with a diameter } \\
\text { of } 2.27 \mathrm{~m}\end{array}$ & - & 166.4 & 6.7 & 6 \\
\hline $\mathrm{T} 1$ & $\begin{array}{l}360 \text { wood pallets measuring } 1200 \times \\
800 \times 150 \mathrm{~mm}, 20 \text { wood pallets } \\
\text { measuring } 1200 \times 1000 \times 150 \mathrm{~mm} \text { and } \\
74 \text { PE plastic pallets measuring } 1200 \\
\times 800 \times 150 \mathrm{~mm} ; 122 \mathrm{~m}^{2} \text { polyester } \\
\text { tarpaulin }\end{array}$ & $\begin{array}{l}32 \text { wood } \\
\text { pallets and } \\
6 \text { PE pallets }\end{array}$ & 11010 & 244 & 202 \\
\hline $\mathrm{T} 2$ & $\begin{array}{l}216 \text { wood pallets and } 240 \text { PUR } \\
\text { mattresses measuring } 1200 \times 800 \times \\
150 \mathrm{~mm} ; 122 \mathrm{~m}^{2} \text { polyester tarpaulin }\end{array}$ & $\begin{array}{l}20 \text { wood } \\
\text { pallets and } \\
20 \text { PUR } \\
\text { mattresses }\end{array}$ & 6853 & 135 & 157 \\
\hline $\mathrm{T} 3$ & $\begin{array}{l}\text { Furniture and fixtures (tightly packed } \\
\text { plastic and wood cabinet doors, } \\
\text { upholstered PUR arm rests, } \\
\text { upholstered sofas, stuffed animals, } \\
\text { potted plant (plastic), toy house of } \\
\text { wood, plastic toys). } 10 \text { large rubber } \\
\text { tyres ( } 800 \mathrm{~kg}) ; 122 \mathrm{~m}^{2} \text { polyester } \\
\text { tarpaulin }\end{array}$ & $\begin{array}{l}\text { Upholstered } \\
\text { sofa and } \\
\text { arm rests }\end{array}$ & 8506 & 179 & 119 \\
\hline $\mathrm{T} 4$ & $\begin{array}{l}600 \text { corrugated paper cartons with } \\
\text { interiors }(600 \mathrm{~mm} \times 400 \mathrm{~mm} \times 500 \\
\mathrm{mm} ; \mathrm{L} \times \mathrm{W} \times \mathrm{H}) \text { and } 15 \% \text { of total } \\
\text { mass of unexpanded polystyrene }(\mathrm{PS}) \\
\text { cups }(18000 \mathrm{cups}) \text { and } 40 \text { wood } \\
\text { pallets }(1200 \times 1000 \times 150 \mathrm{~mm}) ; 10 \\
\mathrm{~m}^{2} \text { polyester tarpaulin }\end{array}$ & - & 2849 & 62 & 66 \\
\hline
\end{tabular}




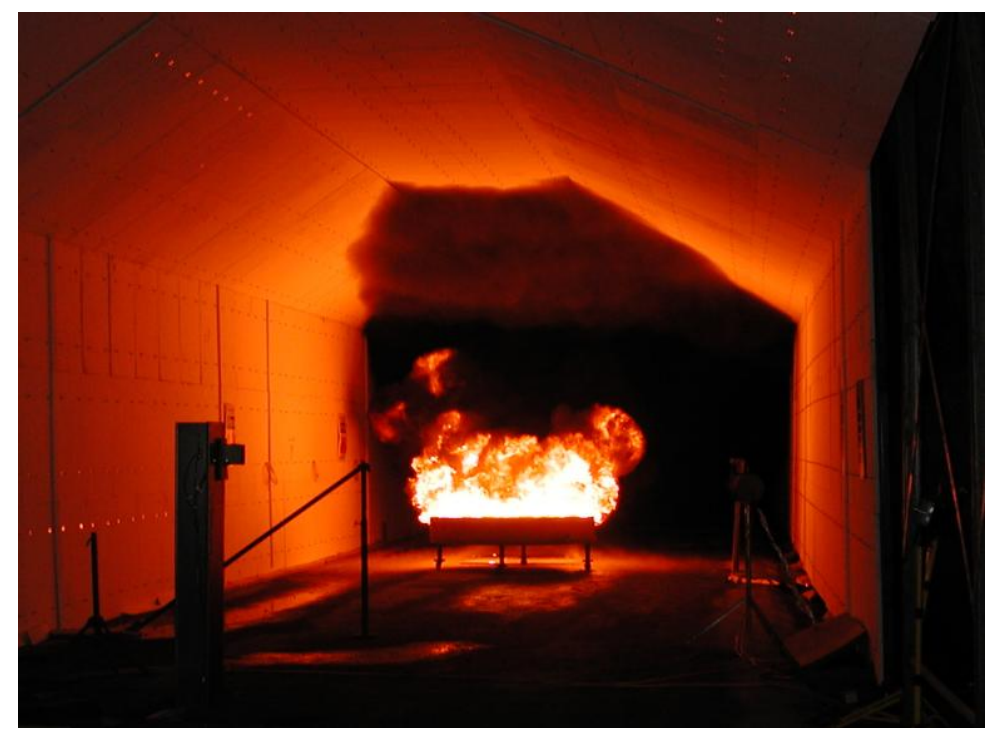

Figure 2.2 The diesel pool fire used in test T0.

\subsection{The fire protection system}

For the safety of the personnel, the tunnel was protected by PROMATECT®-T fire protection boards near the position of the fire, see Figure 2.3. The boards were attached to a steel frame system from GERCO consisting of crossbar steel beams and pipes over a length of $75 \mathrm{~m}$. The steel frame system was in a straight line and equal in geometry over the entire $75 \mathrm{~m}$ length. The ceiling consisted of boards covering the entire length of the steel framework $(75 \mathrm{~m})$. The walls were $39 \mathrm{~m}$ long and consisted of vertical boards (30 $\mathrm{mm}$ thick) attached to the steel framework. The centre of the fire was $21.5 \mathrm{~m}$ from the east end (upstream) of the protection and $53.5 \mathrm{~m}$ from the west end (downstream). The boards in the ceiling near the fire (a $25 \mathrm{~m}$ long region) were $45 \mathrm{~mm}$ thick, while the thickness of the other ceiling boards was $25 \mathrm{~mm}$. The vertical wall started $12.5 \mathrm{~m}$ upstream of the centre of the fire and ended $26.5 \mathrm{~m}$ downstream of the fire. The ceiling was divided into three parts, two sloping and one horizontal (see Figure 2.4).

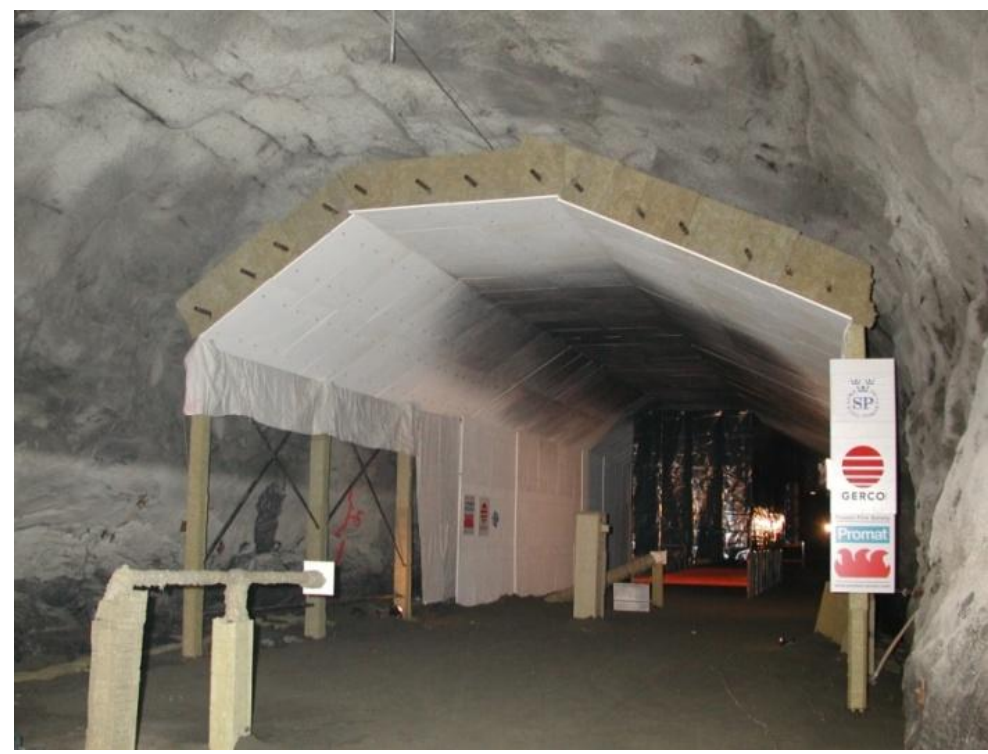

Figure 2.3 The fire protection shown from the east (upstream) side and the HGV trailer mock-up $21.5 \mathrm{~m}$ from the east end of the protection. 


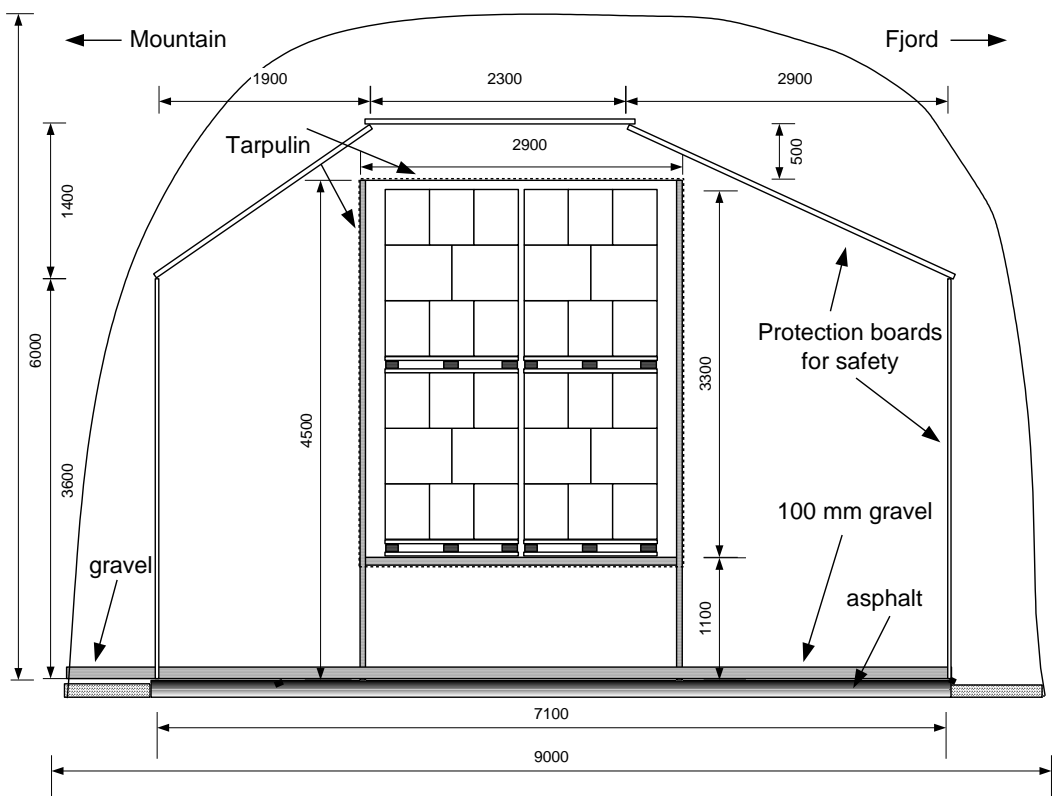

Figure 2.4 Tunnel cross section at the fire site.

For the parts of the sides of this protective inner tunnel that were not covered by protective boards, ceramic curtains were used to prevent the hot gases from reaching the steel structure holding the protection boards. The gap at the ceiling between the protective inner tunnel and the rock tunnel was $1-1.5 \mathrm{~m}$ at the position with the largest gap, but for most positions along the ceiling the gap was much smaller due to the variation in ceiling height along the tunnel. The protective structure was designed to be a best fit inside the rock tunnel, using laser based surveying equipment to establish the structure of the rock tunnel, prior to construction. To minimize the risk of flames and hot back-layering gases to reach above the protection ceiling, the gap was covered by $0.6 \mathrm{~m}$ high insulation boards at the inlet of the protective inner tunnel (see Figure 2.3). The gaps between the walls of the inner protective tunnel and the natural blasted tunnel were not covered, but on the mountain side of the tunnel (left side when facing from east to west) the construction was so close to the inner protective tunnel that air passage could occur only very close to the road surface. On the fjord side (right side when facing downstream or from east to west) the gap was approximately $1 \mathrm{~m}$ at the base decreasing to zero near the top of the wall. In Figure 2.4, a schematic figure is shown of the cross-section at the fire location. The contour of the outer tunnel in Figure 2.4 is only for illustration; the gaps were narrower, especially at the walls. Pillars and other parts of the steel construction holding up the protective wallboards (and obstructing air flow) are not included in the figure. A layer of sand protected the road along the length of the protective inner tunnel. Other parts of the tunnel consisted of about $7 \mathrm{~m}$ wide asphalted roadway and the tunnel walls consisted of blasted hard Gneiss. The relative roughness of the tunnel is not clearly known but the roughness of the rock surface could range from few centimetres up to several decimetres.

\subsection{Flow obstructions}

The flow obstructions in the tunnel consisted of the HGV trailer mock-up, the $75 \mathrm{~m}$ long wall protection with its steel framework and narrow passages, the two measuring cabins (3 $\mathrm{m} \times 1.2 \mathrm{~m} \times 1.2 \mathrm{~m}$ ) adjacent to the mountain wall at $-50 \mathrm{~m}$ and $+458 \mathrm{~m}$ respectively, two water tanks $\left(1 \mathrm{~m}^{3}\right)$, an electrical diesel generator $\left(1.5-2 \mathrm{~m}^{3}\right)$ and some other small pieces of equipment stored inside the tunnel close to the east entrance. The west entrance was made of a $50 \mathrm{~m}$ long concrete ceiling with supporting columns on the fjord side and concrete wall on the mountain side. The purpose of this ceiling was to protect cars from falling stones and snow. A photo of the west entrance is shown in Figure 2.5. 


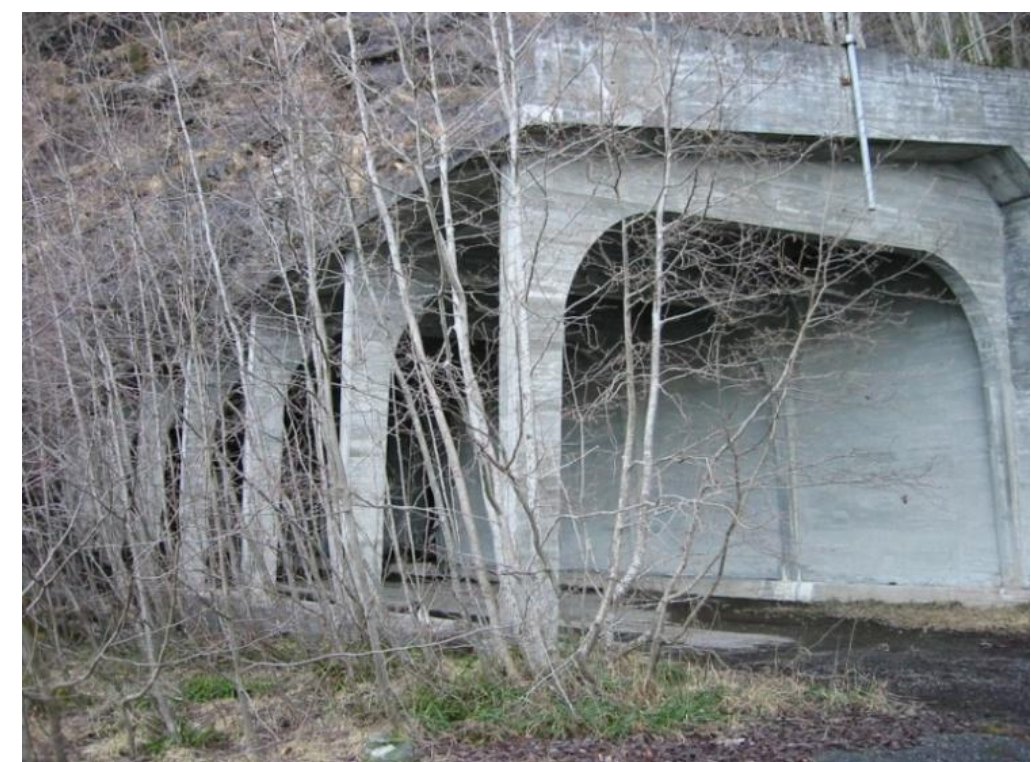

Figure 2.5 The west entrance was made of $50 \mathrm{~m}$ long concrete ceiling with supporting columns on the fjord side.

\subsection{Measurements}

Temperatures were measured at several positions along the tunnel, from -100 $\mathrm{m}$ upstream of the fire to a measurement station $+458 \mathrm{~m}$ downstream of the fire, i.e. $105 \mathrm{~m}$ from the west entrance. Upstream of the fire the thermocouples were located at $-15 \mathrm{~m},-25 \mathrm{~m},-40 \mathrm{~m}$, $-70 \mathrm{~m}$ and $-100 \mathrm{~m}$ and $0.3 \mathrm{~m}$ beneath the ceiling. Downstream of the fire the thermocouples were located at $0 \mathrm{~m},+10 \mathrm{~m},+20 \mathrm{~m},+40 \mathrm{~m},+70 \mathrm{~m},+100 \mathrm{~m},+150 \mathrm{~m},+250 \mathrm{~m},+350 \mathrm{~m}$ and $+458 \mathrm{~m}$. The majority of the temperatures were measured using unsheathed thermocouples, $0.25 \mathrm{~mm}$ type K. Near the fire, sheathed thermocouples with a diameter of $1 \mathrm{~mm}$ were used. Most of the gas temperatures downstream of the fire were measured $0.3 \mathrm{~m}$ below the tunnel ceiling, which means $4.8 \mathrm{~m}$ above the road surface in the region with fire protection boards and about $5.7 \mathrm{~m}$ above the road elsewhere. At two positions, $+100 \mathrm{~m}$ and $+250 \mathrm{~m}$, respectively, temperatures were also measured $1.8 \mathrm{~m}$ above the road surface. At the measurement station at $+458 \mathrm{~m}$, thermocouples were placed at five different heights; $0.7 \mathrm{~m}$, $1.8 \mathrm{~m}, 2.9 \mathrm{~m}, 4.1 \mathrm{~m}$, and $5.1 \mathrm{~m}$, respectively. Gas concentrations, including $\mathrm{O}_{2}, \mathrm{CO}_{2}$ and $\mathrm{CO}$, were also measured in the corresponding locations. In addition, the temperatures at the same vertical height and $2.25 \mathrm{~m}$ from the centre line of the tunnel were measured to check the symmetry in the flow, as shown in Figure 2.6. Note that the fire load was moved $2 \mathrm{~m}$ upstream in T3 and further $5 \mathrm{~m}$ upstream in T4 due to damage to the tunnel from previous tests. For simplicity, the locations referred to correspond to original locations in T1.

Five bi-directional pressure difference probes [11] were used at the measurement station at $+458 \mathrm{~m}$ (see Figure 2.6), together with one located upstream at $-50 \mathrm{~m}$ and $3 \mathrm{~m}$ above the road surface. Each probe was connected to a Furness mod FC0332 instrument. In tests T3 and $\mathrm{T} 4$ velocity data is available also at $-150 \mathrm{~m}$ using hot sphere anemometers. The thermocouples and velocity probes on the centreline steel rod at $+458 \mathrm{~m}$ were used to calculate the air mass flow rate through the tunnel. No corrections due to radiation effects were carried out. The low gas temperature $\left(10-140^{\circ} \mathrm{C}\right)$ and the relatively small wire diameter $(0.25 \mathrm{~mm})$ imply that the error due to radiation was negligible.

The gas velocity was determined with aid of the measured pressure difference, $\Delta p$, for each probe and the corresponding gas temperature. The diameter of the probes, D, used was $16 \mathrm{~mm}$ and the probe length, L, was $32 \mathrm{~mm}$. The velocity was obtained from Equation (1) [8]: 


$$
u=\frac{1}{k^{\prime}(\operatorname{Re})} \sqrt{\frac{2 \Delta p T}{\rho_{0} T_{0}}}
$$

where $k^{\prime}(\operatorname{Re})$ is a correction coefficient given by McCaffrey and Heskestad [11] which depends on the Reynolds number (Re). From the calibration curve presented by McCaffrey and Heskestad it is observed that $k(\mathrm{Re})$ is constant for larger Reynolds number than 2000 and the value of the constant is 1.08 . In the large-scale tests presented here the Reynolds number was found to be in the range of $2000-3200$ for the probes, which means that $k$ is equal to 1.08. The characteristic length in the Reynolds number is the diameter of the probe. The ambient values used in equation (1) were $T_{0}=283 \mathrm{~K}$ and $\rho_{0}=1.24 \mathrm{~kg} / \mathrm{m}^{3}$.

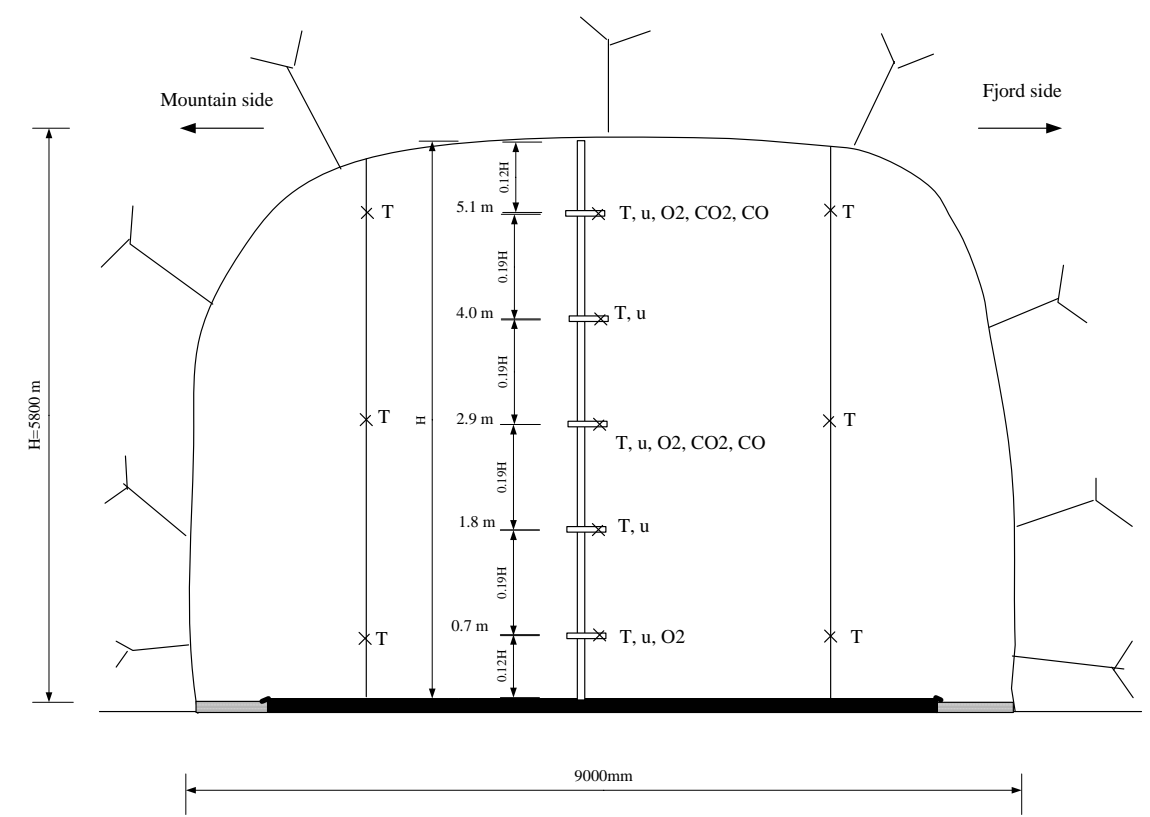

Figure 2.6 The measurement station $458 \mathrm{~m}$ downstream of the fire $(+458 \mathrm{~m})$. $T=$ gas temperature, $u=$ gas velocity, $O 2=$ oxygen, $\mathrm{CO} 2=$ carbon dioxide, $\mathrm{CO}=$ carbon monoxide, $\mathrm{H}=$ tunnel height at the measurement station, $H=5800 \mathrm{~mm}$. The probes were placed at elevations $0.7 \mathrm{~m}, 1.8 \mathrm{~m}, 2.9 \mathrm{~m}$, $4.0 \mathrm{~m}$, and $5.1 \mathrm{~m}$. The total area of the cross-section at the measurement station was $47.4 \mathrm{~m}^{2}$.

Heat fluxes close to the fire site were measured using Schmidt-Boelter heat flux meters and plate thermometers. Four plate thermometers were placed on the ceiling at $0 \mathrm{~m}, 10 \mathrm{~m}, 20 \mathrm{~m}$ and $40 \mathrm{~m}$ downstream of the fire centre respectively, and a plate thermometer was placed under the target and towards the fire load at $20 \mathrm{~m}$ downstream. Two Schmidt Boelter heat flux meters were placed $20 \mathrm{~m}$ upstream $(-20 \mathrm{~m})$ and downstream of the fire $(+20 \mathrm{~m})$ respectively. The flux meters were flush with the wall, facing the target, placed $1.6 \mathrm{~m}$ above the floor. The incident heat fluxes are calculated by the following equation [12-13]:

$$
\left[\dot{q}_{\text {inc }}^{\prime \prime}\right]^{i+1}=\frac{\varepsilon_{P T} \sigma\left[T_{P T}^{4}\right]^{i}+\left(h_{P T}+K_{\text {cond }}\right)\left(\left[T_{P T}\right]^{i}-\left[T_{g}\right]^{i}\right)+C_{\text {heat }, \beta=1 / 3} \frac{\left[T_{P T}\right]^{i+1}-\left[T_{P T}\right]^{i}}{t^{i+1}-t^{i}}}{\varepsilon_{P T}}
$$

where the conduction correction factor $K_{\text {cond }}=0.00843 \mathrm{~kW} / \mathrm{m}^{2} \cdot \mathrm{K}$, and the lumped heat capacity coefficient $C_{\text {heat }, \beta=1 / 3}=4.202 \mathrm{~kJ} / \mathrm{m}^{2} \cdot \mathrm{K}$, the surface emissivity of Plate thermometer 
$\varepsilon_{P T}=0.8$.

To estimate the performance of the fire resistant material, Promatect T, placed in the vicinity of the fire, backside surface temperatures of four boards with different thickness were measured at the tunnel ceiling level $10 \mathrm{~m}$ downstream of the fire centre using thermocouples B1 to B6, as shown in Figure 2.7. The ceiling board No. 4 and side board No.1 are $45 \mathrm{~mm}$ and $30 \mathrm{~mm}$ thick respectively. The thicknesses of the side boards No.2 and No. 3 are $25 \mathrm{~mm}$.

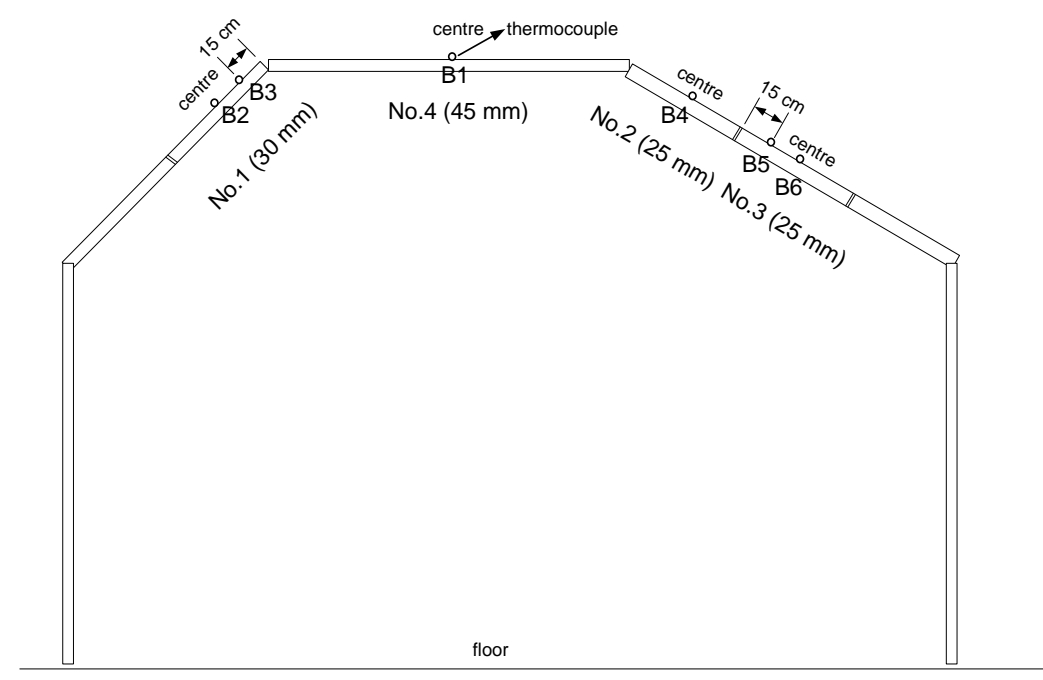

Figure 2.7 Measurement of backside temperature of the Promatect $T$ at $10 \mathrm{~m}$ downstream of the fire centre.

The visibility was also measured at the measurement station $458 \mathrm{~m}$ downstream and $2.9 \mathrm{~m}$ above the tunnel floor.

All the measured data including gas temperatures, concentrations, velocities and heat fluxes were recorded on a laptop computer every 1 second.

\subsection{Meteorological conditions}

The outside temperature varied between $9-14{ }^{\circ} \mathrm{C}$ whereas the temperature inside the tunnel at the fire location varied between $10-11{ }^{\circ} \mathrm{C}$ before the tests. There was some wind outside the tunnel entrances during the tests. The longitudinal velocity inside the tunnel was also measured some hours prior to the tests. Prior to T1 it was measured to be in the range of $1.3-1.4 \mathrm{~m} / \mathrm{s}$ and about $1.6 \mathrm{~m} / \mathrm{s}$ prior to T2. In T3 there was a positive longitudinal velocity of about $0.3 \mathrm{~m} / \mathrm{s}$, i.e. in the same direction as the fans were blowing. In the fourth test there was no longitudinal velocity inside the tunnel before the fans were started. Since the velocities were measured several hours before the tests, the external winds may be different during the tests. The effect of the external winds on the tunnel flow will be discussed later according to the test data before the ignition of the fire source. 


\section{A short summary of test results}

All the detailed test results for each test are given in Appendices A to E. In this chapter, a short summary of the main results, including heat release rate, fire growth rate, gas temperature, gas concentration and heat flux, are presented.

\subsection{Heat release rate}

In Table 3.1, the main test results related to the flow conditions and the heat release rates are given. The test number is given in the first column. The second column shows the average velocity of fresh air flowing into the tunnel. The average velocity is in a range of approximately $2.0 \mathrm{~m} / \mathrm{s}$ to $2.5 \mathrm{~m} / \mathrm{s}$ in all the tests. The third column shows the heat release rates (HRR), which were obtained by oxygen consumption method. The transport time to the downstream measurement station was also corrected. The maximum HRR varied from $66 \mathrm{MW}$ to $202 \mathrm{MW}$ for the four tests with a HGV mock-up. The parameter $t_{\max }$ shown in the fourth column is the time in minutes from ignition when the maximum heat release rate occurs. The maximum HRR occurred in the range about 9 min to $19 \mathrm{~min}$. The fire growth rates shown in the fifth column were calculated based on the HRR data in a range of about $20 \%$ to $80 \%$ of the maximum heat release rate in these tests. This means that heat release rate value at $80 \%$ of the maximum heat release rate minus the heat release rate value at $20 \%$ of the maximum heat release rate was divided by corresponding time difference. Thus, the fire growth rate is assumed to be linear in this range. The linear trend can be easily seen by observing the measured data, see Figure B1, C1, D1, and E1 in Appendix. The fire growth rate ranged from $264 \mathrm{~kW} / \mathrm{s}$ to $433 \mathrm{~kW} / \mathrm{s}$, corresponding to about $16 \mathrm{MW} / \mathrm{min}$ to 26 $\mathrm{MW} / \mathrm{min}$.

\subsection{Ceiling gas temperature}

Test results related to the measured gas temperatures $0.3 \mathrm{~m}$ below the ceiling are also shown in Table 3.1. The maximum ceiling temperature at distance $X_{f}$ from the centre line of the fire source is shown in columns six to twenty-one. The values listed here are the maximum values measured by the thermocouple during each test. In all the tests with a HGV mock-up the measured maximum ceiling temperatures are over $1280{ }^{\circ} \mathrm{C}$, with a maximum value of $1360{ }^{\circ} \mathrm{C}$. The ceiling gas temperature upstream of the fire, which corresponds to a backlayering, decreases much rapidly than downstream of the fire.

\subsection{Data measured at the measurement station}

The data measured at the measurement station $458 \mathrm{~m}$ downstream of the fire are presented in Table 3.2. The velocities were all measured at the centre line of the tunnel. The measured velocities at different height were almost the same, i.e. approximately $3 \mathrm{~m} / \mathrm{s}$. Therefore, only one value was given for each test. The maximum gas temperatures were all measured at different heights at the centre line of the tunnel. There were only a small temperature gradient in the vertical direction. The measured temperatures ranged from 50 to $150{ }^{\circ} \mathrm{C}$ in tests with a HGV mock-up and about $20{ }^{\circ} \mathrm{C}$ in the pool fire test T0. The gas temperatures closer to the wall are not presented here but can be found in the appendices. Maximum gas concentrations, including $\mathrm{CO}_{2}, \mathrm{CO}$ and $\mathrm{O}_{2}$ are measured at two locations: $5.1 \mathrm{~m}(0.85 \mathrm{H})$ and $2.9 \mathrm{~m}(0.5 \mathrm{H})$ above the floor. In $\mathrm{T} 1$ to $\mathrm{T} 4$, the measured $\mathrm{CO} 2$ volume concentration ranged from about $4 \%$ to $13.5 \%$, and the measured $\mathrm{CO}$ volume concentration ranged from $0.05 \%$ to $0.31 \%$. The measured $\mathrm{O} 2$ volume concentration in $\mathrm{T} 1$ to $\mathrm{T} 4$ ranged from $7.3 \%$ to $16.3 \%$. The concentration of $\mathrm{O}_{2}$ at $0.7 \mathrm{~m}$ above floor was also measured but not presented here due to few data available. 


\subsection{Heat flux}

The heat fluxes measured by the plate thermometers and the Schmidt-Boelter flux meters in the vicinity of the fire source are presented in Table 3.3. The plate thermometers were placed on the ceiling at $0 \mathrm{~m}, 10 \mathrm{~m}, 20 \mathrm{~m}$ and $40 \mathrm{~m}$ downstream of the fire centre. In the pool fire test, the measured maximum incident heat fluxes using the plate thermometers were quite low. However, in the tests with a HGV mock-up, the measured incident heat fluxes varied from $20 \mathrm{~kW} / \mathrm{m}^{2}$ to $400 \mathrm{~kW} / \mathrm{m}^{2}$. The Schmidt-Boelter flux meters were placed $1.6 \mathrm{~m}$ above the floor and at $-15 \mathrm{~m}$ and $20 \mathrm{~m}$, respectively. In addition, one plate thermometer was placed at $20 \mathrm{~m}$ downstream and $1.6 \mathrm{~m}$ above floor with surface towards the fire load.

\subsection{Fire spread to the targets}

Several targets were placed downstream of the fire at different distances to model the potential for fire spread to neighbouring vehicles. Most of these targets were placed at the floor level. The spread time to each target cannot be given due to difficulty in measuring this parameter. Furthermore, these positions could not be observed during the tests. However, the distances beyond which the fire cannot spread are summarized in Table 3.4 based on the information obtained after each test. The maximum ceiling temperatures above the corresponding targets are also given for application in the ensuing analysis. These data have been obtained either by direct measurement or interpolation of the ceiling temperatures along the tunnel. The region just downstream of the main set-up was registered using a video camera and thereby the times for fire spread to a wood pallet and to the large target were documented.

\subsection{Backside temperature of fire protection boards}

The maximum back surface temperature of Promatect $T$ boards above the fire source registered during the $\mathrm{T} 0$ and T1, i.e. B1 to B6 (see Figure 2.7), are presented in Table 3.5. In other tests, the results are not reliable due to failure of the thermocouples and are therefore not presented here nor in the appendixes. All the data presented were measured at the ceiling level. In test T0, the measured backside wall temperatures varied from $19.4{ }^{\circ} \mathrm{C}$ to $32.4^{\circ} \mathrm{C}$ for a Promatect $\mathrm{T}$ board with a thickness of $25 \mathrm{~mm}$ to $45 \mathrm{~mm}$, and ranged from $90{ }^{\circ} \mathrm{C}$ to $211{ }^{\circ} \mathrm{C}$ in test $\mathrm{T} 1$.

\subsection{Backlayering}

When the fire became very intensive, the average longitudinal velocity of the fresh air flowing into the tunnel, $u_{o}$, was reduced from approximately $2.5 \mathrm{~m} / \mathrm{s}$ down to approximately $2.0 \mathrm{~m} / \mathrm{s}$, creating a backlayering of smoke for approximately $100 \mathrm{~m}$. The information about the maximum backlayering lengths and the corresponding minimum longitudinal velocities were obtained and are summarized in Table 3.6. In all tests, but for test T0 when the backlayering was $15-25 \mathrm{~m}$, the backlayering length was approximately $100 \mathrm{~m}$. 
Table 3.1 Measured data relevant to heat release rate and gas temperature.

\begin{tabular}{|c|c|c|c|c|c|c|c|c|c|c|c|c|c|c|c|c|c|c|c|c|}
\hline \multirow[t]{2}{*}{ Test no. } & \multirow[t]{2}{*}{$\begin{array}{c}u_{o} \\
(\mathrm{~m} / \mathrm{s})\end{array}$} & \multirow[t]{2}{*}{$\begin{array}{c}Q_{\max } \\
(\mathrm{MW})\end{array}$} & \multirow[t]{2}{*}{$\begin{array}{c}t_{\max } \\
(\min )\end{array}$} & \multirow[t]{2}{*}{$\begin{array}{c}\frac{d Q}{d t} \\
(\mathrm{~kW} / \mathrm{s})\end{array}$} & \multicolumn{16}{|c|}{ Maximum gas temperature, $0.3 \mathrm{~m}$ beneath the ceiling along the tunnel, $T_{c, \max }(x)$} \\
\hline & & & & & $-100^{\mathrm{a}}$ & $-70^{\mathrm{a}}$ & $-40^{\mathrm{a}}$ & $-25^{a}$ & $-15^{\mathrm{a}}$ & $0^{\mathrm{a}}$ & $10^{\mathrm{a}}$ & $20^{\mathrm{a}}$ & $40^{\mathrm{a}}$ & $70^{\mathrm{a}}$ & $100^{\mathrm{a}}$ & $150^{\mathrm{a}}$ & $200^{\mathrm{a}}$ & $250^{\mathrm{a}}$ & $300^{\mathrm{a}}$ & $458^{\mathrm{a}}$ \\
\hline 0 & $2.1-2.5$ & 6 & $*$ & $*$ & 11.0 & 11.0 & 11.0 & 11.0 & 144.4 & 267.2 & 166.1 & 135.7 & 113.9 & 94.2 & 73.9 & 54.9 & 44.7 & 36.5 & 27.7 & 23.2 \\
\hline 1 & $1.9-2.5$ & 202 & 18.4 & 409 & 96.0 & 153.3 & 248.4 & 359.5 & 530.2 & 1213 & 1359.6 & 1301 & 1169.3 & 798 & 585.7 & 446.1 & 336.9 & 253.5 & 180.5 & 142.8 \\
\hline 2 & $2.0-2.5$ & 157 & 14.0 & 433 & 133.9 & 180 & 269 & 427.4 & 753.8 & 1281.5 & 1312.7 & 1225.8 & 1086.7 & 709.6 & 508.2 & 386.6 & 289.5 & 213.8 & 147.0 & 100.6 \\
\hline 3 & $2.0-2.5$ & 119 & 9.63 & 267 & 71.5 & 120.7 & 186.8 & 284.6 & 462.0 & 1280.8 & 1195.1 & 911.6 & 740.4 & 572.0 & 421.3 & 335.4 & 261.1 & 193.0 & 128.2 & 86.2 \\
\hline 4 & $2.1-2.5$ & 66 & 14.0 & 264 & 43.0 & 87.4 & 148.9 & 213.9 & 447.5 & 1305.3 & $*$ & $*$ & 556.1 & 426.1 & 329.2 & 265.9 & 214.2 & 170.4 & 116.1 & 78.9 \\
\hline
\end{tabular}

“**" indicates no data measured. ${ }^{a}$ Values of $x(\mathrm{~m})$.

\section{Table 3.2 Measured data at the measurement station $458 m$ downstream of the fire.}

\begin{tabular}{|c|c|c|c|c|c|c|c|c|c|c|c|c|}
\hline \multirow{3}{*}{$\begin{array}{l}\text { Test } \\
\text { no. }\end{array}$} & \multirow{3}{*}{$\begin{array}{c}\text { Measured } \\
\text { central velocity } \\
u(\mathrm{~m} / \mathrm{s})\end{array}$} & \multirow{2}{*}{\multicolumn{5}{|c|}{ Maximum gas temperature $\left({ }^{\circ} \mathrm{C}\right)$}} & \multicolumn{6}{|c|}{ Maximum gas concentration $(\%)$} \\
\hline & & & & & & & \multicolumn{2}{|c|}{$\mathrm{CO}_{2}, \max$} & \multicolumn{2}{|c|}{$\mathrm{CO}, \max$} & \multicolumn{2}{|c|}{$\mathrm{O}_{2}, \min$} \\
\hline & & $5.1 \mathrm{~m}$ & $4.0 \mathrm{~m}$ & $2.9 \mathrm{~m}$ & $1.8 \mathrm{~m}$ & $0.7 \mathrm{~m}$ & $5.1 \mathrm{~m}$ & $2.9 \mathrm{~m}$ & $5.1 \mathrm{~m}$ & $2.9 \mathrm{~m}$ & $5.1 \mathrm{~m}$ & $2.9 \mathrm{~m}$ \\
\hline 0 & $\sim 3$ & 23.2 & 23.2 & 21.8 & 20.7 & 19.0 & 0.237 & 0.102 & - & - & 20.6 & 20.6 \\
\hline 1 & $\sim 3$ & 151.2 & 149.3 & 137.4 & 121.9 & 108.9 & 13.5 & $>10.5 \% *$ & 0.268 & 0.193 & 7.37 & 7.36 \\
\hline 2 & $\sim 3$ & 108.1 & 102.9 & 96.2 & 85.1 & 76.2 & 10.2 & 10.1 & 0.313 & 0.269 & 9.44 & 9.63 \\
\hline 3 & $\sim 3$ & 98.3 & 87.8 & 79.1 & 67.7 & 60.5 & 7.16 & 7.08 & 0.073 & 0.050 & 12.6 & 12.6 \\
\hline 4 & $\sim 3$ & 83.2 & 81.2 & 75.7 & 66.9 & 58.2 & 4.02 & 3.78 & 0.097 & 0.076 & 16.3 & 16.3 \\
\hline
\end{tabular}

"** Above the measurement limit of $10.5 \%$.

"-" indicates that the measured values are ignorable due to small values. 
Table 3.3 Measured heat fluxes close to the fire.

\begin{tabular}{|c|c|c|c|c|c|c|c|}
\hline \multirow[t]{2}{*}{ Test } & \multicolumn{5}{|c|}{ Plate thermometer $\left(\mathrm{kW} / \mathrm{m}^{2}\right)$} & \multicolumn{2}{|c|}{ Schmidt Boelter gauge $\left(\mathrm{kW} / \mathrm{m}^{2}\right)$} \\
\hline & $\begin{array}{l}+0 \mathrm{~m}, \\
\text { ceiling }\end{array}$ & $\begin{array}{l}+10 \mathrm{~m} \\
\text { ceiling }\end{array}$ & $\begin{array}{l}+20 \mathrm{~m} \\
\text { ceiling }\end{array}$ & $\begin{array}{l}+40 \mathrm{~m}, \\
\text { ceiling }\end{array}$ & $\begin{array}{l}+20 \mathrm{~m}, \\
\text { floor }^{\mathrm{a}}\end{array}$ & $-15 \mathrm{~m}^{\mathrm{a}}$ & $+20 \mathrm{~m}^{\mathrm{b}}$ \\
\hline 0 & 14.5 & 3.4 & 1.6 & 1.3 & 0.9 & - & \\
\hline 1 & 244.5 & 406.2 & 323.9 & 222.8 & 373.6 & 14.5 & 343.9 \\
\hline 2 & 343.0 & 401.7 & 246.0 & 168.2 & 231.3 & 16.5 & 204.8 \\
\hline 3 & 330.1 & - & 103.3 & 47.3 & 85.6 & 9.06 & 79.8 \\
\hline 4 & 367.6 & - & - & 23.9 & 17.0 & 38.2 & 18.4 \\
\hline
\end{tabular}

${ }^{a} 1.6 \mathrm{~m}$ above the floor, and towards the main fire load.

b $1.6 \mathrm{~m}$ above floor, beside the target and flush with the wall.

Table 3.4 Fire spread to the targets.

\begin{tabular}{ccccc}
\hline Test & \multicolumn{2}{c}{ Edge of fire spread } & \multicolumn{2}{c}{ Corresponding ceiling gas temperature } \\
& wood & plastic & wood & plastic \\
& & & & - \\
\hline 0 & - & - & - & - \\
1 & - & $>53.5 \mathrm{~m}$ & $709^{\circ} \mathrm{C}-955^{\circ} \mathrm{C}$ & $<710^{\circ} \mathrm{C}$ \\
2 & $50 \mathrm{~m}-70 \mathrm{~m}$ & $>70 \mathrm{~m}$ & $674{ }^{\circ} \mathrm{C}-740^{\circ} \mathrm{C}$ & $<672{ }^{\circ} \mathrm{C}$ \\
3 & $42 \mathrm{~m}-52 \mathrm{~m}$ & $>52 \mathrm{~m}$ & $607^{\circ} \mathrm{C}-800{ }^{\circ} \mathrm{C}^{\mathrm{a}}$ & $466{ }^{\circ} \mathrm{C}-514^{\circ} \mathrm{C}$ \\
\hline
\end{tabular}

${ }^{\mathrm{a}}$ Estimated by extrapolation of the temperature curve.

Table 3.5 Backside wall temperatures.

\begin{tabular}{ccccccc}
\hline Test no. & \multicolumn{5}{c}{ Backside temperature $\left({ }^{\circ} \mathrm{C}\right)$} \\
& $45 \mathrm{~mm}^{*}$ & $\begin{array}{c}\text { B2 } \\
30 \mathrm{~mm}^{*}\end{array}$ & $\begin{array}{c}\text { B3 } \\
30 \mathrm{~mm}^{*}\end{array}$ & $\begin{array}{c}\text { B4 } \\
25 \mathrm{~mm}^{*}\end{array}$ & $\begin{array}{c}\text { B5 } \\
25 \mathrm{~mm}^{*}\end{array}$ & $\begin{array}{c}\text { B6 } \\
25 \mathrm{~mm}^{*}\end{array}$ \\
\hline 0 & 19.4 & 27.4 & 29.7 & 32.4 & 31.1 & 31.0 \\
1 & 89.5 & 137.2 & 181.0 & 210.8 & 200.7 & 201.7 \\
\hline
\end{tabular}

*thickness of the board.

Table 3.6 Results related to maximum backlayering lengths.

\begin{tabular}{cccccc}
\hline Test no. & HRR & $u_{\mathrm{o}, \mathrm{min}}$ & $L_{b}$ & \multicolumn{2}{c}{ Smoke front } \\
\cline { 5 - 7 } & $\mathrm{MW}$ & $\mathrm{m} / \mathrm{s}$ & $\mathrm{m}$ & $\begin{array}{c}\text { Approximate } \\
\text { location }(\mathrm{m})\end{array}$ & $\begin{array}{c}T_{\max } \\
\left({ }^{\circ} \mathrm{C}\right)\end{array}$ \\
\hline 0 & 6 & 2.09 & $15 \sim 25$ & -15 & 144.5 \\
1 & 202 & 1.93 & $\sim 100$ & -100 & 96.0 \\
2 & 157 & 1.99 & $\sim 100$ & -100 & 133.6 \\
3 & 119 & 2.04 & $\sim 100$ & -100 & 71.5 \\
4 & 66 & 2.09 & $\sim 100$ & -100 & 42.6 \\
\hline
\end{tabular}




\section{$4 \quad$ Discussion of results}

Both results from previous analyses and new results are presented here. In the following, heat release rate, fire growth rate, gas temperature, flame length, radiation, fire spread, gas production, ventilation, backside wall temperature, and backlayering are investigated. The main aim has been to develop some simple and robust methods to estimate these important parameters.

\subsection{Heat release rate}

Ingason and Lönnermark [1-2] provided detailed information about the HGV trailer fire loads, and estimated the heat releases rates in $\mathrm{T} 1$ to $\mathrm{T} 4$ based on the measured gas concentration $458 \mathrm{~m}$ downstream of the fire and the measured mass flow rate, see Figure 4.1. A theoretical method was proposed to calibrate the time delay due to the measurement station far away from the fire source. The heat release rates of T1 to T4 are presented in Figure 4.1 and in Appendix B to E. Peak HRRs in the range of 66-202MW were estimated.

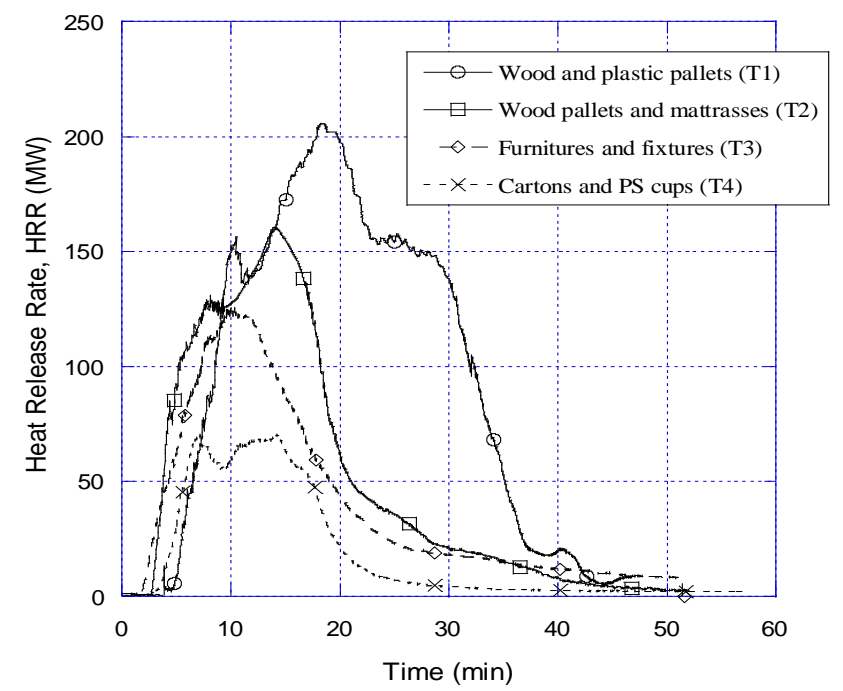

Figure 4.1 The estimated HRR from the four large-scale fire tests with HGV trailer fire load.( from Ingason and Lönnermark [1])

The heat release rate was estimated by the following equation:

$$
Q=14330 \dot{m}\left(\frac{X_{0, O_{2}}\left(1-X_{\mathrm{CO}_{2}}\right)-X_{\mathrm{O}_{2}}\left(1-X_{0, \mathrm{CO}_{2}}\right)}{1-X_{\mathrm{O}_{2}}-X_{\mathrm{CO}_{2}}}\right)
$$

The mass flow rate, $\dot{m}$, in Equation (3) was calculated using:

$$
\dot{m}=\rho_{o} u_{o} A \text { or } \dot{m}=\xi \sum \rho_{j} u_{j} A_{j}
$$

The correlation between the concentration of $j$ th species and the temperature at a crosssection, was also used to estimate the average gas concentration. This correlation can be expressed as follows:

$$
\frac{\Delta X_{k, h}}{\Delta X_{k, a v g}}=\frac{\Delta T_{h}}{\Delta T_{a v g}}
$$


where $Q$ is the heat release rate, $\dot{m}$ is the mass flow rate, $X_{02}$ is the oxygen concentration (\%), $X_{\mathrm{CO} 2}$ is $\mathrm{CO} 2$ concentration, $X_{0,02}$ is the ambient $\mathrm{O} 2$ concentration, $X_{\mathrm{CO} 2}$ is the ambient $\mathrm{CO} 2$ concentration, $\Delta X_{k, h}$ is the concentration difference of species $k$ at height $h, \Delta X_{k, \text { avg }}$ is the average concentration difference of species $k, \Delta T_{h}$ is the temperature difference at height $h, \Delta T_{\text {avg }}$ is the average temperature difference, $\rho_{o}$ is ambient density, $u_{\mathrm{o}}$ is longitudinal ventilation velocity, $A$ is tunnel cross-sectional area, $\xi$ is a flow coefficient, $\rho_{j}$ is gas density of jth layer, $u_{j}$ is gas velocity of jth layer, $A_{j}$ is cross-sectional area of jth layer.

It was argued by Ingason and Lönnermark [1] that the method used here to estimate the HRR include many uncertainties. Calculations show that the combined expanded relative standard uncertainty with $95 \%$ confidence interval was $14.9 \%$. The largest contribution to combined relative uncertainty of the HRR was related to the volume flow measurements (6.7\%), followed by the contribution of the oxygen measurements $(2.1 \%)$ and from the Efactor $\left(13.1 \mathrm{MJ} / \mathrm{kg} \mathrm{O}_{2}\right) 2 \%$. Other contributions are calculated to be lower than $1 \%$.

Here a simple method is proposed to estimate the maximum heat release rate in a ventilated tunnel fire. According to the earlier work [14-16], the heat release rate in a tunnel fire can be directly related to the fuel mass burning rate or the ventilation condition. In other words, the fuel mass burning rate increases with the ventilation velocity for fuel controlled fires and approaches constant for well ventilated fires. In most of tunnel fires, such as the Runehamar tunnel fire tests, the fires are well ventilated. No blockages in front or the rear of the fuel were used which explains the easy access of oxygen into the core of the fuel. The peak heat release rate in the tunnel fires can be estimated by the following equation:

$$
Q_{\max }=\dot{m}_{f}^{\prime \prime} \chi \Delta H_{c} A_{f}
$$

where $\dot{m}_{f}^{\prime \prime}$ is the mass burning rate per unit fuel area $\left(\mathrm{kg} / \mathrm{m}^{2} \cdot \mathrm{s}\right), \chi$ is the combustion efficiency, $\Delta H_{c}$ is the heat of combustion $\left(\mathrm{MJ} / \mathrm{kg}\right.$ ) and $A_{f}$ is the total exposed fuel surface $\left(\mathrm{m}^{2}\right)$. The relevant fuel properties can be found in Table 4.1. The estimated total fuel surface area is $4 \mathrm{~m}^{2}$ (T0), $1024 \mathrm{~m}^{2}$ (T1), $607 \mathrm{~m}^{2}$ (T2), $268 \mathrm{~m}^{2}$ (T3)and $195 \mathrm{~m}^{2}$ (T4), respectively.

Table 4.1 Properties of fuels used in the analysis.

\begin{tabular}{c|c|c|c|c}
\hline Material & $\begin{array}{c}\text { Burning rate } \\
\text { per unit area } \\
\left(\mathrm{kg} / \mathrm{m}^{2} \cdot \mathrm{s}\right)\end{array}$ & $\begin{array}{c}\text { Heat of } \\
\text { Combustion } \\
(\mathrm{MJ} / \mathrm{kg})\end{array}$ & $\begin{array}{c}\text { Relevant } \\
\text { tests }\end{array}$ & Reference \\
Diesel & 0.035 & 39.7 & $\mathrm{~T} 0$ & {$[17]$} \\
Wood & 0.013 & 16.7 & $\mathrm{~T} 1-\mathrm{T} 4$ & {$[14-16]$} \\
PE Plastic & 0.014 & 43.6 & $\mathrm{~T} 1$ & {$[18-19]$} \\
PUR mattresses & 0.032 & 25.0 & $\mathrm{~T} 2$ & {$[18-19]$} \\
Furniture* & 0.020 & 25.0 & $\mathrm{~T} 3, \mathrm{~T} 4$ & {$[20]$} \\
\hline
\end{tabular}

$* \dot{m}_{f}^{\prime \prime} \Delta H_{c}$ was estimated between $0.4-0.5 \mathrm{MW} / \mathrm{m}^{2}$ for furniture by Ingason [20].

A comparison of calculated maximum HRR and measured HRR is presented in Figure 4.2. A combustion efficiency of 0.9 was assumed in the calculation. It is shown that the calculated HRR correlate well with the measured values. The uncertainty is about $20 \%$. This shows that the simple equation used, i.e. Equation (6), is suitable to estimate the maximum HRR in a fuel controlled tunnel fire (well ventilated). 


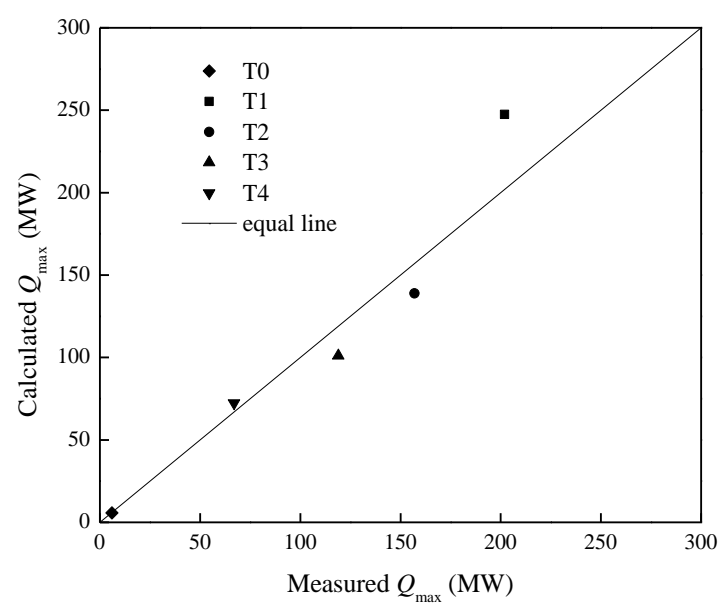

Figure 4.2 Comparison of measured maximum HRR with calculated values using Eq. (6)

\subsection{Fire Growth rate}

$\mathrm{Li}$ and Ingason [21] proposed a theoretical approach to model the fire growth rate in a ventilated tunnel fire. The relationship between the flame spread and the fire growth rate in a ventilated flow was analyzed theoretically. A large amount of data relevant to the fire growth rate from model and large scale tunnel fire tests, including Runehamar tests and Second Benelux tests [22], were collected and applied to a detailed analysis of the effect of ventilation on the fire growth rate. It was proven that the longitudinal flame spread dominates the fire spread in a ventilated tunnel fire. The thermal inertia, heat of combustion, the wet perimeter, and the mass burning rate per unit area of the fuel play important roles in the fire growth rate. In addition, the fire growth rate increases linearly with the ventilation velocity. A robust formula that fits all the data of the fire growth rate from model and large scale tunnel fire tests very well was proposed, see Figure 4.3. Further, the proposed equation is applicable to predict the fire growth rate for different types of fuels, even for fuels consisting of several parts.

$$
\frac{d Q}{d t}=1.2 \times 10^{-3} u_{o} \sum_{i=1}^{N} C_{f, i} w_{p, i}
$$

where the ith material property

$$
C_{f, i}=\frac{\dot{m}_{f, i}^{\prime \prime} \Delta H_{c, i}}{(k \rho c)_{f, i}}
$$

where $d Q / d t$ is the fire growth rate, $C_{f, i}$ is the ith material property, $w_{p, i}$ is the wet perimeter of ith material, $\dot{m}_{f, i}^{\prime \prime}$ is the mass burning rate per unit area of ith fuel, $\Delta H_{c, i}$ is the heat of combustion of ith material, $(k \rho c)_{f, i}$ is thermal inertia of ith fuel. Any type of blockage of the ventilation flow on the upstream side (front) or the downstream side of the fuel (rear) may influence the fire growth rate given by equation (7). 


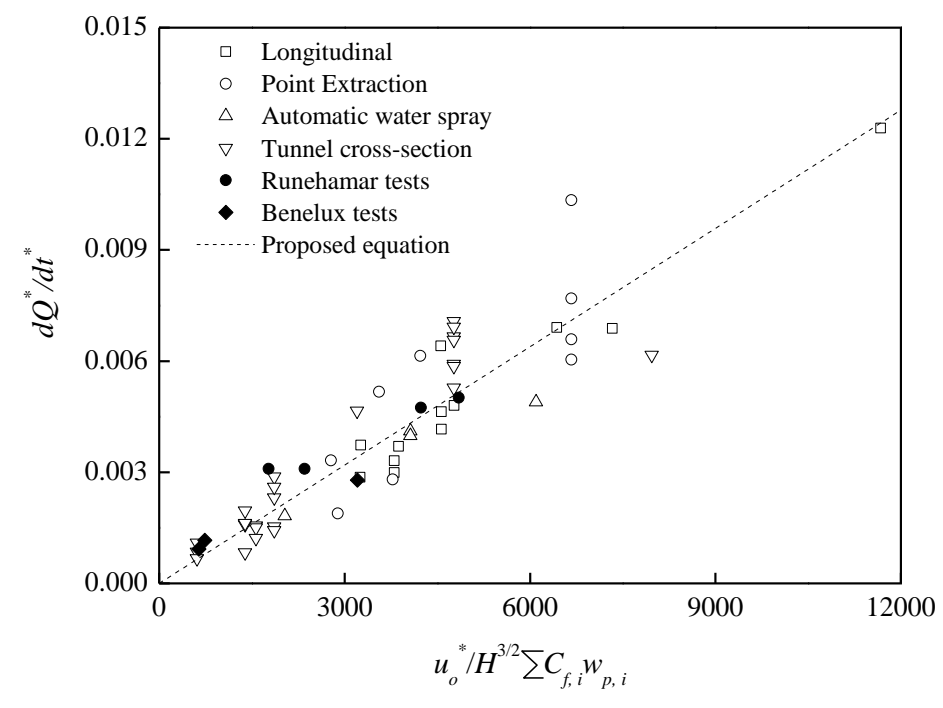

Figure 4.3 The fire growth rate in a ventilated tunnel fire. (from Li and Ingason [21])

\subsection{Gas temperature}

Lönnermark and Ingason [3-4] investigated the maximum ceiling gas temperature data from the Runehamar tests and compared them with the standard temperature time curves. The maximum heat release rates produced by the four different HGV fire loads varied between 66 and $202 \mathrm{MW}$ resulting in maximum gas temperatures at the ceiling ranging between 1281 and $1360{ }^{\circ} \mathrm{C}$. The temperatures measured downstream of the fire were very high and the measurements indicated that the flaming zone could expand up to a length of $70-100 \mathrm{~m}$. The high temperatures affected the entire tunnel ceiling downstream of the fire causing considerable spalling of the unprotected tunnel ceiling after T1, resulting in considerable rock debris completely covering the road. The long flames and high temperatures would also be expected to cause the fire to spread to other vehicles. A comparison with literature values of maximum ceiling temperatures shows that the gas temperatures obtained in the Runehamar tests were uniformly higher than those obtained in other similar large-scale test series conducted using solid materials, see Figure 4.4. The standard ISO 834 curve, The Hydrocarbon curve, the RWS curve and the RABT/ZTV curve are all plotted in Figure 4.4. A mathematical correlation of a temperature-time curve is given, which best represents the measured temperature and a combination of frequently used temperature curves for tunnels (the HC curve and the RWS curve). 


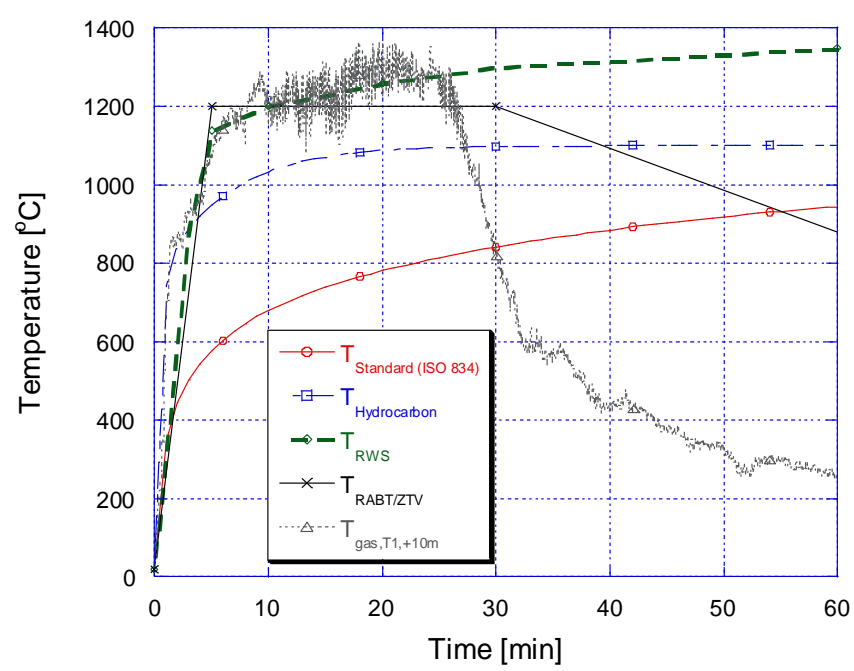

Figure 4.4 The gas temperatures in test T1 are compared with different fire temperature curves used for testing reaction of structures to heat exposure. The initial time delay has been subtracted from the experimental curves. (from Lönnermark and Ingason [3])

$\mathrm{Li}$ and Ingason [23-25] investigated the maximum ceiling temperature in a tunnel fire using most of the data available all over the world, including the Runehamar tests data. It was proposed that the maximum excess gas temperature beneath the ceiling in a tunnel fire can be divided into two regions depending on the dimensionless ventilation velocity, $V^{\prime}$ (see definition given by equation (10))Each can be subdivided into two regions with transition from linear increase to a constant plateau according to the fire size and ventilation. The maximum excess gas temperature beneath the ceiling can be expressed respectively as [23-25]:

Region I ( $\left.V^{\prime} \leq 0.19\right)$ :

$$
\Delta T_{\text {max }}= \begin{cases}\text { DTR } 1, & \text { DTR } 1<1350 \\ 1350, & \text { DTR } 1 \geq 1350\end{cases}
$$

Region II ( $\left.V^{\prime}>0.19\right)$ :

$$
\Delta T_{\text {max }}= \begin{cases}\text { DTR 2, } & \text { DTR } 2<1350 \\ 1350, & \text { DTR } 2 \geq 1350\end{cases}
$$

where

$$
\begin{aligned}
& \text { DTR } 1=17.5 \frac{Q^{2 / 3}}{H_{e f}^{5 / 3}}, \\
& \text { DTR } 2=\frac{Q}{u_{o} b_{f o}^{1 / 3} H_{e f}^{5 / 3}} .
\end{aligned}
$$

In Equation (8) and (9), DTR1 means Delta Temperature in Region I $\left({ }^{\circ} \mathrm{C}\right)$ and DTR2 means Delta Temperature in Region II $\left({ }^{\circ} \mathrm{C}\right), H_{e f}$ is the effective tunnel height (m), i.e. the vertical distance between the bottom of the fire source and tunnel ceiling, $b_{f o}$ is the equivalent radius of fire source $(\mathrm{m})$. The dimensionless ventilation velocity, $V^{\prime}$, in Equations(8) and (9) is defined as: 


$$
V^{\prime}=\frac{u_{o}\left(b_{f o} \rho_{o} c_{p} T_{o}\right)^{1 / 3}}{\left(g Q_{c}\right)^{1 / 3}}
$$

where $g$ is gravity acceleration $\left(\mathrm{m}^{2} / \mathrm{s}\right), c_{p}$ is heat of capacity $(\mathrm{kJ} / \mathrm{kg} \cdot \mathrm{K}), T_{o}$ is ambient temperature $(\mathrm{K}), Q_{c}$ is the convective heat release rate $(\mathrm{kW})$.

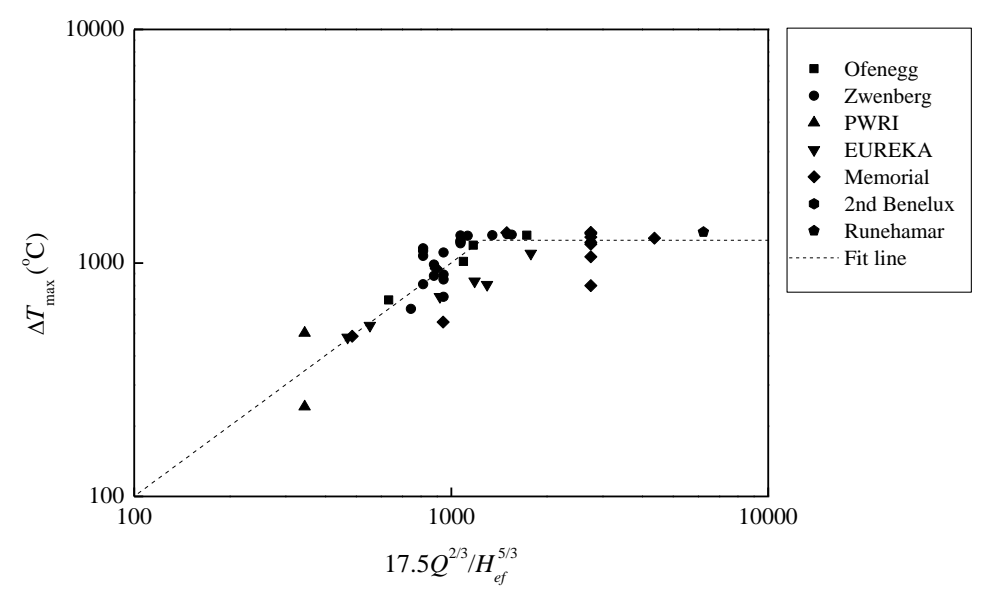

Figure 4.5 The maximum excess temperature beneath the tunnel ceiling in large scale tests (Region I, $V^{\prime} \leq 0.19$ ). (from Li and Ingason[23-25])

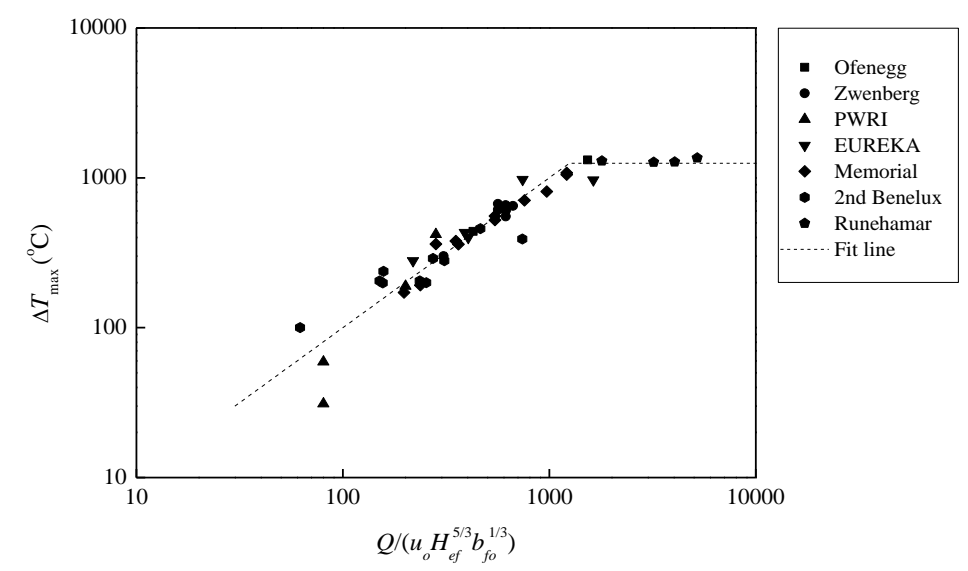

Figure 4.6 The maximum excess temperature beneath the tunnel ceiling in large scale tests (Region II, $V^{\prime}>0.19$ ). (from Li and Ingason[23-25])

Ingason and $\mathrm{Li}$ [14] also investigated the distribution of the ceiling gas temperature and data from a series of model scale tests and Runehamar tests and Memorial tests were used in the analysis. Generally, the ceiling temperature decrease sharply with the distance away from the fire and then turns to decrease gradually with the distance. For T1 and T2, obvious virtual origins were observed, for which the continuous flame were expected to be responsible [14]. The distribution of ceiling temperature is shown in Figure 4.7. The proposed equation to estimate the ceiling temperature distribution can be expressed as:

$$
\frac{\Delta T_{c}(x)}{\Delta T_{c, \max }}=0.57 \exp \left(-0.13 \frac{x}{H}\right)+0.43 \exp \left(-0.021 \frac{x}{H}\right)
$$

where $\Delta T_{c}(x)$ is the excess ceiling gas temperature at $x\left({ }^{\circ} \mathrm{C}\right), \Delta T_{c, \max }$ is the maximum excess gas temperature $\left({ }^{\circ} \mathrm{C}\right), x$ is the downstream distance from the fire source $(\mathrm{m})$. 
Note that the dimensionless excess gas temperatures from the Memorial tunnel tests are slightly higher when the dimensionless distance away from the fire source is about 30 , corresponding to a distance of approximately $238 \mathrm{~m}$ in large scale. The possible reason is that this thermocouple was placed beside the fan room at the south portal, which blocked the smoke flowing outside. This means that the fire scenario here is similar to a smoke filling process. Thus, the smoke layer could be lower in height and the temperature beneath the ceiling would therefore be expected to increase. In any case, Figure 4.7 strongly indicates that the distribution of gas temperature beneath the ceiling can be modeled well in a model scale tunnel even with a scale of 1:23.

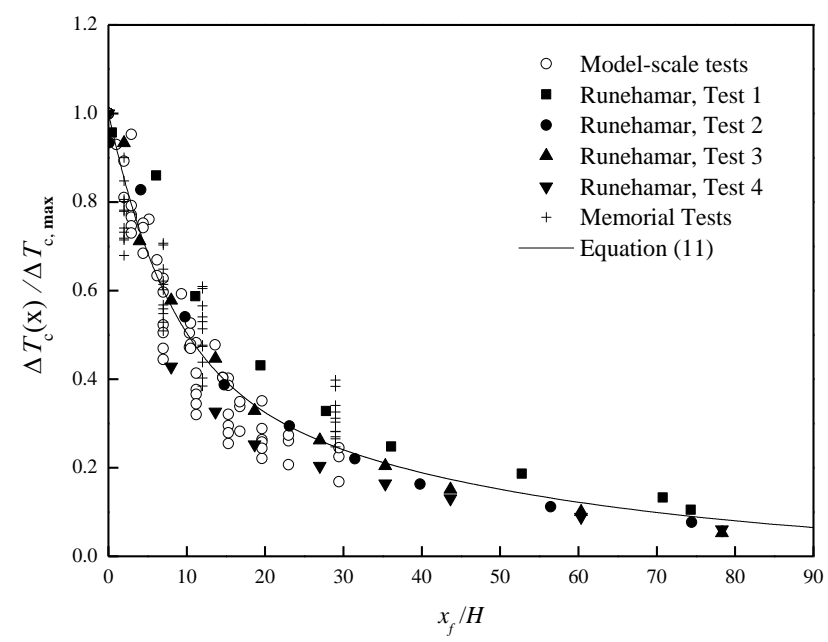

Figure 4.7 The dimensionless excess gas temperature beneath the ceiling downstream of the fire as a function of dimensionless distance away from the fire. (from Ingason and $\mathrm{Li}[14]$ )

\subsection{Flame length}

Lönnermark and Ingason [5] investigated the flame lengths of the Runehamar tests. Alpert's equation for ceiling jet temperatures was used to estimate the shape of the equation for the flame length, and the uncertainty coefficients were determined by regression analysis which gave a best fit for an exponent of 0.8 for the heat release rate, see Figure 4.8. Data from Runehamar tests and some data from Memorial tests were used in the analysis. The proposed equation can expressed as follows:

$$
L_{f}=\frac{1370 Q^{0.8} u_{o}^{-0.4}}{\left(T_{f}-T_{o}\right)^{3 / 2} H^{3 / 2}}
$$

where $L_{f}$ is the flame length and $T_{f}$ is the flame tip temperature. 


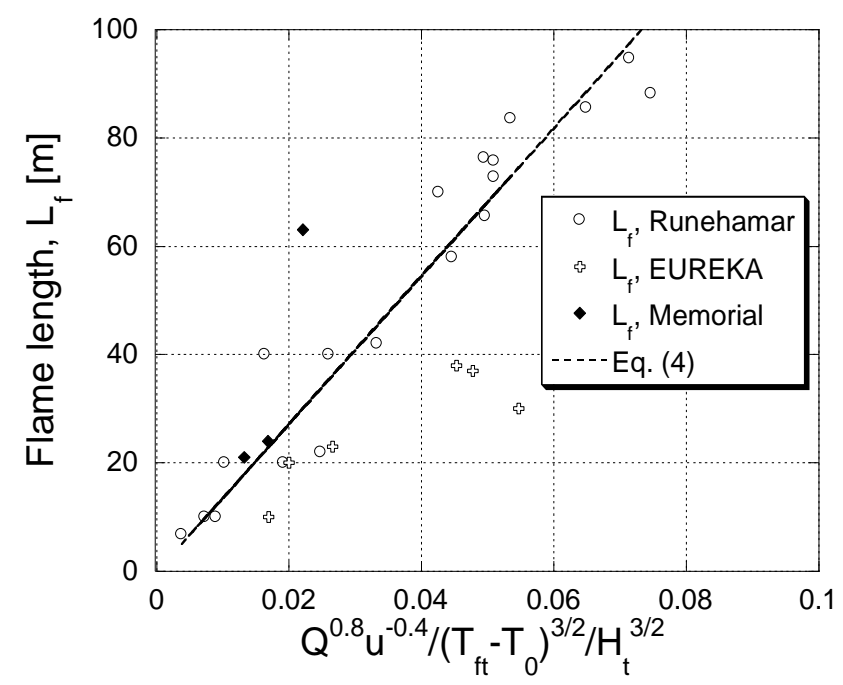

Figure 4.8 Comparison between flame length data from Runehamar, EUREKA, and Memorial and the proposed correlations. (from Lönnermark and Ingason [5])

Ingason and $\mathrm{Li}[14,16]$ also investigated the flame length based on data from a series of model and large scale tests. The results show that the effect of ventilation on the flame length is limited. The heat release rate and the width of the tunnel play the two key roles in the flame length in a large tunnel fire. A dimensionless equation that can fit all the data from model and full scale data well in longitudinally ventilated tunnel fires was proposed, as shown in Figure 4.9, which can be expressed as follows:

$$
L_{f}^{*}=4.3 Q_{f}^{*}
$$

where

$$
L_{f}^{*}=\frac{L_{f}}{H}, \quad Q_{f}^{*}=\frac{Q}{\rho_{o} c_{p} T_{o} g^{1 / 2} A H_{f}^{1 / 2}}
$$

where $L_{f}^{*}$ is the dimensionless flame length, $Q_{f}{ }^{*}$ is the dimensionless heat release rate and $H_{f}$ is the vertical distance between the fire source centre and tunnel ceiling $(\mathrm{m})$.

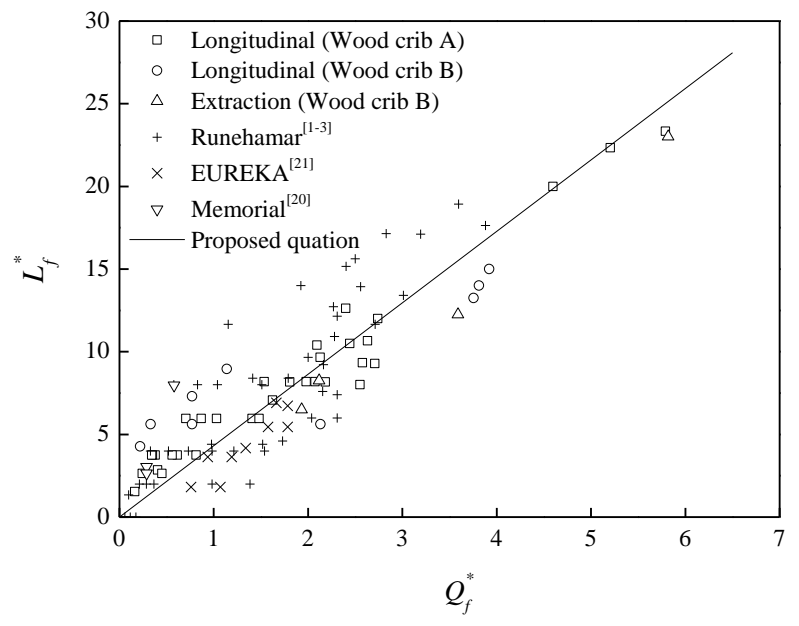

Figure 4.9 Flame lengths from series of model and large-scale tests are plotted as a function of dimensionless heat release rate $Q_{f}{ }^{*}$. (from Ingason and $\mathrm{Li}[14,16])$ 


\subsection{Radiation}

Based on the heat fluxes it is possible to estimate the conditions for a material to ignite at a certain distance from the fire and determine whether the environment in the tunnel is tenable for evacuees.

Lemaire [9] investigated the heat fluxes measured by four Schmidt-Boelter flux meters close to the fire site. All flux sensors were facing the fire except for sensor $3(+10 \mathrm{~m})$ which lay on the floor, facing the ceiling. Sensor $1(+0 \mathrm{~m})$ was mounted in the wall of the fire protection, $1 \mathrm{~m}$ above the floor. In T1 and T2, sensor 2 and 4 were located at a distance of $5 \mathrm{~m}(-10 \mathrm{~m})$ and $20 \mathrm{~m}(-25 \mathrm{~m})$ behind the cargo, also at a height of $1 \mathrm{~m}$. In T3 and T4 positions were slightly changed, because the cargo had to be moved upstream and sensor 3 could not be moved accordingly. The results of heat fluxes are shown in Figure 4.10. In $\mathrm{T} 1$ heat fluxes on the floor of $250 \mathrm{~kW} / \mathrm{m}^{2}$ (Sensor 3) occurred during 15 minutes. In the same test peak values of $200 \mathrm{~kW} / \mathrm{m}^{2}$ and average values of about $120 \mathrm{~kW} / \mathrm{m}^{2}$ on the wall were observed. At a distance of $5 \mathrm{~m}$ upstream of the fire the heat flux was still 50 $\mathrm{kW} / \mathrm{m}^{2}$. A risk of fire spread to a vehicle at that location existed in all tests, but for different periods of time. In T1 the risk exists during 55 minutes. In the other, less severe tests, there was a significant risk for fire spread to adjacent vehicles during shorter periods of time, from approximately 7 to 10 minutes occur.
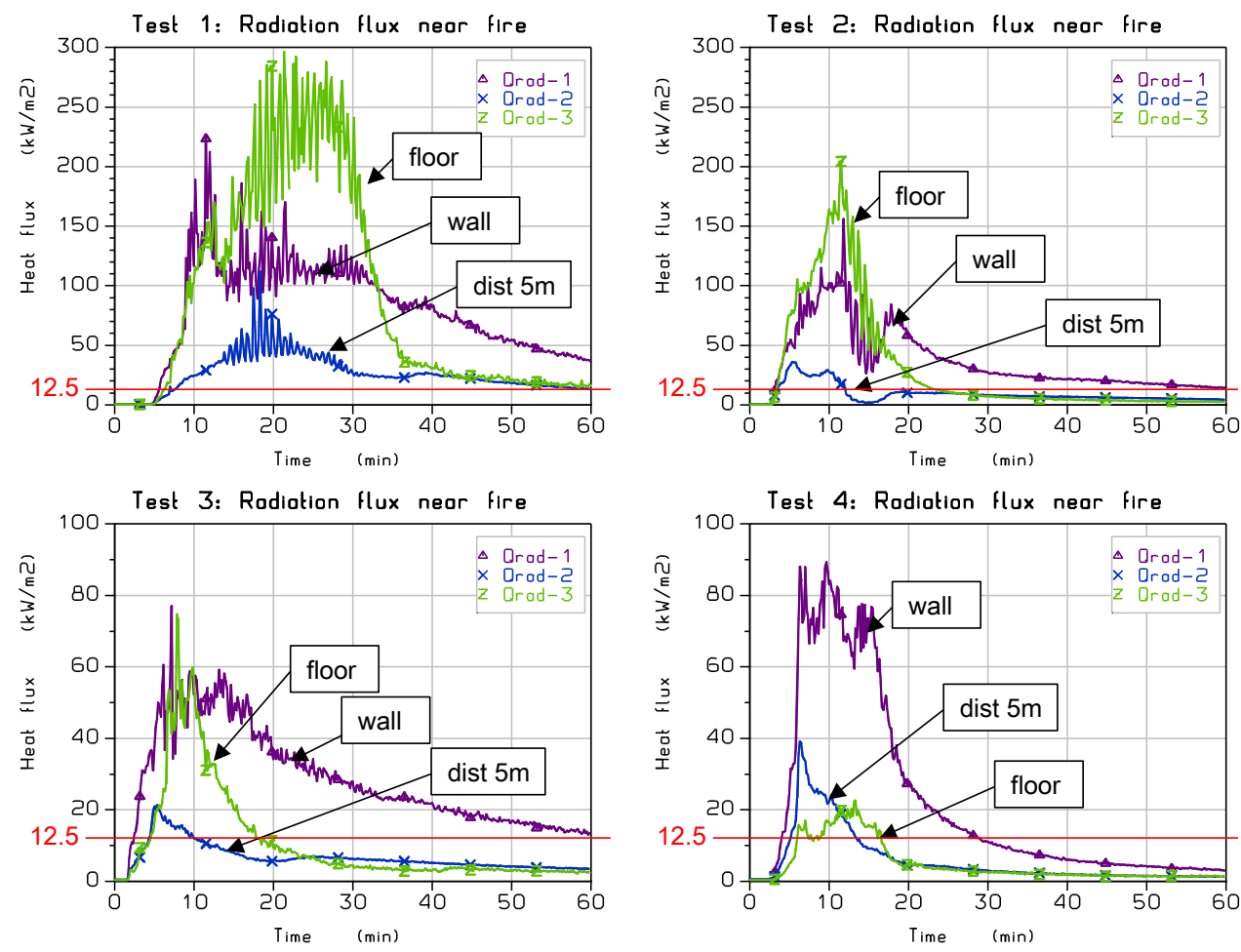

Figure 4.10 Radiation fluxes near the fire for each test.(from Lemaire [9])

Figure 4.11 shows the incident heat flux measured by plate thermometers at the ceiling in the vicinity of the fire in T1. The highest incident heat flux of about $400 \mathrm{~kW} / \mathrm{m}^{2}$ was measured $10 \mathrm{~m}$ downstream of the fire based on Equation (2). The incident heat flux above the fire lay at the same level as $40 \mathrm{~m}$ downstream of the fire, where a highest value of $223 \mathrm{~kW} / \mathrm{m}^{2}$ was measured in T1. All the measured heat fluxes increased sharply in the growth period of the fire and approached a constant during a long period between 13 min to $30 \mathrm{~min}$. 


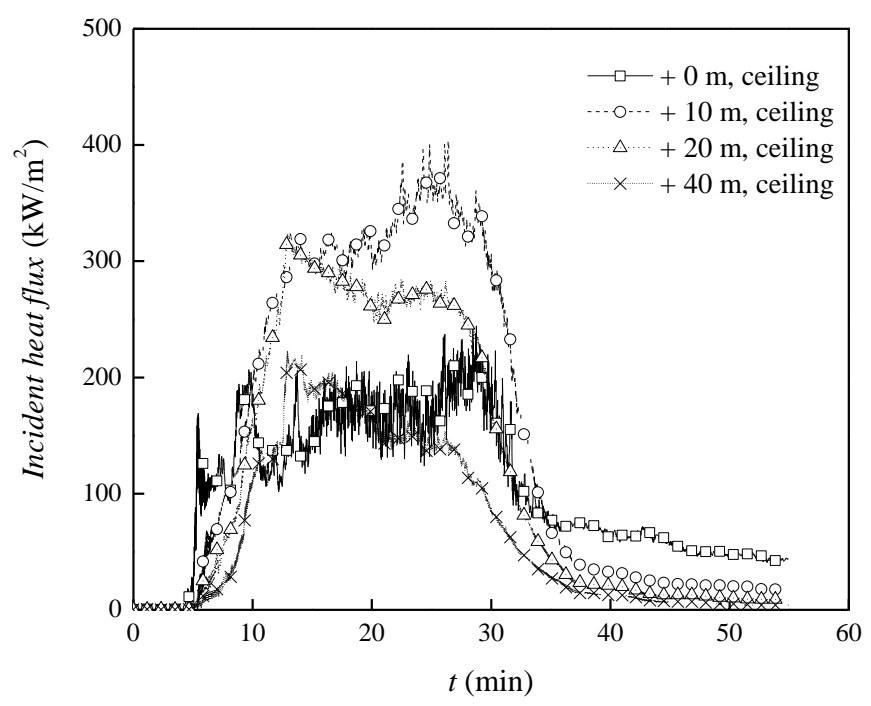

Figure 4.11 Incident heat flux measured by plate thermometer at the ceiling close to the fire in $T 1$.

In the vicinity of a fire, the radiation dominates the heat transfer. The incident heat flux represents the intensity of incident radiation from surroundings. Since the tunnel ceiling is enclosed by the flame and hot gases, the view factor can be regarded as being unity. Thus the incident heat flux at the ceiling can be simply expressed as:

$$
\dot{q}_{i n c}^{\prime \prime}=\varepsilon_{g} \sigma T_{g}^{4}
$$

where $\varepsilon_{g}$ is the gas emissivity, $T_{g}$ is the gas temperature. Note that $T_{g}$ must be expressed in degrees Kelvin for this equation to be valid. Also, note that the view factor could not be equal to one in some other cases, e.g. a surface at the floor level. In such cases, the view factor needs to be considered on the right-hand side of Equation (14). In tests T1 to $\mathrm{T} 4$, large amounts of smoke particles were produced and thus the emissivity of the flame and hot gases under the ceiling could be considered as unity.

Figure 4.12 shows a comparison between the measured maximum ceiling incident heat flux and the values calculated using Equation (14). In the calculations, the emissivity was assumed to be equal to one. The correlation is found to be very good in Figure 4.12. This indicates the emissivity of the flames and hot gases in the vicinity of the fire approximately equals one. Two data measurements for heat fluxes at $20 \mathrm{~m}$ downstream and at floor level were little lower than the calculated values due to the location of the measuring probes (at floor level).

The equation for the incident heat fluxes is useful for calculation of thermal impact on constructions. 


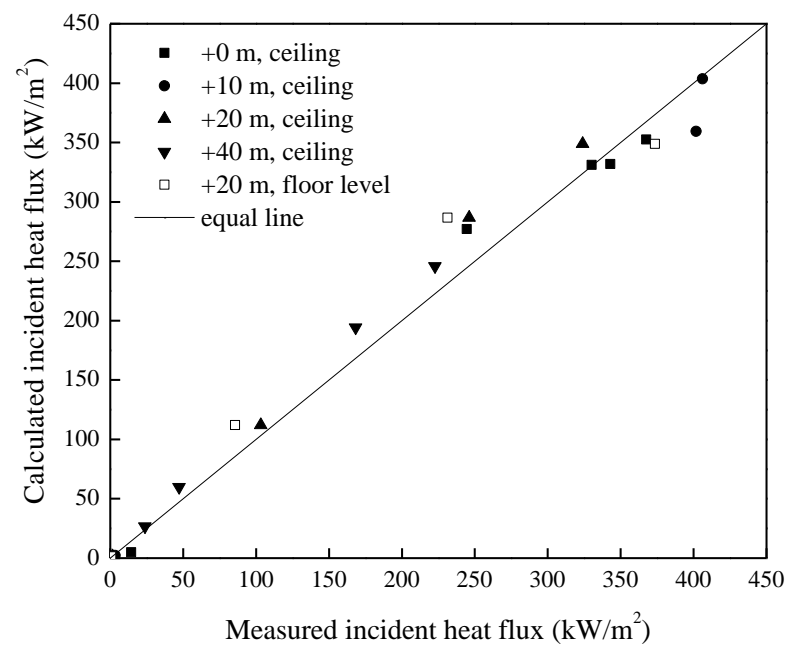

Figure 4.12 Comparison of measured maximum ceiling incident heat flux with calculated values using Eq. (14).

The incident heat fluxes measured at $20 \mathrm{~m}$ downstream of fire are presented in Figure 4.13. This figure clearly shows that the ceiling heat flux was generally higher than the corresponding values measured $1.6 \mathrm{~m}$ above the floor. The main reason is the difference in the view factor and the characteristic temperature. However, the values are close to each other.

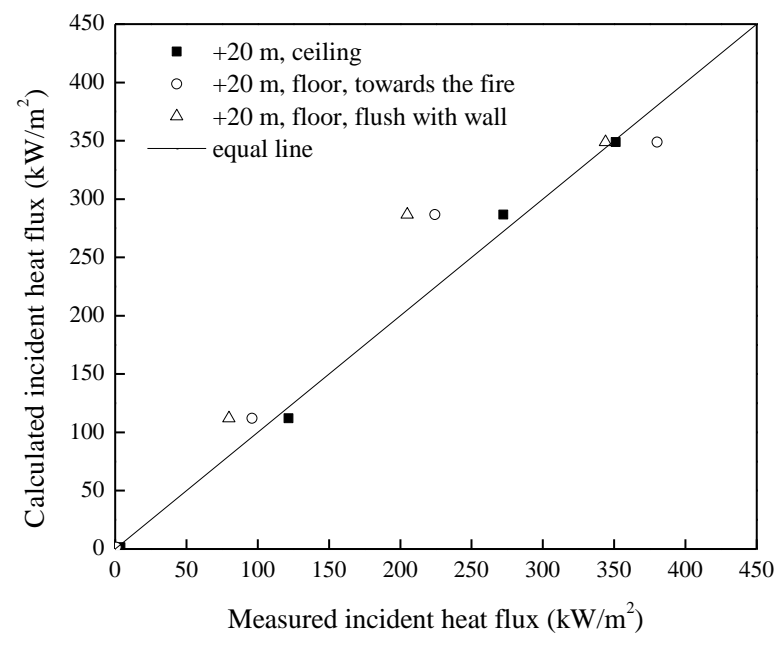

Figure 4.13 Comparison of measured maximum ceiling incident heat flux with calculated values using Eq. (14).

Note that the plate thermometers measure the incident heat flux (calculated with equation (2)), $\dot{q}_{i n c}^{\prime \prime}$, however, the Schmidt Boelter gauge measure the total absorbed heat flux at a cooled surface, $\dot{q}_{e}^{\prime \prime}$. The difference in heat flux measurement can be found from the following equation [26]:

$$
\dot{q}_{t o t}^{\prime \prime}=\varepsilon_{s}\left(\dot{q}_{i n c}^{\prime \prime}-\sigma T_{s}^{4}\right)+h_{c}\left(T_{\infty}-T_{s}\right)
$$


where $\dot{q}_{t o t}^{\prime \prime}$ is the total absorbed heat flux at the surface, $\varepsilon_{s}$ is the surface emissivity of the gauge, $T_{s}$ is the surface temperature of the gauge, $T_{\infty}$ is the gas temperature surrounding the Schmidt Boelter gauge, $h_{c}$ is the convective heat transfer coefficient.

Figure 4.14 shows the heat flux measured by Schmidt-Boelter flux meter at two locations close to the fire in test T1. Note that the Schmidt-Boelter flux meters were placed $1.6 \mathrm{~m}$ above floor. In such cases, generally the contribution of convective heat transfer to the total heat flux is quite limited. Also, note that the emissivity of the flux meter is little lower than unit. Therefore, it can be concluded, based on Equation (15), that the heat flux measured by a Schmidt Boelter gauge placed should be slightly lower than the incident heat flux measured by a plate thermometer at floor level. The difference is mainly dependent on the emissivity of the Schmidt Boelter gauge.

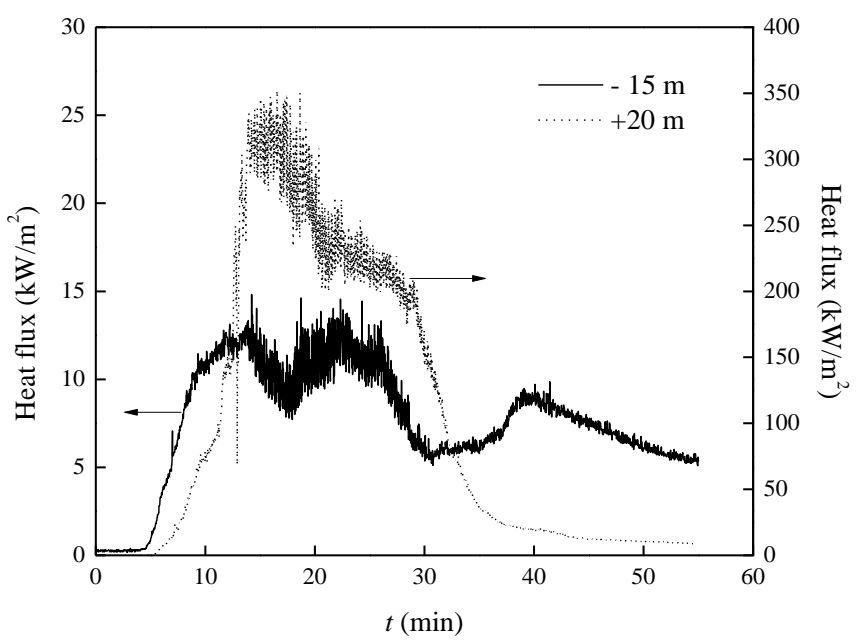

Figure 4.14 Heat flux measured by Schmidt-Boelter flux meter at two locations close to the fire, $T 1$. The heat flux meter at $-15 \mathrm{~m}$ was towards the fire load and the heat flux meter at $+20 \mathrm{~m}$ was flush with the wall. Both were placed $1.6 \mathrm{~m}$ above the floor

\subsection{Fire spread}

Lönnermark and Ingason [5] investigated the fire spread in the Runehamar tests. Several targets were placed at different locations downstream of the fire, see Figure 4.15. In actual fact even more targets were used to investigate the fire spread, which are not shown in this figure. Models of the average temperature for the cross-section were used to study the connection of this parameter to fire spread. For the region of fire spread, a large temperature difference between the temperature in the upper layer and the calculated average temperature of the cross-section exists. This temperature difference has an important affect on the incident radiation, which in most cases is the cause of fire spread. The use of an average temperature in fire spread calculations might, therefore, be misleading. However, an average temperature of approximately $500{ }^{\circ} \mathrm{C}$ seems to give the best correlation with fire spread. 


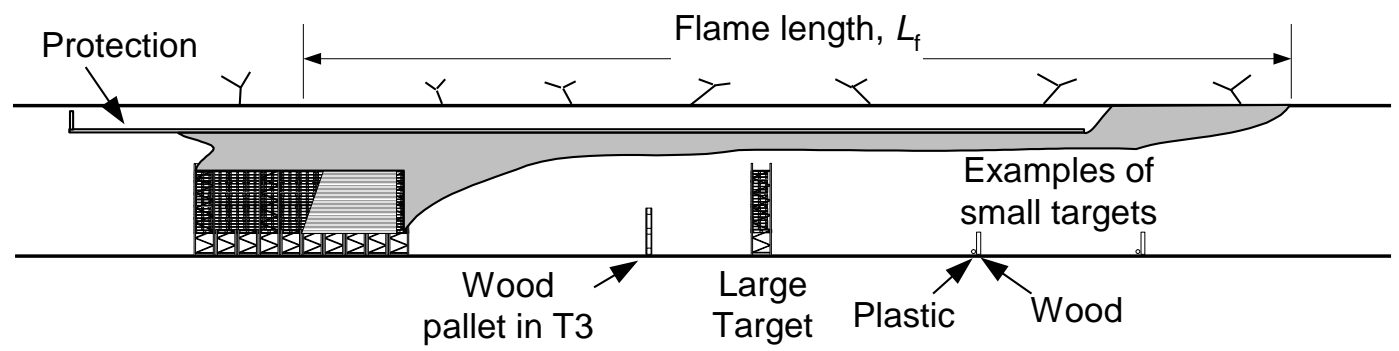

Figure 4.15 A diagram of the fire load and the targets placed downstream of the fire. (from Lönnermark and Ingason[6])

The mechanism of the fire spread to a vehicle downstream of the fire in a large tunnel fire is the ignition of the downstream vehicle, which is directly related to the exposed heat flux (or gas temperature) and the duration time (or exposure time). It is well known that there are two types of ignition: piloted ignition and spontaneous ignition. The ignition of the samples placed on the floor and at a distance downstream of the fire are definitely spontaneously ignited, however, the ignition may be piloted for samples placed close to the ceiling. It is much easier for the samples placed closer to the ceiling to ignite due to piloted ignition and enhancement of heat transfer. The ignition temperature for piloted ignition is much lower than for spontaneous ignition [27].

The ignition of a material can be categorized into two stages: the heat-up stage and the mixture ignition stage. In the heat-up stage, the material is heated up by an exposed heat flux or convective gas flow and produces combustible volatiles continuously, i.e. pyrolysis. In the mixture ignition stage, the produced combustible volatiles above the material surfaces are ignited by the heat flux or the hot gas flow.

The critical condition for this ignition is difficult to identify. In the literature, the critical ignition condition varies significantly, including ignition temperature, critical heat flux, critical fuel mass flow rate, etc. In spite of the significant difference in determination of the critical ignition condition, it can be expected that there is a strong correlation between the ignition and the ceiling gas temperature in a ventilated tunnel fire. Here we analyze the ignition condition using the critical ceiling gas temperature, i.e. the minimum ceiling gas temperature required to ignite the material. A corresponding critical incident heat flux can also be defined in a similar way, i.e. the minimum incident heat flux required to ignite the material. In actual fact, the total heat flux absorbed by the material surface may be more reasonable instead of the incident heat flux. This means that the emissivity or the absorptivity of the material surface also has a strong influence on the ignition.

At the ignition state, the controlling equation for the energy in the surface layer of the sample can be expressed as:

$$
\dot{q}_{i g}^{\prime \prime}=\varepsilon_{s}\left(\dot{q}_{i n c}^{\prime \prime}-\sigma T_{i g}^{4}\right)+h_{c}\left(T_{\infty}-T_{i g}\right)
$$

where $\dot{q}_{i g}^{\prime \prime}$ is the critical heat flux at ignition $\left(\mathrm{kW} / \mathrm{m}^{2}\right), \dot{q}_{i n c}^{\prime \prime}$ is incident heat flux the surface is exposed to $\left(\mathrm{kW} / \mathrm{m}^{2}\right), \varepsilon_{s}$ is the surface emissivity of the sample and $T_{i g}$ is the ignition temperature $(\mathrm{K})$. Since the emissivities of the common materials, such as wood and PE plastic, are generally in a range of 0.8 to 0.95 , the surface emissivity of the sample is not supposed to have a strong influence on the total heat flux absorbed by the sample, except for some special materials.

As a rough estimation, only the critical ceiling gas temperature is investigated here assuming that the exposure time is long enough for the ignition. The critical ceiling gas 
temperature discussed here corresponds to the vehicle fire load and its specific duration time. It should, therefore, be noted that the material may still be ignited for a ceiling gas temperature below the critical value if exposed for a sufficiently long time.

It is shown in Table 3.4 that for wood the ceiling gas temperature at the edge of fire spread, i.e. the critical ceiling gas temperature, is in a range of $709{ }^{\circ} \mathrm{C}$ to $955^{\circ} \mathrm{C}$ in $\mathrm{T} 2$, $674{ }^{\circ} \mathrm{C}$ to $740{ }^{\circ} \mathrm{C}$ in $\mathrm{T} 3$ and 674 to $740{ }^{\circ} \mathrm{C}$ in $\mathrm{T} 4$. This means that a ceiling gas temperature of about $700{ }^{\circ} \mathrm{C}$ is required to ignite the wood crib placed on the floor level. The mechanism of ignition should be the spontaneous ignition by thermal radiation. According to reference [23], a surface temperature of $600{ }^{\circ} \mathrm{C}$ should be obtained for wood before its spontaneous ignition. Given the differences between experimental conditions in the tunnel and those in the reference, these temperatures correlate well with each other. This suggests that the critical ceiling gas temperature for wood crib placed on the floor level is about $700{ }^{\circ} \mathrm{C}$ in a tunnel fire.

In the previous study of the fire spread, the critical ceiling gas temperature for fire spread to the second wood cribs based on the model scale tests data was discussed [17-18]. Since the emissivity of the flame and hot gases from a wood crib fire is approximately the same, the heat fluxes in the model scale tests are also approximately the same as in the full scale tests. Therefore, a critical ceiling gas temperature of $700{ }^{\circ} \mathrm{C}$ should also be obtained for fire spread to the wood placed on the floor level. However, in the previous study, a critical ceiling gas temperature of $600{ }^{\circ} \mathrm{C}$ was obtained for the second wood cribs in the model scale tests [16-18]. The reason for the difference is that we focused on the fire spread to the second wood crib with top surface close to the ceiling in the model scale tests. The top surface of wood crib is about $75 \%$ of the tunnel height from floor level. The mechanism of the fire spread is mainly spontaneous ignition due to radiation but heat convection has a stronger influence on the fire spread which thus makes it much easier to ignite the wood in the model scale tests. Moreover, the view factor approximately equals unit for the wood crib in the model scale tests but is much lower for the wood crib placed at the floor in the Runehamar tests. Therefore, it is concluded that the critical ceiling gas temperature is about $700{ }^{\circ} \mathrm{C}$ for fire spread to a wood at the floor level and about $600{ }^{\circ} \mathrm{C}$ for fire spread to the wood with surface close to the ceiling in a tunnel fire.

The above analysis suggests that the location of wood crib surface relative to the smoke layer height plays an important role in the fire spread. It can be argued that the fire spread to the second vehicle is very difficult to occur if a tunnel height is very high, say up to twice the vehicle height.

It is also shown in Table 3.4 that for plastic material the critical ceiling gas temperature, is below $1001{ }^{\circ} \mathrm{C}$ in $\mathrm{T} 1$, below $710{ }^{\circ} \mathrm{C}$ in $\mathrm{T} 2$, below $672{ }^{\circ} \mathrm{C}$ in $\mathrm{T} 3$ and in a range of $466{ }^{\circ} \mathrm{C}$ to $514{ }^{\circ} \mathrm{C}$ in $\mathrm{T} 4$. It can be concluded that the critical ceiling gas temperature for fire spread to the plastic materials placed at the floor level can be considered as $490{ }^{\circ} \mathrm{C}$, i.e. an average value of $466{ }^{\circ} \mathrm{C}$ to $514{ }^{\circ} \mathrm{C}$ in $\mathrm{T} 4$. Compared to the wood, the plastic material in these tests was much easier to ignite.

\subsection{Gas production}

The gas concentration of $\mathrm{CO}_{2}$ and $\mathrm{CO}$ are important in determining the tenability inside the tunnel.

The production rate of the $i$ th species in a tunnel fire can be estimated by the following equations: 


$$
\dot{m}_{i}=\dot{m} \frac{\Delta X_{i} M_{i}}{M_{a i r}}
$$

where $\dot{m}_{i}$ is the production rate of the $i$ th species, $\dot{m}$ is the total mass flow rate, $M$ is the molecular weight.

The average gas concentration, $\Delta X_{i, a v g}$, can be estimated by the correlation between the concentration of ith species and the temperature at a cross-section, which can be expressed as follows:

$$
\frac{\Delta X_{i, h}}{\Delta X_{i, a v g}}=\frac{\Delta T_{h}}{\Delta T_{\text {avg }}}
$$

The production rate of $\mathrm{CO}_{2}$ is plotted as a function of the heat release rate in Figure 4.16. It is clearly shown that the production rate of $\mathrm{CO}_{2}$ increases linearly with the heat release rate. Note that different materials were used in the tests, including wood cribs, PE materials, PUR mattress, furniture and paper cartons with polystyrene cups. It seems that for these types of materials the production rates of $\mathrm{CO}_{2}$ are independent of the materials and only dependent on the heat release rate. The reason may probably be that the main fire load consist of the cellulose materials. The proposed line in Figure 4.16 can be expressed as:

$$
\dot{m}_{\mathrm{CO2}}=0.087 Q
$$

A correlation coefficient of 0.9934 can be found for Equation (19). Note that the unit of $Q$ in Equation (19) is MW.

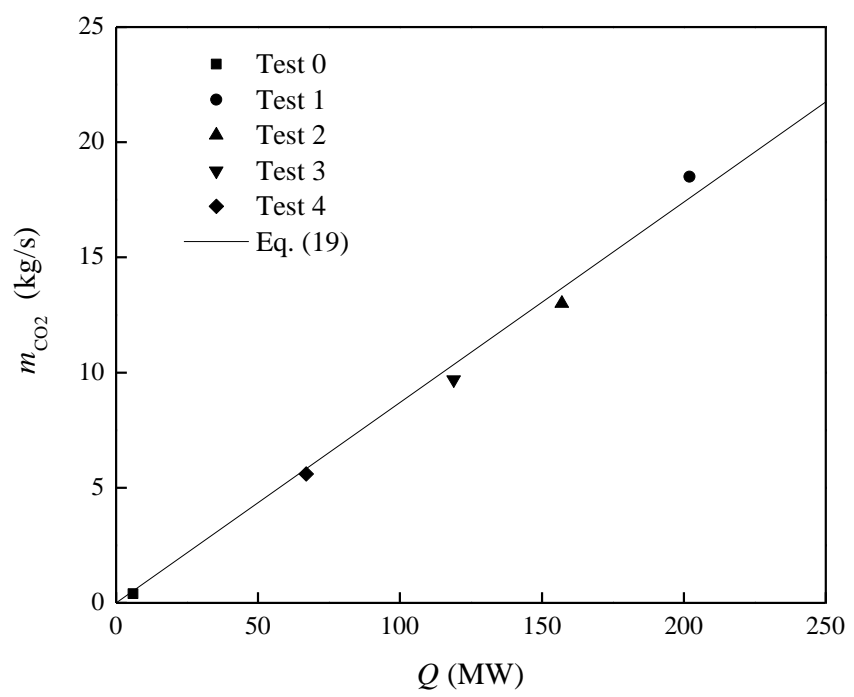

Figure 4.16 The production rate of $\mathrm{CO}_{2}$ as a function of the heat release rate.

The production rate of $\mathrm{CO}$ is plotted as a function of the heat release rate in Figure 4.17. It is shown that there is no simple correlation between the production rate of $\mathrm{CO}$ and the heat release rate. The production rate of $\mathrm{CO}$ strongly depends on the type and geometry of the fuels. The production rate of $\mathrm{CO}$ ranges between 0.05 and $0.3 \mathrm{~kg} / \mathrm{s}$, corresponding to average values of $400 \mathrm{ppm}$ to $2500 \mathrm{ppm}$. Most of the $\mathrm{CO}$ was produced at the beginning of each test and in the rest of each test the combustion appears to have been very good, with the possible exception of the test T2, which involved PUR. 


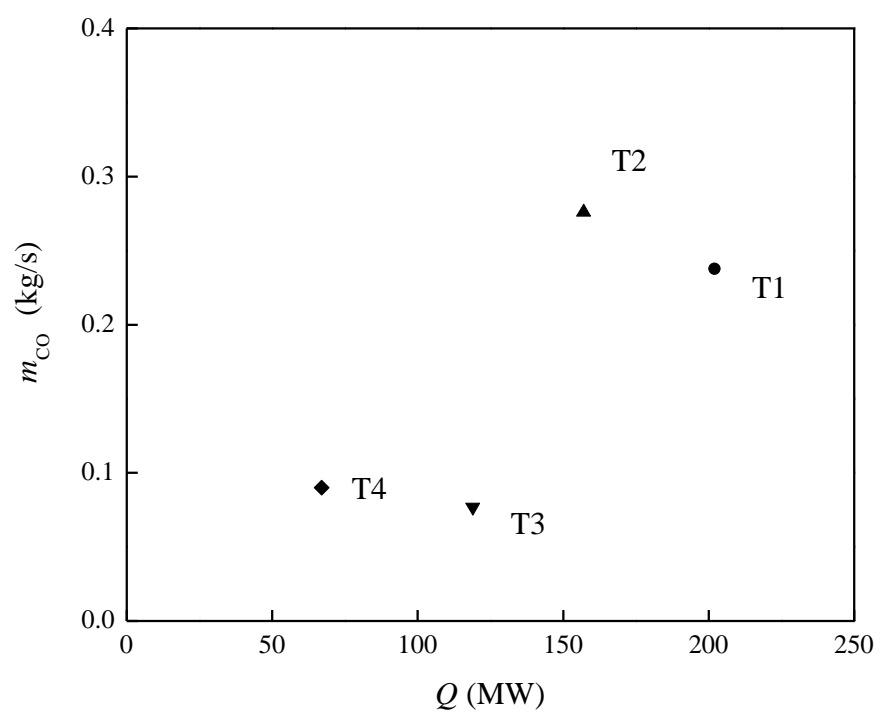

Figure 4.17 The production rate of $\mathrm{CO}$ as a function of the heat release rate.

\subsection{Ventilation}

The longitudinal ventilation velocity in a tunnel fire is dependent on the balance of forces, including the pressure changes produced by fans, wind, the thermal stack effects due to temperature difference, pressure losses over the fire source and obstructions, and hydraulic resistance induced by the tunnel walls, wall protection and the HGV trailer. A model of ventilation flow during large tunnel fires has been developed, see our paper [28]. The average velocity of fresh air in the Runehamar tunnel fire tests can be expressed as [28]:

$$
u_{o}=\sqrt{\frac{2}{\rho_{o}}} \sqrt{\frac{\left(\eta_{o}+\eta_{t}\right) \frac{M_{\text {fan }, t}}{A_{t}}-\rho_{o} g \Delta h\left(1-\frac{T_{o}}{T_{m}}\right)-\Delta p_{w}}{\xi_{\text {in }}+\xi_{\text {out }} \frac{T_{\text {out }}}{T_{o}}+\lambda \frac{L-L_{s}}{D}+\lambda \frac{L_{s}-\Delta L}{D} \frac{T_{m}}{T_{o}}+\left(\frac{\lambda^{\prime}}{D^{\prime}} \Delta L+\xi_{H G V}\right) k_{p}^{2}\left(\frac{A_{t}}{A_{p}}\right)^{2} \frac{T_{\text {avg }}(0)}{T_{o}}+\xi_{o b}}}
$$

Note that the velocity, $u_{0}$, represents the average longitudinal ventilation velocity at ambient condition. It is calculated based on measured mass flow rate. The friction coefficient $\lambda$ of the tunnel is dependent on the relative roughness and the Reynolds number of the tunnel (Moody chart). The Reynolds number is about $1.5 \times 10^{6}$ for the ambient flow within the tunnel, and about $0.3 \times 10^{6}$ at an average gas temperature of 400 ${ }^{\circ} \mathrm{C}$. This means that the friction coefficient $\lambda$ is nearly constant for all the tests carried out. An ocular inspection of pictures taken inside the Runehamar tunnel at several locations, indicate that the average height of asperities, $\Delta_{o}$, is somewhere in the range of $0.1 \mathrm{~m}$ to $0.3 \mathrm{~m}$ (conservative estimation). The relative roughness, $\Delta_{o} / D$, of the rock surface can therefore be in the range of 0.016 to 0.05. From the Moody chart [29] we find that $\lambda$ is in the range of 0.045 to 0.072 (using Colebrook-White formula and $\operatorname{Re}>$ $\left.10^{5}\right)$. An average value of 0.0585 is used in the present study. The friction coefficient of the protected section, $\lambda^{\prime}$, is 0.025 . The length of the fully protected section using Promatect $\mathrm{T}$ is $\Delta L$. The coefficient $k_{p}$, ratio of the mass flowing in the protected region to the total mass flow rate, equals 0.77 , which is determined by the tests data. $L$ is length of the whole tunnel, and $L_{s}$ is length of the downstream section. $D$ and $D^{\prime}$ are the characteristic lengths of the tunnel and the protected section respectively. $M_{f a n, t}$ is the momentum flux of the fan $\left(M=\right.$ impulse force $\left.=\rho u^{2}\right)$, and the corresponding term in Eq. (20) represents the pressure rise due to the fan. $\Delta h$ is the stack height, $T_{m}$ is the 
characteristic temperature downstream that will be discussed later, $\Delta p_{w}$ is the natural wind induced pressure difference, $\xi_{H G V}$ is the local friction coefficient of $\mathrm{HGV}, \xi_{i n}$ is the inlet local friction coefficient, $\xi_{\text {out }}$ is the outlet local friction coefficient, $T_{\text {out }}$ is the outlet gas temperature, $\xi_{o b}$ is the local friction coefficient of the other instruments and $T_{\text {avg }}(0)$ is the average temperature at the fire site.

The characteristic temperature, $T_{m}$, existing in the expressions for the friction pressure loss and the thermal pressure difference, is the characteristic temperature of the whole downstream section. It plays a very important role in the calculation of the longitudinal velocity inside the tunnel. Two possible methods of calculating The characteristic temperature, $T_{m}$, are used here to validate the model proposed here.

The first method is to consider the average temperature over the cross section at the middle point between the fire source and the downstream exit as the characteristic temperature, thus it can be calculated by the following equation [30]:

$$
T_{\text {avg }}(x)=T_{o}+\left(T_{\text {avg }}(0)-T_{o}\right) e^{-\frac{h P}{\dot{m} c_{p}} x}
$$

where

$$
T_{a v g}(0)=T_{o}+\frac{2}{3} \frac{Q}{\dot{m} c_{p}}
$$

where $P$ is the perimeter of the tunnel, $h$ is the lumped heat transfer coefficient, and $x$ $=L_{s} / 2$ (at the middle of the downstream section).

The second method is to consider an average downstream temperature based on the energy equilibrium of the whole downstream section as the characteristic temperature. Ingason [30] defined the parameter to estimate the average gas velocity due to buoyancy effects in a sloped tunnel, assuming that the heat transfer to the walls dominates the heat loss term. Here a full expression of the energy equation is proposed to define the downstream temperature. Consider the region between the fire source and downstream exit as a control volume and the conservation of energy can be expressed as follows:

$$
\rho L_{s} A c_{p} \frac{\partial T}{\partial t}=Q-\dot{m} c_{p}\left(T-T_{o}\right)-h_{c} A\left(T-T_{o}\right)-\varepsilon \sigma F A\left(T^{4}-T_{o}^{4}\right)
$$

This equation can be rearranged into the following:

$$
T_{i+1}=T_{i}+\frac{t_{i+1}-t_{i}}{\rho L_{s} A c_{p}}\left[Q-\left(\dot{m} c_{p}+h P L_{s}\right)\left(T_{i}-T_{o}\right)\right]
$$

where the time step ( $i$ to $i+1$ ) has to fulfilled the following requirement:

$$
\Delta t=\left(t_{i+1}-t_{i}\right) \leq \frac{\rho L_{s} A c_{p}}{\dot{m} c_{p}+h P L_{s}}
$$

where $T_{i+l}$ is the average downstream temperature at time $i+1$ according to Eq. (23). 
In the following, the theoretical model proposed above has been validated using the data from the tests. The two methods of calculating characteristic temperature presented above are compared and analyzed.

Figure 4.18 to Figure 4.21 show comparison of the results based on the two different characteristic temperature methods. The $x$ axis represents the time after ignition. The characteristic temperature given by Equation (21) represents the average temperature at the middle point between the fire and the downstream exit, and the characteristic temperature given by Equation (23) represents average downstream temperature of the whole downstream section. It is clearly shown that the calculated velocity based on Equation (23) is significantly underestimated in the peak period. It can be concluded that it is better to use the average temperature at the middle point between the fire source and the downstream exit $\left(\mathrm{x}=L_{s} / 2\right)$ according to Equation (21), especially in a large tunnel fire. However, the average temperature according to Equation (23) could also be reasonable to consider as the characteristic temperature in a small fire, since the difference in the results based on two different methods decreases with the heat release rate.

It is also clearly shown in Figure 4.18 to Figure 4.21 that the calculated data using the characteristic temperature according to Equation (21) fit the measured data well from all the tests, especially for T4 where a perfect match can be found, and the differences between the calculated and measured data decreases from $\mathrm{T} 1$ to $\mathrm{T} 4$. When the heat release rate approaches its maximum value in the tests with a large fire except T4, there is a clear underestimation of the velocity, $u_{0}$. There could be two possible reasons for the underestimation of the velocity at a higher heat release rate. Firstly, the fraction of radiation could be greater than $1 / 3$ in a large tunnel fire due to the long flame length, in contrast to an enclosure fire. The trend of underestimation of velocity is not shown in Figure 4.21, and also not clear in Figure 4.20. Note that the heat release rate gradually decreases from $\mathrm{T} 1$ to $\mathrm{T} 4$. This means that the calculated velocities fit the measured values better at lower heat release rates. The reason could be that the thermal resistance gets less sensitive to the calculation methods of characteristic temperatures for small fires.

In addition, there is an overestimation in the decay period of $\mathrm{T} 1$ to $\mathrm{T} 3$, especially $\mathrm{T} 1$ and $\mathrm{T} 2$. The reason is that the calculated characteristic temperature changes immediately with the heat release rate, however, in practice a large amount of heat is still contained in the downstream tunnel and thus heats up the air in the decay period.

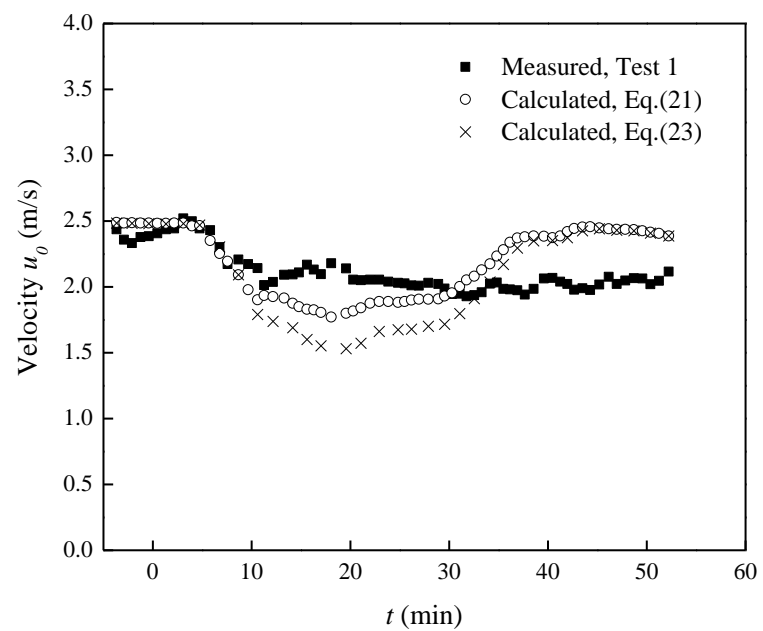

Figure 4.18 Comparison of the velocity in test T1 based on two characteristic temperature methods(Eq. (21) and Eq. (23)). 


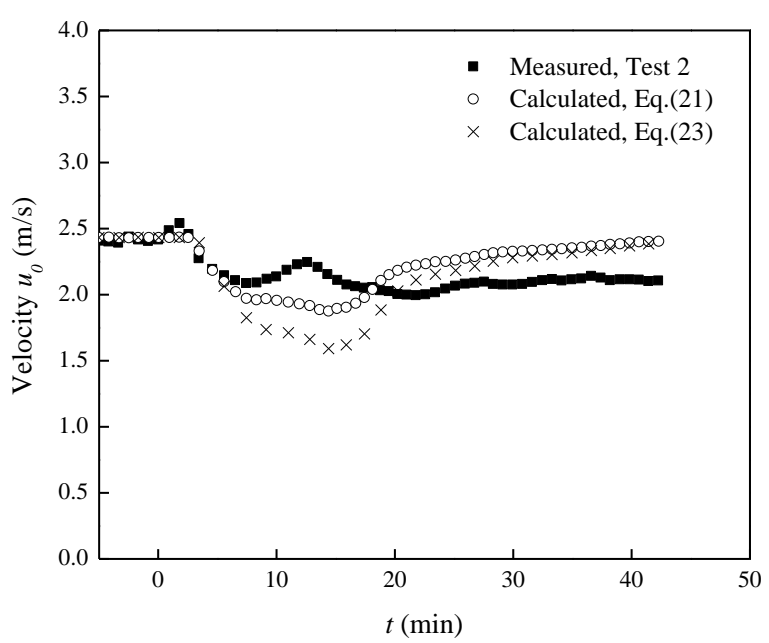

Figure 4.19 Comparison of the velocity in test T2 based on two characteristic temperature methods (Eq. (21) and Eq. (23)).

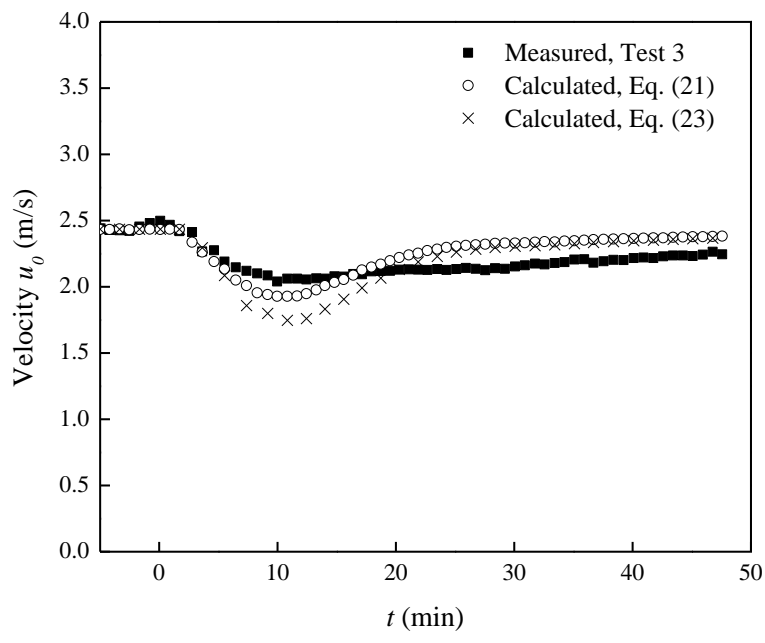

Figure 4.20 Comparison of the velocity in test T3 based on two characteristic temperature methods (Eq. (21) and Eq. (23)).

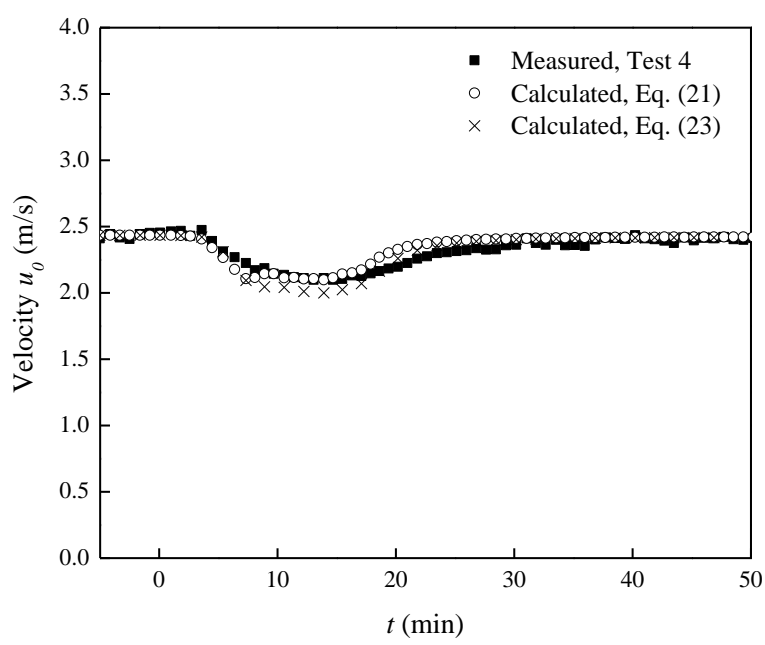

Figure 4.21 Comparison of the velocity in test T4 based on two characteristic temperature methods in T4 (Eq. (21) and Eq. (23)). 


\subsection{Backside wall temperatures}

Figure 4.22 and Figure 4.23 show the backside temperatures of Promatect $\mathrm{T}$ boards with different thickness placed at $10 \mathrm{~m}$ downstream of the fire centre in Test $\mathrm{T} 0$ and $\mathrm{T} 1$, respectively. The location of the fire protection boards B1 to B6 can be found in Figure 2.7. It is clearly shown that the back surface temperature B1 with a thickness of $45 \mathrm{~mm}$ is lower than that with a thickness of $30 \mathrm{~mm}$, and the board with a thickness of $25 \mathrm{~mm}$ obtained the highest values. For $30 \mathrm{~mm}$ boards, B3 is little higher than B2 since the location of B3 is slightly higher than B2. For $25 \mathrm{~mm}$ boards, the sequence from high to low is B4 to B6. However, the differences between the measured values with different locations and same thickness are insignificant. It can be concluded that the backside wall temperatures above the fire source are mainly dependent on the wall thickness and not sensitive to the location in relation to the fire.

The results suggest that a similar fire resistant board like Promatect $T$ with a thickness of about $25 \mathrm{~mm}-30 \mathrm{~mm}$ is very effective in preventing the tunnel structure from damage.

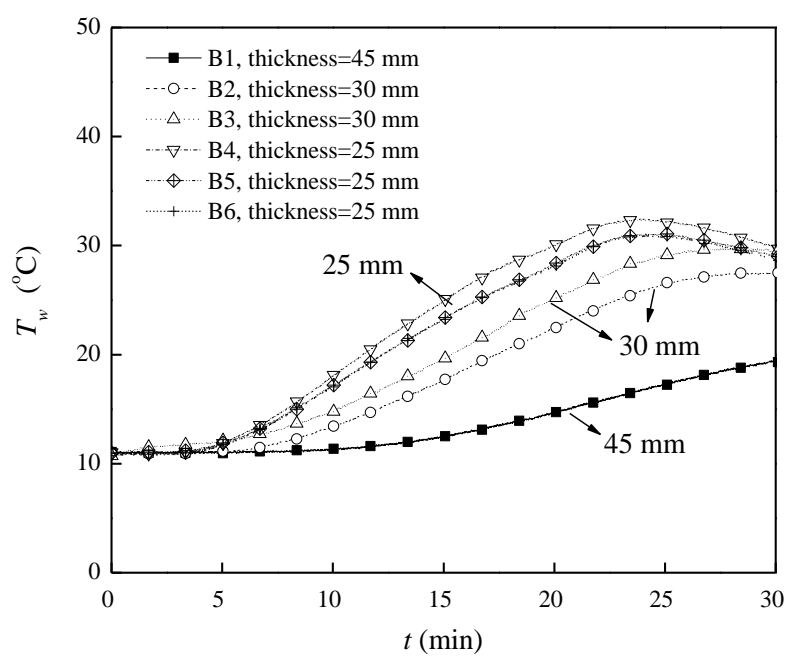

Figure 4.22 Back surface temperature of the Promatect $T 10 \mathrm{~m}$ downstream of the pool fire test, TO.

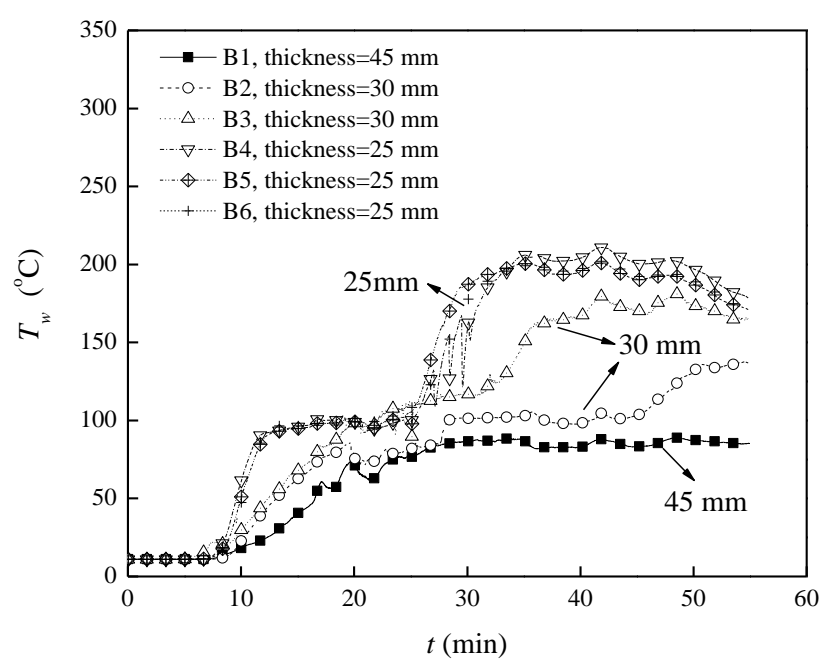

Figure 4.23 Back surface temperature of the Promatect $T 10 \mathrm{~m}$ downstream of the wood pallet and plastic pallet fire test, T1.

A simple one-dimensional analysis was conducted to compare with the measured data. The energy equation can be simply expressed as: 


$$
\frac{\partial T}{\partial t}=a \frac{\partial^{2} T}{\partial z^{2}}
$$

The boundary condition on the fire exposed side can be expressed as:

$$
-\lambda \frac{d T_{w}}{d z}=h\left(T_{g}-T_{w}\right)+\varepsilon\left(\dot{q}_{i n c}^{\prime \prime}-\sigma T_{w}^{4}\right)
$$

where $T_{w}$ is the wall temperature (K), $a$ is the thermal diffusivity $\left(\mathrm{m}^{2} / \mathrm{s}\right), x$ is the thickness of the wall $(\mathrm{m}), \lambda$ is thermal conductivity $(\mathrm{kW} / \mathrm{m} \cdot \mathrm{K}), h$ is convective heat transfer coefficient $\left(\mathrm{kW} / \mathrm{m}^{2} \cdot \mathrm{K}\right), T_{g}$ is the gas temperature below the ceiling $(\mathrm{K}), \varepsilon$ is the emissivity, $q_{i n c}^{\prime \prime}$ is the incident heat flux $\left(\mathrm{kW} / \mathrm{m}^{2}\right), \sigma$ is the Stefan-Boltzmann constant $\left(\mathrm{kW} / \mathrm{m}^{2} \mathrm{~K}^{4}\right)$ and $z$ is the depth from the surface $(\mathrm{m})$.

Generally the boundary condition on the other side can be considered as the blasted tunnel surface temperature (close to ambient), assuming that heat is not penetrated into the other side. This assumption can be easily fulfilled by setting a relatively large thickness. In the tests, the back sides of the Promatect T boards were exposed to the cold gas flow. Thus at the back sides of the boards, the same boundary condition as Eq. (26) should be used here but the incident heat flux approximately represents the ambient radiation and the gas temperature represents the ambient temperature.

In the calculation of the backside temperatures, the measured gas temperatures and incident heat fluxes should be known. Since it has been shown that the incident heat flux is proportional to the $4^{\text {th }}$ power of the gas ceiling temperature, only the gas temperatures was needed as input. The thermal conductivity, the density and thermal capacity of Promatect T used in the analysis were $0.212 \mathrm{~W} / \mathrm{m} \mathrm{K}, 900 \mathrm{~kg} / \mathrm{m}^{3}$ and $1100 \mathrm{~J} / \mathrm{kg} \cdot \mathrm{K}$, respectively. In practice, the properties of Promatect $\mathrm{T}$ could change significantly at high temperatures, however, no high temperature data were available.

Figure 4.24 to Figure 4.26 show a comparison of back surface temperature of the Promatect T $10 \mathrm{~m}$ downstream of the fire in T0 (pool fire test) with a thickness of $25 \mathrm{~mm}$, $30 \mathrm{~mm}$ and $45 \mathrm{~mm}$, respectively. It is clearly seen that the numerical results of back surface temperature in test $\mathrm{T} 0$ correlates very well with the experimental data.

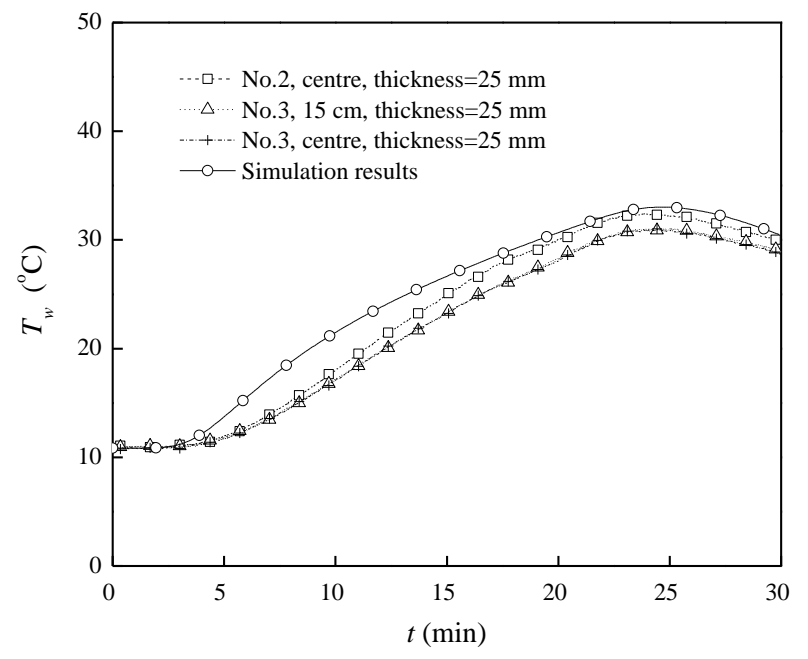

Figure 4.24 Comparison of back surface temperature of the $25 \mathrm{~mm}$ thick Promatect $T 10 \mathrm{~m}$ downstream of the fire, TO. 


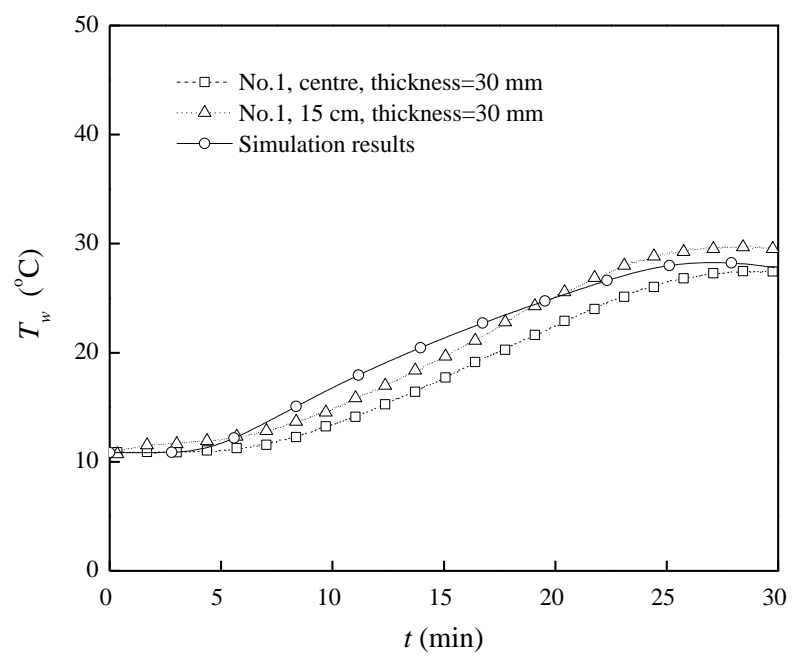

Figure 4.25 Comparison of back surface temperature of the $30 \mathrm{~mm}$ thick Promatect $T 10 \mathrm{~m}$ downstream of the fire, TO.

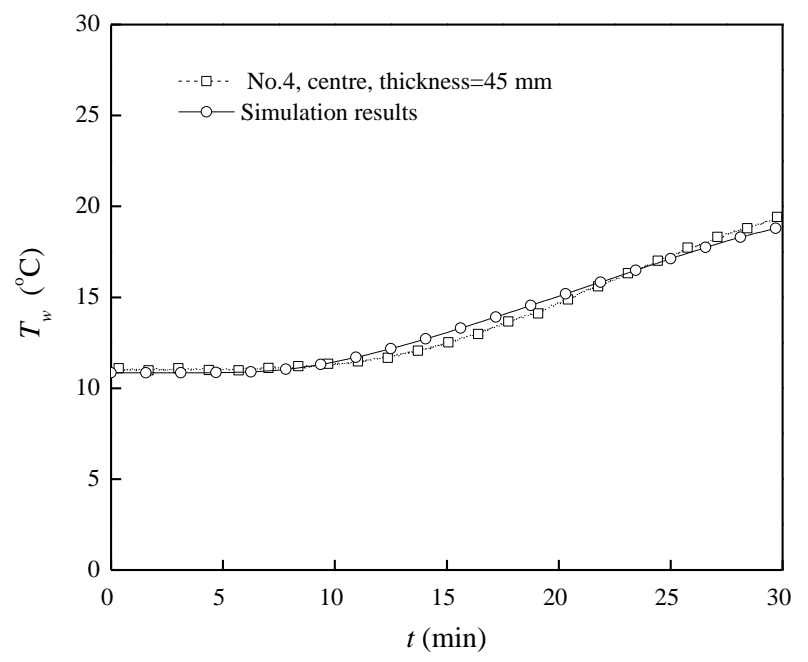

Figure 4.26 Comparison of back surface temperature of the $45 \mathrm{~mm}$ thick Promatect $T 10 \mathrm{~m}$ downstream of the fire, TO.

Figure 4.27 to Figure 4.29 shows the comparison of back surface temperature of the Promatect $\mathrm{T} 10 \mathrm{~m}$ downstream of the fire in $\mathrm{T} 1$ (wood and plastic pallets) with a thickness of $25 \mathrm{~mm}, 30 \mathrm{~mm}$ and $45 \mathrm{~mm}$, respectively. It is shown that the numerical results correlate well with the tests data during first few minutes and then become much higher than the measured values in T1. There could be several reasons for this deviate. The most important reason is probably the uncertainty in the thermal properties of Promatect T at high temperatures. Secondly, the moisture of Promatect T has not been considered in the calculation. The water inside the board evaporates after the temperature rises up to about $100{ }^{\circ} \mathrm{C}$. The latent heat absorbed by the water reduces the temperature inside the Promatect T. Thirdly, some thick boards consisted of two thin boards. At high temperatures there could be a gap between the boards which would increase the thermal resistance of the board and thus reduce the backside temperature. Fourthly, most of the boards, except the $45 \mathrm{~mm}$ thick board, were not placed directly above the fire source. Therefore the exposed temperatures should be little lower than the measured ceiling temperatures.

In any case, the simple calculation method seems appropriate to predict the temperature inside the tunnel walls or fire protection materials provided the thermal properties are known. 


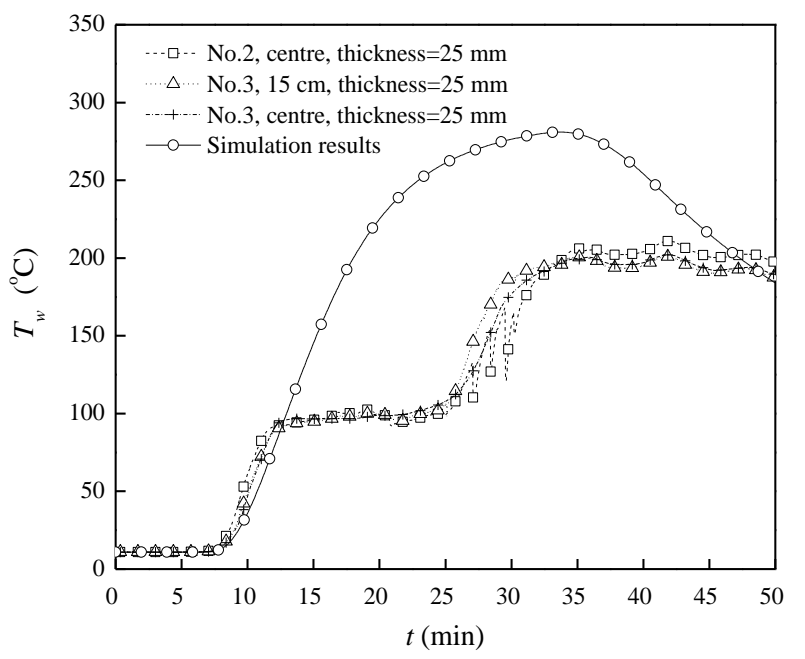

Figure 4.27 Comparison of back surface temperature of the $25 \mathrm{~mm}$ thick Promatect $T 10 \mathrm{~m}$ downstream of the fire, $T 1$.

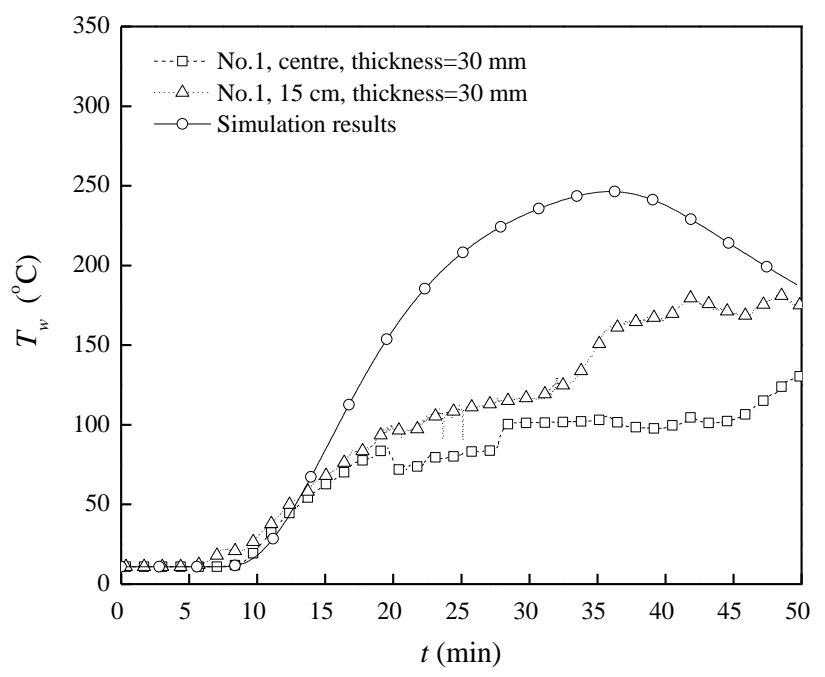

Figure 4.28 Comparison of back surface temperature of the $30 \mathrm{~mm}$ thick Promatect $T 10 \mathrm{~m}$ downstream of the fire, T1.

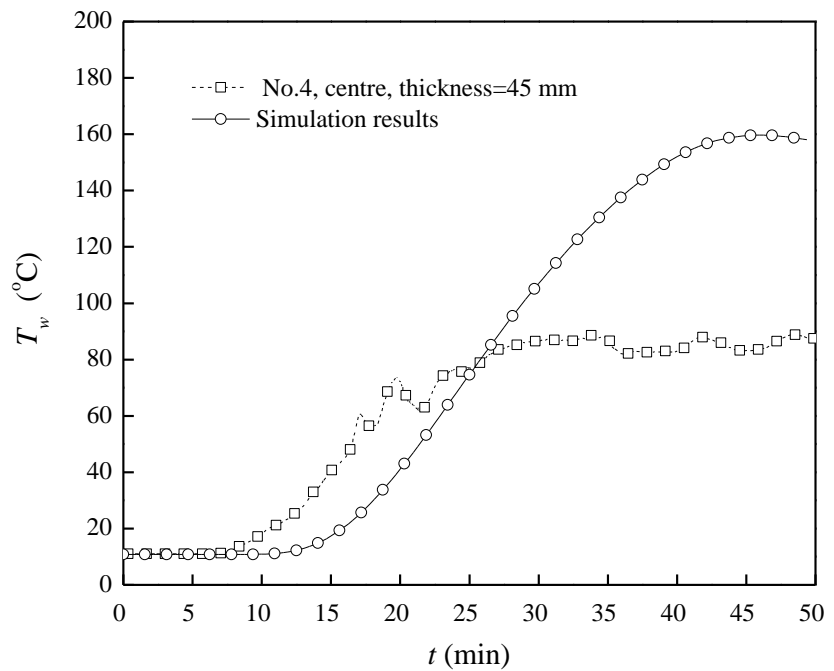

Figure 4.29 Comparison of back surface temperature of the $45 \mathrm{~mm}$ thick Promatect $T 10 \mathrm{~m}$ downstream of the fire, $T 1$. 


\subsection{Pulsation}

Pulsations (oscillation) of the main airflow were observed during the tests with fires that exceeded $125 \mathrm{MW}-135 \mathrm{MW}$. Two different periods of the pulsations were registered, short periods of about $4 \mathrm{~s}$ and longer periods of approximately $18 \mathrm{~s}$. These pulsations have been discussed thoroughly by Lönnermark and Ingason [7-8]. It has been shown with simple acoustic calculations that the oscillation periods ( $4 \mathrm{~s}$ and $18 \mathrm{~s}$, respectively) are properties of the system. The test results have also recently been compared to results from models scale tests.

A frequency analysis of a tunnel system represented by impedances was performed. All cases showed resonance peaks, with different periods for the different cases. Most similar to the experimental results were the cases with constant pressure at the inlet. The case with disturbance at the tunnel outlet gave results very close to those registered during the fire tests. This is probably due to the fact that in this case, the whole tunnel system with its impedances was included and could affect the results. The disturbance at the outlet does not mean that the wind necessarily was the reason for the oscillations (even if it was quite windy during both of the experiments where the oscillations occurred). The wind can, however, affect the onset of the oscillations and the good correlation between the result of this case and the experiments may indicate that a disturbance at the outlet of the tunnel can give rise to oscillations in the tunnel.

It is known from small-scale experiments with thermoacoustic instabilities that when a flame is near the point of oscillation, an external sound or air movement across the end of the air tube can initiate the oscillation. The analyses in the paper discussing the effects of the mass flow pulsations at the tunnel exit show that the system reacts with pulsations (resonance peaks) at some special frequencies. In many cases, however, no external source is needed, e.g. the vortex shedding at the set-up can excite the oscillations. An analysis of the vortex shedding of a fire with the dimensions of the experimental set-up in the tests discussed here gave an oscillating period between 1 and $2 \mathrm{~s}$. In connection to this one can also mention the very rapid increase in temperature of the gases, which leads to a rapid increase in the volume of the gases. This may also play an important role for the pressure drop of the fire and the setup, as well as for the vortex shedding.

One interesting observation is the fact that the oscillations start when the HRR increases above a certain value (between $125 \mathrm{MW}$ and $135 \mathrm{MW}$ ). This situation has not been modelled quantitatively, but the above-mentioned thermoacoustic instabilities have been described in the literature and to excite the acoustic modes in the tunnel (in a tube), the acoustic losses need to be overcome. Such relationships define the stability limits of the system and these stability limits describe relationships between HRR and flow rate where the system can become unstable [31]. It is also interesting to note that in the experiments conducted in Runehamar, the amplitude of the oscillations was small in the beginning and largest when the HRR was the highest with ensuing decrease in the amplitude as the HRR decreased. In all the calculated cases, resonances with shorter periods could be seen. This could be explained as harmonics of the resonances at longer periods. However, the higher the frequency, the larger the losses and since not all losses are quantified in the system, these peaks may not be as pronounced in reality. During the course of the work a few explanations, other than those discussed above, for the initiation of the pulsations have been suggested. These explanations are not fundamental to the oscillations, but can affect the system in different ways and are therefore discussed briefly below.

The tunnel had a slope varying between $0.5 \%$ uphill and $1 \%$ downhill, with the highest point near the centre of the tunnel. The fire was positioned in the downhill part of the tunnel and the hot gases could cause a driving force against the flow in the tunnel. This will certainly be a force that has to be overcome and can probably together with the 
pressure drop over the fire and the set-up affect the flow situation in the tunnel, but it has been deemed unlikely that these could be the reason for the oscillation. The pulsations look somewhat similar to the pulsations of smoke through openings that sometimes can be seen in connection with under-ventilated fires in enclosures. This gave rise to the question of whether the fire in the tunnel could have been vitiated and whether this could have caused the pulsations. The fire was, however, not under-ventilated. The measurements also show that it is the velocity (pressure) that is affected, not the gas concentrations or the temperatures. The distance between the fire and the measurement station, and the response time of the analyzers might smooth out the effect of the short pulsation, but again none of the measurements indicate that the oscillations in the tunnel were due to oscillations in the HRR. Despite this, the HRR and the heat transfer to the flow were affected by the pulsations and it is difficult to completely separate the HRR from the behavior of the flow since the calculations of the HRR include the flow rate as a parameter. Furthermore, the heat transfer to the flow is a fundamental part of the type of oscillations called thermoacoustic instabilities. Oscillating HRR could, therefore, be included as one of the causes of thermoacoustic instabilities.

\subsection{Backlayering}

For a tunnel with longitudinal ventilation, it is most important to prevent the backlayering of smoke and hot combustion gases upstream of the fire to create a safe route for evacuees. The approximate maximum backlayering lengths in the tests are presented in Table 3.6.

Li et al. [32] proposed a simple equation to predict the backlayering length in a large tunnel fire. Based on this equation [32], the critical velocity in T0 is about $2.45 \mathrm{~m} / \mathrm{s}$, which correlate well with the test data. Li et al.'s results show that in a large tunnel fire, the backlayering length is independent of the heat release rate and only dependent on the ventilation velocity. It is shown in Table 3.6 that the maximum backlayering length in tests $\mathrm{T} 1$ to $\mathrm{T} 4$ are approximately $100 \mathrm{~m}$, although the corresponding heat release rate ranges from $66 \mathrm{MW}$ to $202 \mathrm{MW}$, which is in support of Li et al.'s theory [32].

The backlayering length can also be observed directly using the ceiling temperature curves upstream of the fire load, see Figure 4.30. At about $6.5 \mathrm{~min}$ after ignition, the backlayering in $\mathrm{T} 1 \mathrm{can}$ be observed at $15 \mathrm{~m}$ upstream of the fire load. The corresponding heat release rate is approximately $38 \mathrm{MW}$. It is shown clearly that the ceiling temperature at $15 \mathrm{~m}$ upstream remained at the same level, i.e. in a range of 400 to $500{ }^{\circ} \mathrm{C}$, between 8 $\min$ to $35 \mathrm{~min}$. Note that during this period the velocities also remained at a same level, i.e. in a range of $2 \mathrm{~m} / \mathrm{s}$ to $2.5 \mathrm{~m} / \mathrm{s}$, however, the corresponding heat release rate varies significantly, i.e. in a range of $50 \mathrm{MW}$ to $202 \mathrm{MW}$. It can be concluded that the effect of heat release rate on the backlayering length is insignificant, again in support of Li et al.'s findings [32]. 


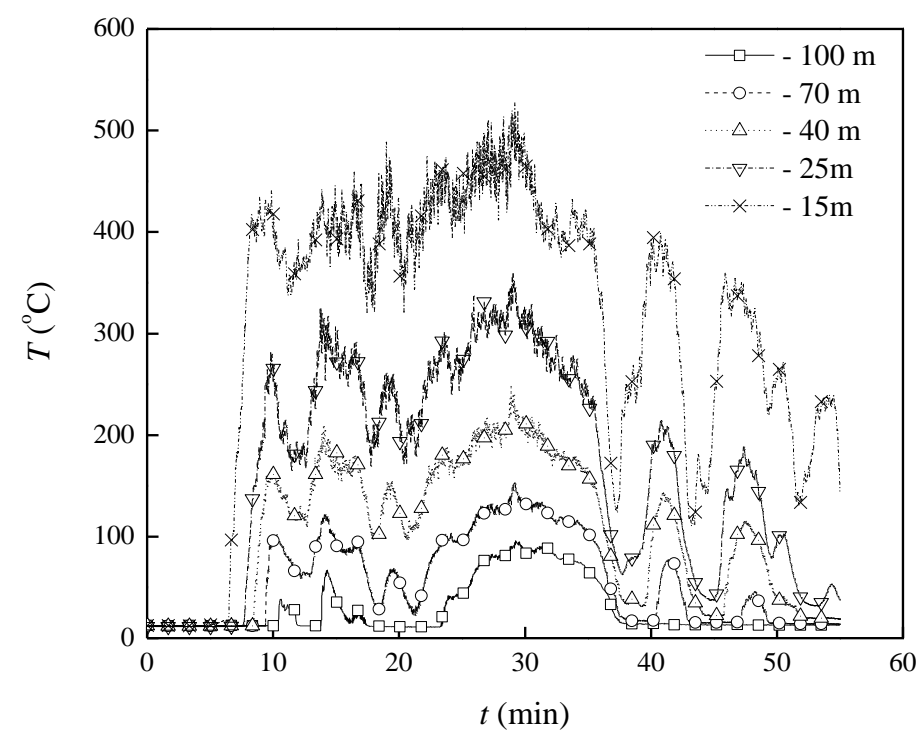

Figure 4.30 Ceiling temperature upstream of the fire, T1.

\subsection{Visibility}

The visibility measured at $458 \mathrm{~m}$ downstream of the fire and $2.9 \mathrm{~m}$ above the floor is discussed here. Note that the distribution of the gas temperatures along the vertical direction is very uniform at this location. Thus it can be speculated that the visibility measured at $2.9 \mathrm{~m}$ approximates to the visibility at the evacuation path at this location.

The extinction coefficient of the smoke can be obtained by the following:

$$
C_{s}=\frac{1}{L_{p}} \ln \left(\frac{I_{o}}{I}\right)
$$

Assuming that the flow is fully mixed in the tunnel, i.e. the well stratification disappears after a certain distance from the fire, the mass optical density, $D_{\text {mass }}$, can be correlated with the extinction coefficient by:

$$
D_{\text {mass }}=\frac{\chi u A_{t} \Delta H_{c}}{\ln (10) Q} C_{s}
$$

where $u$ is the local average ventilation velocity over the whole cross-section of the measurement station.

For walls, floor and doors by reflectance, the visibility can be simply estimated [30]:

$$
V_{i s}=\frac{2}{C_{s}}
$$

Note that the visibility is not only dependent on the soot productions but also the light intensity. An emergency illuminating light gives stronger light intensity compared to a reflecting sign and thus corresponds to a better visibility. Along the path with continuous 
illuminating lights, the value at numerator could be in a range of 5 to 10. Therefore, using the value of 2 in Eq. (29) generally gives conservative results.

Combing Eq. (28) and Eq. (29) gives:

$$
V_{i s}=\frac{2}{C_{s}}=0.87 \frac{\chi u A_{t} \Delta H_{c}}{Q D_{\text {mass }}}
$$

The results of the measured extinction coefficient $C_{s}$ and estimated visibility $V_{i s}$ in Test 0 are shown in Figure 4.31. The results of the other tests can be found in the Appendices A to E. To express the results more clearly in the figures, a maximum visibility of $30 \mathrm{~m}$ was used, that is, $30 \mathrm{~m}$ was used if the estimated visibility was over $30 \mathrm{~m}$. Clearly, it shows that the visibility decreases to a very low level a few minutes after ignition, especially in the tests with HGV mock-ups.

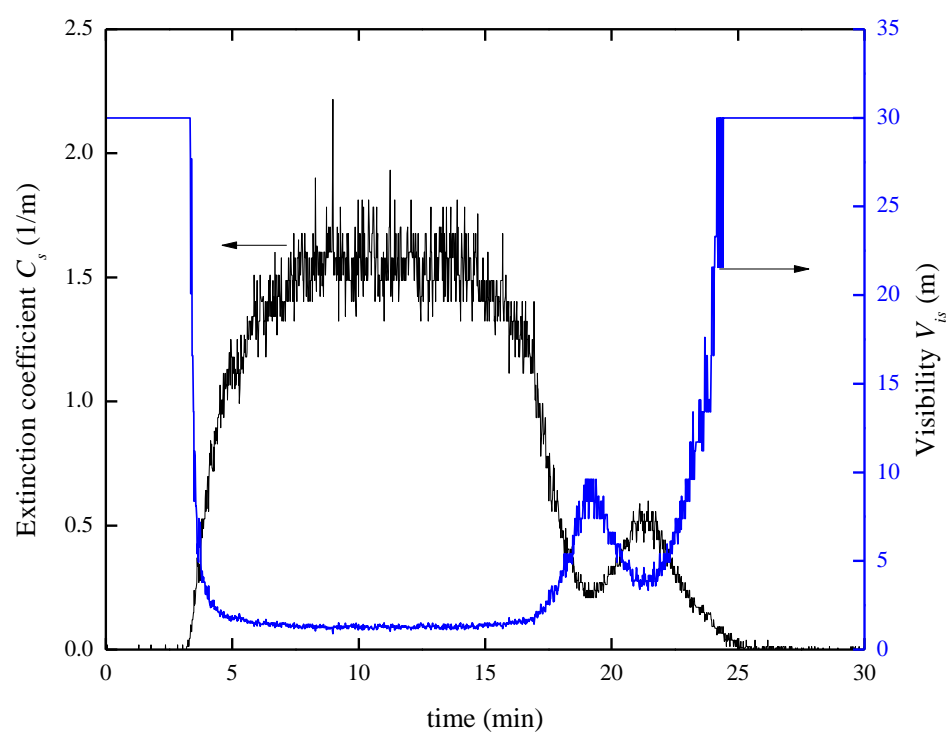

Figure 4.31 Measured extinction coefficient and estimated visibility at measurement station $+458 \mathrm{~m}, 2.9 \mathrm{~m}$ above floor, T0.

The mass optical density obtained from the tests are summarized in Table 4.2. Clearly it shows that the mass optical density was much higher in Test 0 where the diesel was the fuel which produced a large amount of soot. In other tests using commodities as the fuels, the mass optical density lay in a range of 10 to $138 \mathrm{~m}^{2} / \mathrm{kg}$. Ingason [30] presented the mass optical densities in Eureka 499 tests which are in a range of 76 to 102 for trucks. These values correlate well with the values for HGV mock-up tests, as shown in Table 4.2. Note that the value of mass optical density is mainly dependent on the fuel type. Based on the mass optical density, the visibility can be easily calculated using Eq. (30).

Table 4.2 Results related to visibility (mass optical density, $D_{\text {mass }}$ ).

\begin{tabular}{cccc}
\hline Test no. & $\begin{array}{c}Q_{\max } \\
\mathrm{MW}\end{array}$ & Fuels & $\begin{array}{c}D_{\text {mass }} \\
\mathrm{m}^{2} / \mathrm{kg}\end{array}$ \\
\hline 0 & 6 & Diesel & $360-450$ \\
1 & 67 & Wood/PE & $13-82$ \\
2 & 119 & Wood/PUR & $47-138$ \\
3 & 157 & Furniture/rubber & $10-87$ \\
4 & 202 & Cartons/PS cups & $30-120$ \\
\hline
\end{tabular}


In Test 0 with diesel, the mass optical density was close to constant during the burning period, see Figure 4.31. However, in the tests with commodities, the mass optical density was higher at the early stage and then decreased to the lower limit in Table 4.2. This is similar to what was observed for $\mathrm{CO}$ production. As the heat release rate increased and the gas temperature reached to a high level, the combustion became more complete and less soot and $\mathrm{CO}$ were produced. Note that a greater mass optical density indicates lower visibility. Therefore, generally the upper values in Table 4.2 are recommended to be used in the design, i.e. in a range of 82 to 138 for a variety of solid materials tested, especially for a small fire or at the early stage of a large fire. 


\section{$5 \quad$ Conclusions}

Five large-scale fire tests, including one pool fire tests and four HGV mock-up fire tests, were carried out in the Runehamar tunnel in Norway in year 2003. Detailed information about these tests is presented in this report, together with a summary of previous work on these tests. Further, simple and robust theoretical models are developed to estimate and predict heat release rate, fire growth rate, gas temperature, flame length, radiation, fire spread, gas production, ventilation, backside wall temperature.

Heat release rates were estimated using oxygen consumption method based on measured data in the measurement station $458 \mathrm{~m}$ downstream of the fire and the transport time was also corrected. The maximum HRR for the four tests with a HGV mock-up was in the rage from $66 \mathrm{MW}$ to $202 \mathrm{MW}$. A simple method to estimate the maximum heat release rate was also proposed since the maximum heat release rate in a well ventilated tunnel fire can be directly proportional to the burning rate per unit fuel area, heat of combustion and the total fuel areas, provided the fuel is fully involved in the fire.

A theoretical approach to model the fire growth rate in a ventilated tunnel fire was proposed. The relationship between the flame spread rate and fire growth rate was correlated since the longitudinal flame spread dominates the fire spread in a ventilated tunnel fire. The thermal inertia, heat of combustion, wet diameter and mass burning rate per unit area of the fuel play important roles in the fire growth rate and the ventilation velocity is proportional to the fire growth rate.

Maximum ceiling gas temperatures in the tests were investigated and it shows a very rapid increase after ignition. For all four tests with a HGV mock up, the maximum ceiling gas temperature exceeded $1280{ }^{\circ} \mathrm{C}$, with a highest excess gas temperature of approximately $1350{ }^{\circ} \mathrm{C}$ in $\mathrm{T} 1$. The RWS curve was found to fit the measured data best and is recommended to be used in structure analysis in large tunnel fires. A robust equation for the maximum ceiling gas temperature was proposed which correlate all the important parameters, including heat release rate, ventilation, tunnel geometry and fuel geometry, with the maximum ceiling gas temperature. It can be used to estimate the maximum ceiling gas temperature under a given condition and help to choose the right temperature-time curve to use in structural analysis of tunnel walls. Another robust equation for ceiling gas temperature distribution along a longitudinally ventilated tunnel was also proposed to estimate the ceiling gas temperature at any given place.

The flame length was investigated and it was found that the data of flame lengths from EUREKA program were much lower than the others. An equation based on traditional ceiling jets theory and a dimensionless equation were proposed. The effect of velocity on the flame length was found to be weak.

The incident heat flux at the ceiling in a large tunnel fire was found to be a blackbody with approximately unit emissivity. It was also shown that a simple equation can be used to calculate the incident heat flux provided the gas temperature is known. This equation for the incident heat fluxes is useful for fire resistance tests. The incident heat flux at the floor level was found to be slightly lower than at the ceiling.

The fire spread to the neighboring vehicle, simulating by wood and plastic targets was tested and investigated. It was found that an average temperature of approximately $500{ }^{\circ} \mathrm{C}$ seems to give the best correlation with the fire spread. The investigation of the ceiling gas temperatures above the targets show the existence of a critical ceiling gas temperature while the target is just ignited. A critical gas temperature beneath the ceiling, $700{ }^{\circ} \mathrm{C}$ for wood materials at floor level and $490{ }^{\circ} \mathrm{C}$ for plastic materials at floor level, is found to be 
responsible for fire spread to the fuels placed on the floor. The critical ceiling gas temperature could be much lower if the materials were placed at a higher level. According to previous study [16-18], a critical gas temperature of $600{ }^{\circ} \mathrm{C}$ was found for fire spread to the wood cribs with their top surfaces at $75 \%$ of the tunnel height from floor level.

Carbon dioxide production is found to be directly proportional to the heat release rate, while $\mathrm{CO}$ production is dependent on the heat release rate, the fuel type, and combustion conditions. The average concentration of $\mathrm{CO}$ was in a range of $400 \mathrm{ppm}$ to $2500 \mathrm{ppm}$ in the Runehamar tests. Most of the $\mathrm{CO}$ was produced at the beginning of each test.

In order to describe the reduction in the longitudinal airflow velocity during the tests due to the fire and hot gases resistances, a theoretical model has been developed and validated using the large-scale tests data from Runehamar tunnel fire tests. Two methods for calculating the characteristic temperature related to the thermal expansion and stack effect are presented and analyzed. The longitudinal ventilation velocity during a large tunnel fire can be estimated well using Equation (20) with aid of Equation (21). The average temperature over the cross section at the middle point between the fire source and the downstream exit according to Equation (21) is appropriate as the characteristic temperature.

A simple theoretical model for thermal conduction is used to compare with the tests data. The numerical results of backside wall temperature in test $\mathrm{T} 0$ correlates very well with the experimental data, but was much higher than tests data in T1. The main reason for this discrepancy was probably the uncertainty in the thermal properties of the Promatect $T$ board material at high temperatures. Nonetheless, the simple calculation method seems appropriate to predict the temperature inside the tunnel walls or fire protection materials provided the thermal properties are known.

Pulsations (oscillation) of the main airflow were observed during the tests with fires that exceeded $125 \mathrm{MW}-135 \mathrm{MW}$. Two different periods of the pulsations were registered, short periods of about $4 \mathrm{~s}$ and longer periods of approximately $18 \mathrm{~s}$. It has been shown with simple acoustic calculations that the oscillation periods ( $4 \mathrm{~s}$ and $18 \mathrm{~s}$, respectively) are properties of the system.

The maximum backlayering length in tests $\mathrm{T} 1$ to $\mathrm{T} 4$ were approximately $100 \mathrm{~m}$, independent of the fact that the corresponding heat release rate ranges from $66 \mathrm{MW}$ to $202 \mathrm{MW}$. This confirms that in a large tunnel fire, the backlayering length is nearly independent of the heat release rate and only dependent on the ventilation velocity.

The mass optical density was much higher and approximately a constant of around 400 $\mathrm{m}^{2} / \mathrm{kg}$ in Test 0 where the diesel produced a large amount of soot. In other tests using commodities as the fuels, the mass optical density lay in a range of 10 to $138 \mathrm{~m}^{2} / \mathrm{kg}$, and it was higher at the early stage and then decreased to a lower level when the fire became fully developed. These values for HGV mock-up tests correlate well with the data from Eureka 499 tests for trucks [30]. Note that the value of mass optical density is mainly dependent on the fuel type. Assuming that the flow is fully mixed in the tunnel, i.e. the well stratification disappears after a certain distance from the fire, the visibility downstream of a tunnel fire can be easily calculated using Eq. (30). 


\section{References}

1. Ingason H., Lönnermark A., Heat release rates from heavy goods vehicle trailers in tunnels, Fire Safety Journal, 2005, 40, 646-668.

2. Ingason H., Lönnermark, A., Large-scale Fire Tests in the Runehamar tunnel Heat Release Rate (HRR), International Symposium on Catastrophic Tunnel Fires (CTF), Borås, Sweden, 20-21 November 2003, pp. 81-92.

3. Lönnermark A., Ingason H., Gas temperatures in heavy goods vehicle fires in tunnels. Fire Safety Journal, 2005, 40, 506-527.

4. Lönnermark, A., Ingason, H., Large Scale Fire Tests in the Runehamar Tunnel Gas Temperature and Radiation, International Symposium on Catastrophic Tunnel Fires (CTF), SP Report 2004:05, Borås, Sweden, 20-21 November, 2003, pp. 93-103.

5. Lönnermark A., Ingason H., Fire spread and flame length in large-scale tunnel fires. Fire Technology, 2006, 42, 283-302.

6. Lönnermark A., On the Characteristics of Fires in Tunnels, Doctoral thesis, Department of Fire Safety Engineering, Lund University, Lund, Sweden, 2005.

7. Lönnermark A., Persson B., Ingason H., Pulsations during large-scale fire tests in the Runehamar tunnel, Fire Technology, 2006, 42, 283-302.

8. Lönnermark A., Ingason H., Acoustic Considerations Regarding Pulsations during Large-scale Fire Tests in a Tunnel, Fire Safety Science - Proceedings of the Eighth International Symposium, International Association for Fire Safety Science, 2005, pp. 1473-1484.

9. Lemaire T, Runehamar tunnel fire tests: radiation, fire spread and back layering, in: Proceedings of the international symposium on catastrophic tunnel fires, SP Swedish National Testing and Research Institute, SP Report 2004:05, Borås, Sweden, 2003, pp.105-115.

10. Brandt A.B., Presentation of test result from large scale fire tests at the Runehamar tunnel, International Symposium on Catastrophic Tunnel Fires (CTF), SP Report 2004:05, Borås, Sweden, 2003, pp. 117-120.

11. McCaffrey B.J., Heskestad G., Brief communications: a robust bidirectional lowvelocity probe for flame and fire application, Combustion and Flame, 1976, 26, 125-127.

12. Wickström U., The Plate Thermometer - A simple Instrument for Reaching Harmonized Fire Resistance Rests, SP Swedish National Testing and Research Institute SP Report 1989:03, Borås, Sweden, 1989.

13. Häggkvist A., The plate thermometer as a mean of calculating incident heat radiation - a practical and theoretical study, Master thesis, Luleå University of Technology, 2009.

14. Ingason H., Li Y.Z., Model scale tunnel fire tests with longitudinal ventilation, Fire Safety Journal, 2010, 45, 371-384.

15. Ingason H., Li Y.Z., Model scale tunnel fire tests with point extraction ventilation, Journal of Fire Protection Engineering, 2011, 21(1), 5-36.

16. Ingason H., Li Y.Z., Model scale tunnel fire tests with point extraction ventilation, SP Report 2010:03, SP Technical Research Institute of Sweden, Borås, Sweden, 2010.

17. Babrauskas B., Heat release rate, in: The SFPE Handbook of Fire Protection Engineering (3rd ed), DiNenno P.J. (ed.), National Fire Protection Association, Quincy, MA, 2002, p. 3/1.

18. Tewardson A., Generation of heat and chemical compounds in fires, in: The SFPE Handbook of Fire Protection Engineering (3rd ed), DiNenno P.J. (ed.), National Fire Protection Association, Quincy, MA, 2002, p. 3/4.

19. Tewardson A., Pion R.F., Flammability of plastics I. Burning intensity, Combustion and Flame, 1976, 26, 85-103. 
20. Ingason H., Fire Testing in Road and Railway Tunnels, in: Flammability testing of materials used in construction, transport and mining (V. Apted, Ed.), Woodhead Publishing, 2006, pp. 231-274.

21. Li Y.Z., Ingason H., The fire growth rate in a ventilated tunnel fire, 10th IAFSS symposium on Fire Safety Science, Maryland, USA, 2011, pp. 347-358.

22. Lemaire A., Van de Leur P.H.E., Kenyon, Y.M., Safety Proef: TNO Metingen Beneluxtunnel - Meetrapport, TNO, TNO-Rapport 2002-CVB-R05572, 2002.

23. Li Y.Z., Ingason H., The maximum temperature of buoyancy-driven smoke flow beneath the ceiling in tunnel fires, Fire Safety Journal, 2011, 46, 204-210.

24. Li Y.Z., Ingason H., The maximum ceiling gas temperature in a large tunnel fire, Fire Safety Journal, 2012, 48, 38-48.

25. Li Y.Z.., Ingason H., The maximum ceiling temperature in a large tunnel fire, SP Report 2010:51, SP Technical Research Institute of Sweden, Borås, Sweden, 2010 .

26. Ingason H., Wickström U., Measuring incident radiant heat flux using the plate thermometer, Fire Safety Journal, 2007, 42, 161-166.

27. Drysdale D., An Introduction to Fire Dynamics $\left(2^{\text {nd }}\right.$ ed.), John Wiley \& Sons, Chichester, 1999.

28. Ingason H., Lönnermark A., Li Y.Z., Model of ventilation flows during large tunnel fires, Tunnelling and Underground Space Technology, 2012, doi:10.1016/j.tust.2012.02.007

29. Fried E., Idelchick I.E., Flow Resistance: A Design Guide for Engineers, Hemisphere Publishing Corporation, New York, 1989.

30. Ingason H., Fire Dynamics in Tunnels, in: The Handbook of Tunnel Fire Safety (2nd Ed), Beard A.N. and Carvel R.O. (Eds.), ICE Publishing, London, 2012, pp. 273-308.

31. Matveev K., Thermoacoustic Instabilities in the Rijke Tube: Experiments and Modeling, Thesis for the Degree of Doctor of Philosophy, California Institute of Technology, Pasadena, California, USA, 2003.

32. Li Y.Z., Lei B., Ingason H., Study of critical velocity and backlayering length in longitudinally ventilated tunnel fires, Fire Safety Journal, 2010, 45, 361-370. 


\section{Appendix A Test Results - Runehamar test T0}

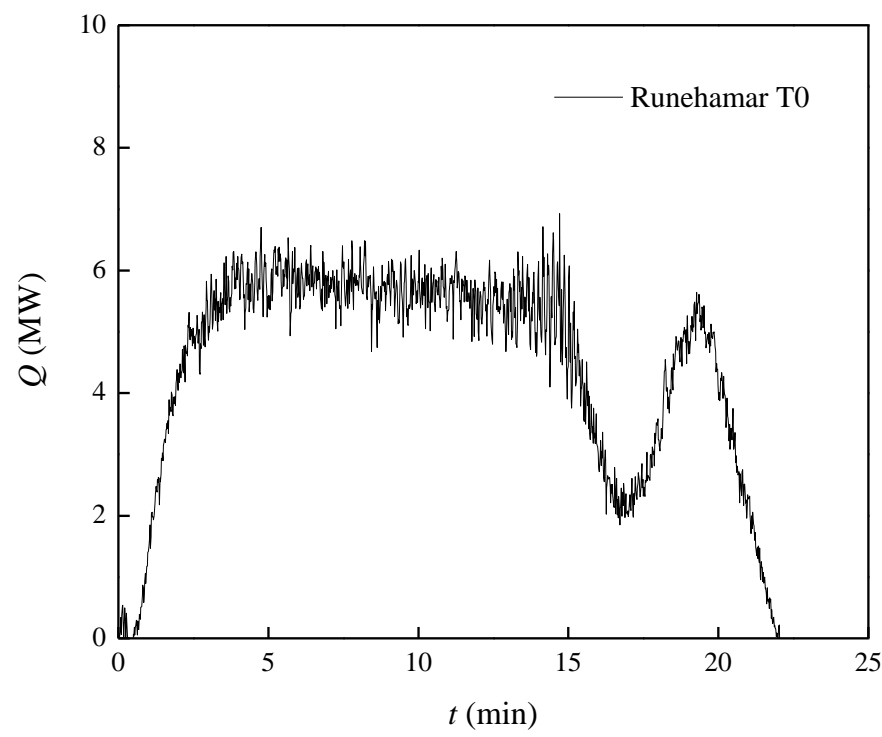

Figure A1 Measured heat release rate, TO.

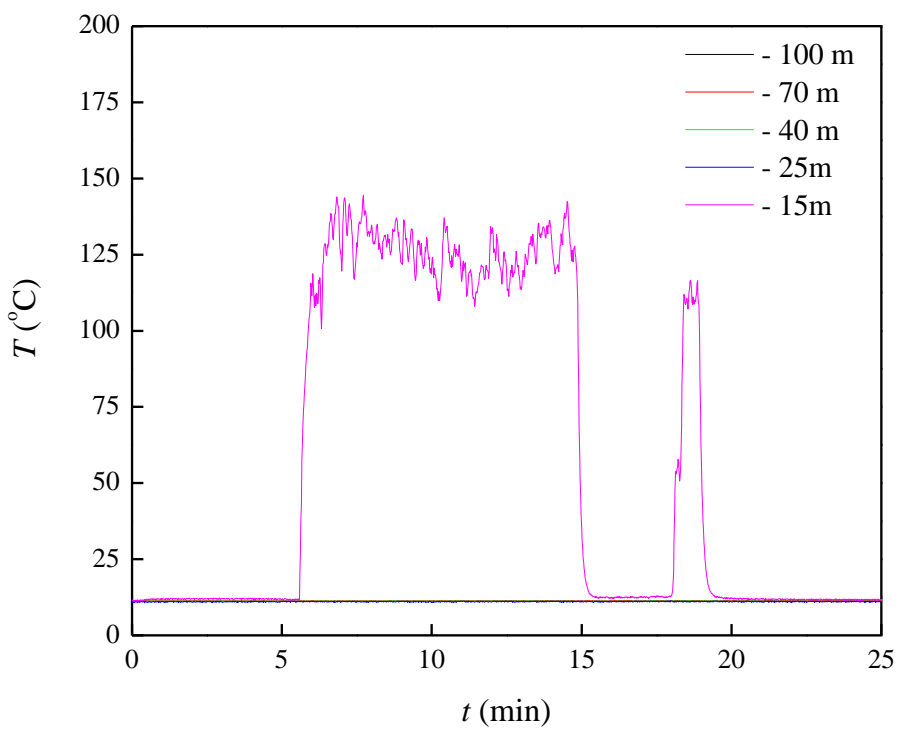

Figure A2 Ceiling temperature upstream of the fire, TO. 


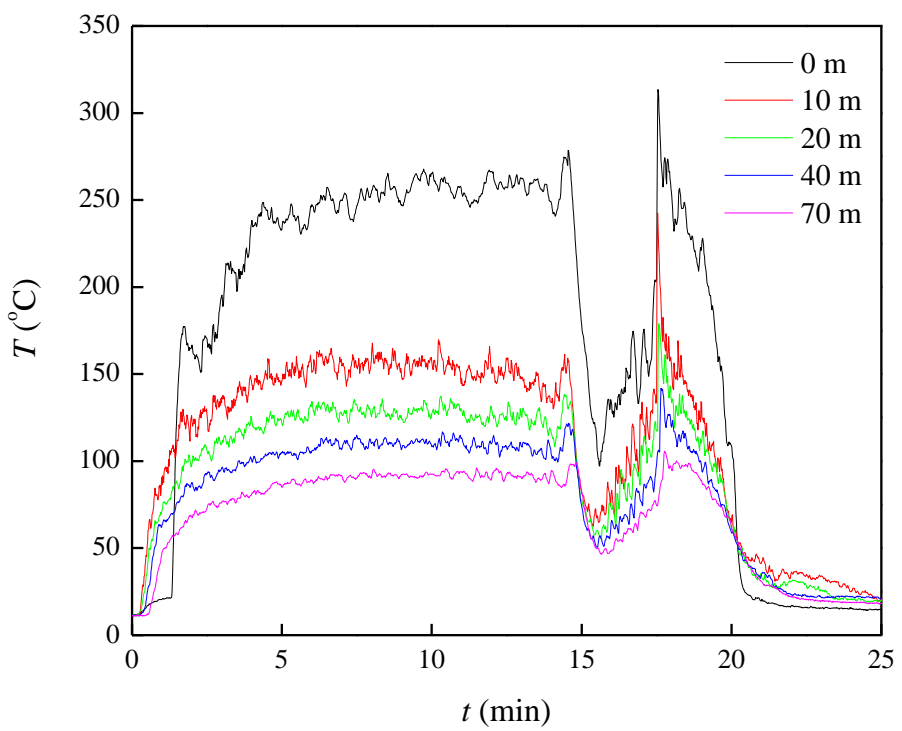

Figure A3 Ceiling temperature downstream of the fire, TO.

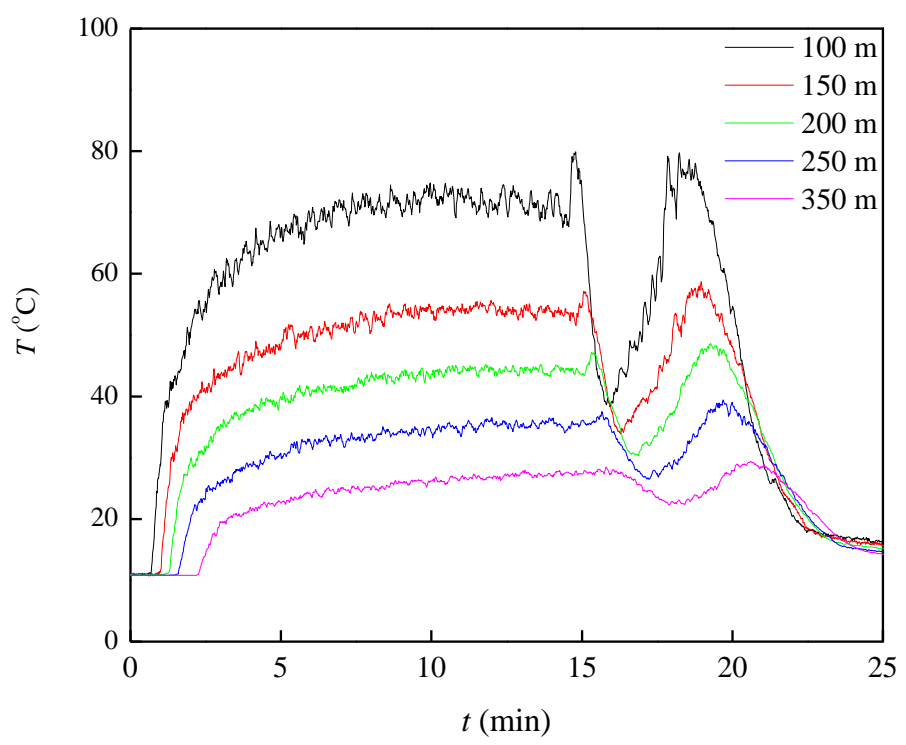

Figure A4 Ceiling temperature downstream of the fire, TO. 


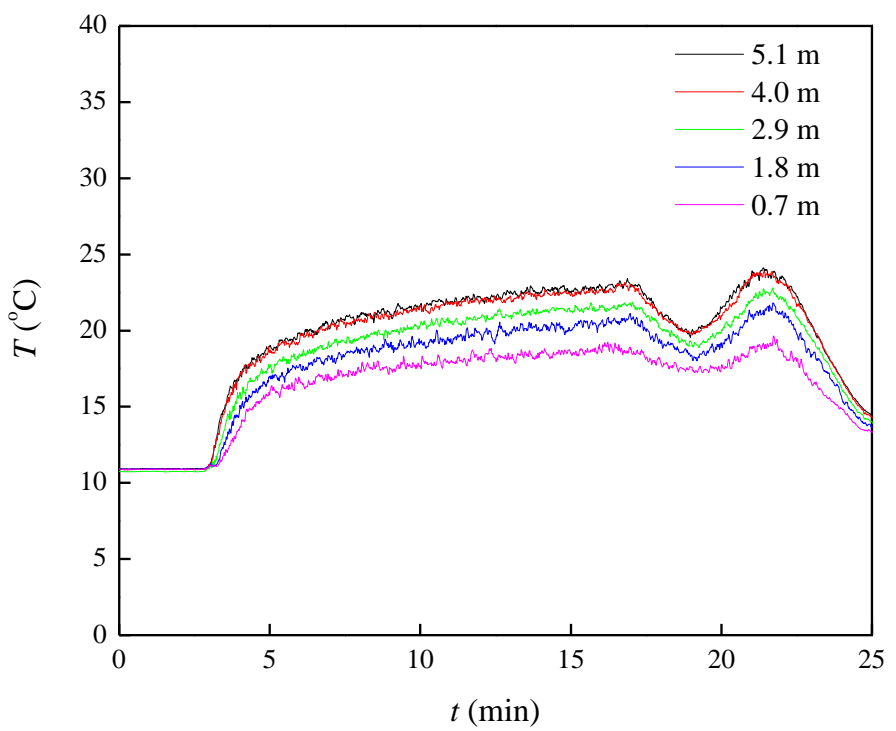

Figure A5 Vertical temperature distribution $458 \mathrm{~m}$ downstream of the fire, T0.

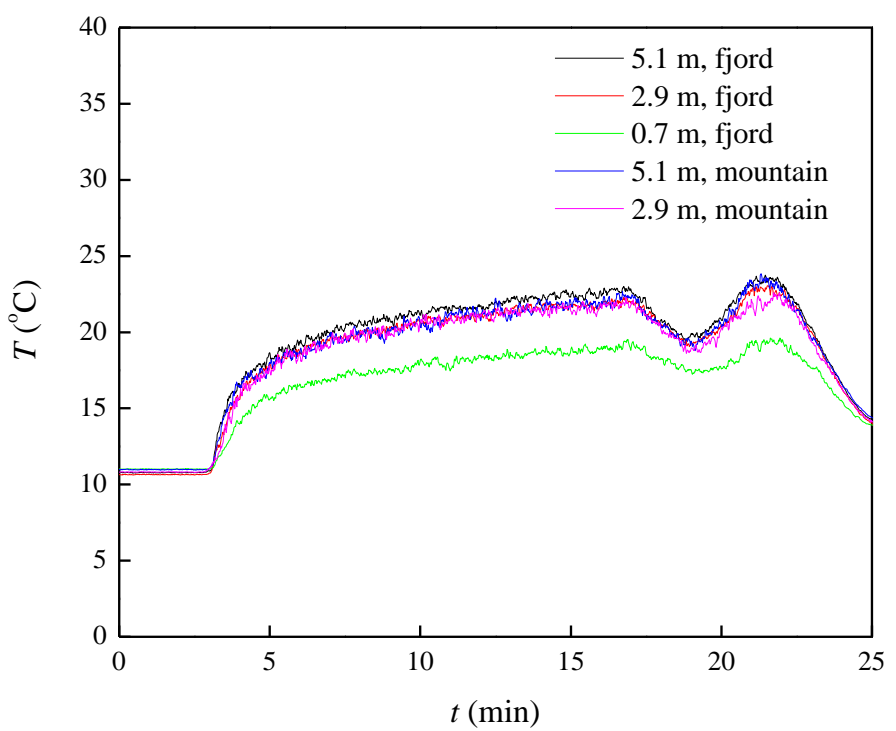

Figure A6 Lateral temperature $458 \mathrm{~m}$ downstream of the fire, T0. 


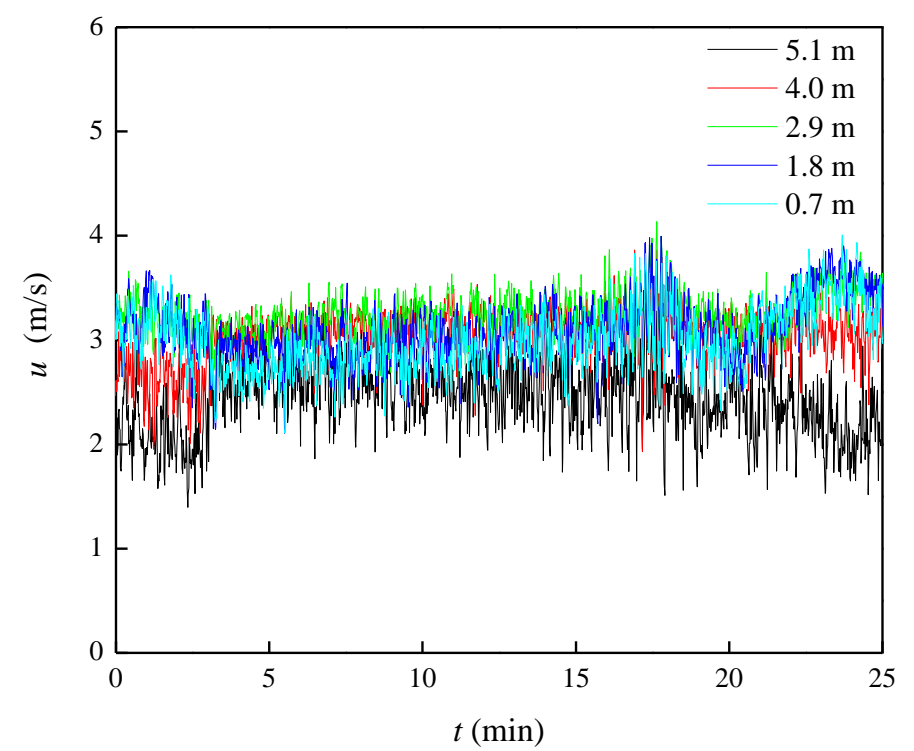

Figure A7 Measured central velocity $458 \mathrm{~m}$ downstream of the fire, T0.

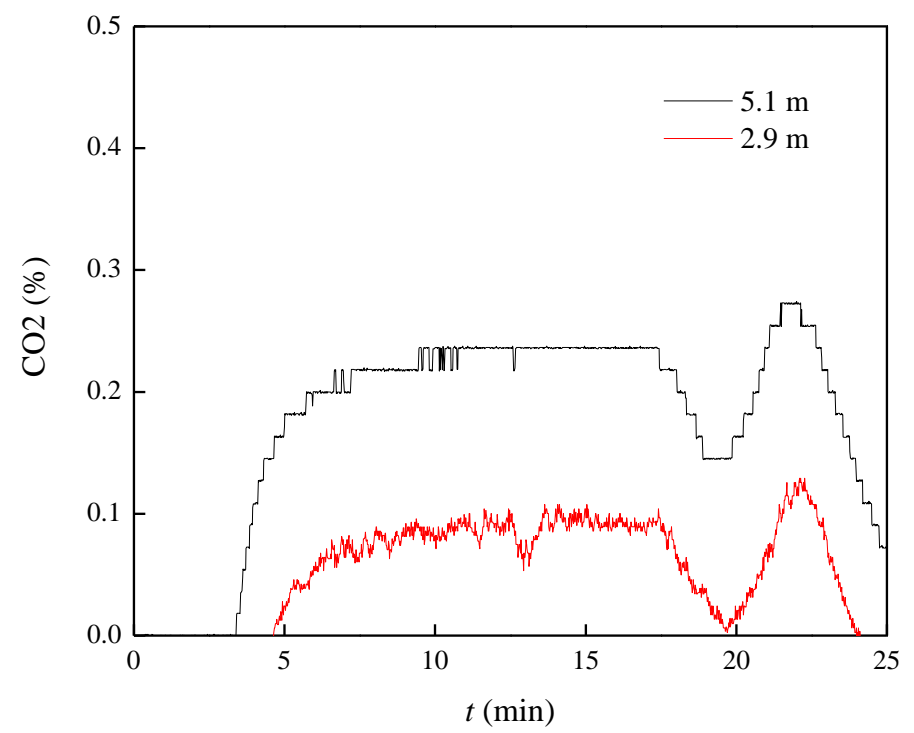

Figure A8 Measured $\mathrm{CO}_{2} 458 \mathrm{~m}$ downstream of the fire, TO. 


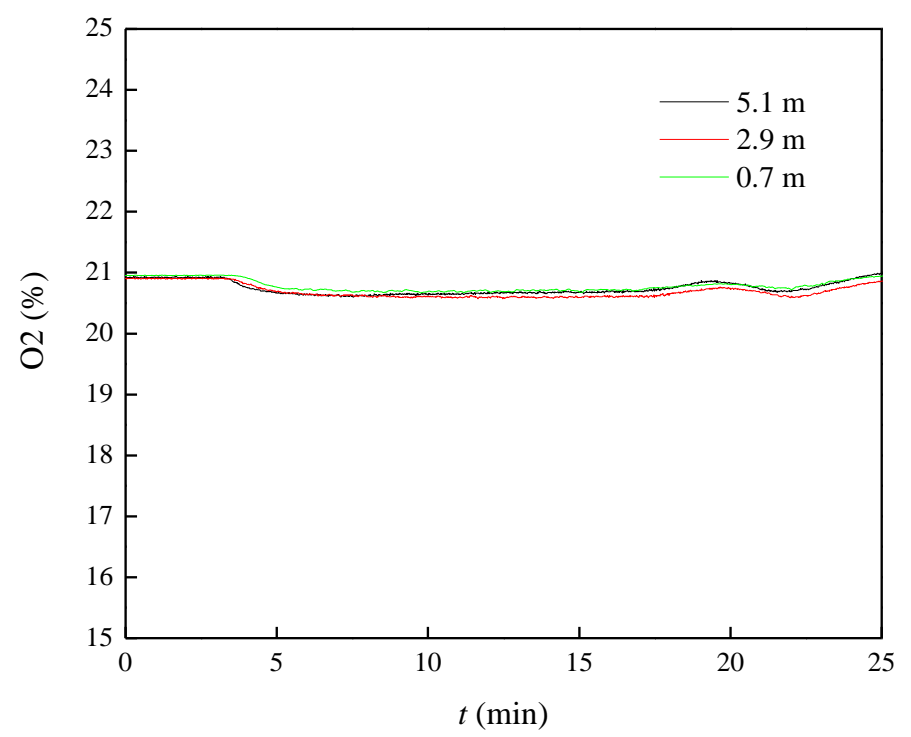

Figure A9 Measured $\mathrm{O}_{2} 458 \mathrm{~m}$ downstream of the fire, T0.

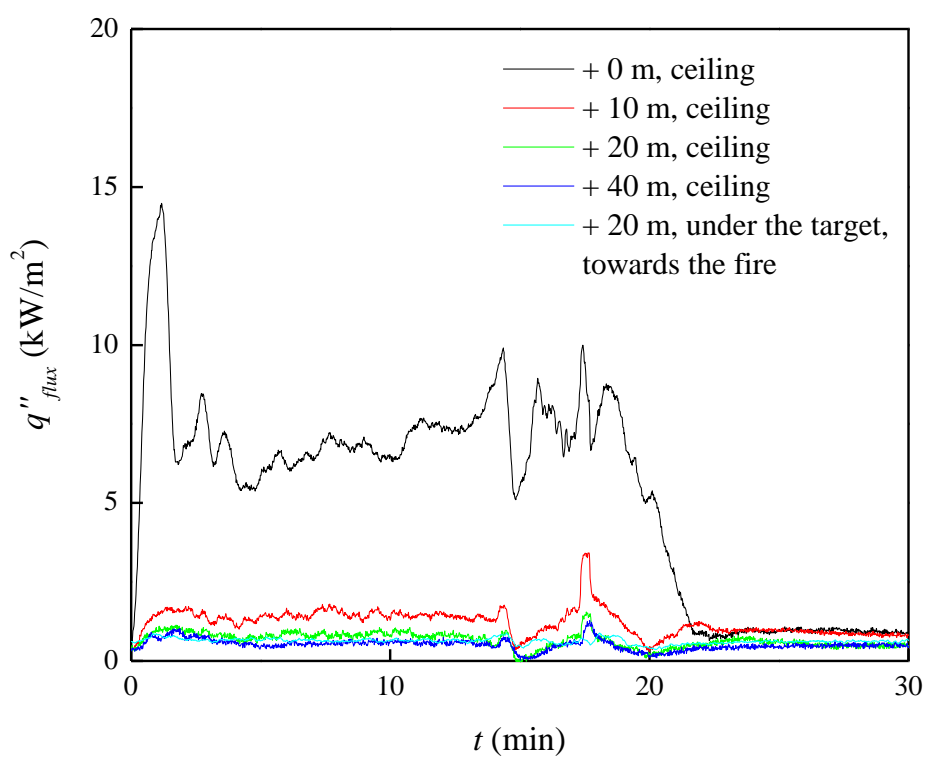

Figure A10 Heat flux measured by plate thermometer at the ceiling close to the fire, T0. 


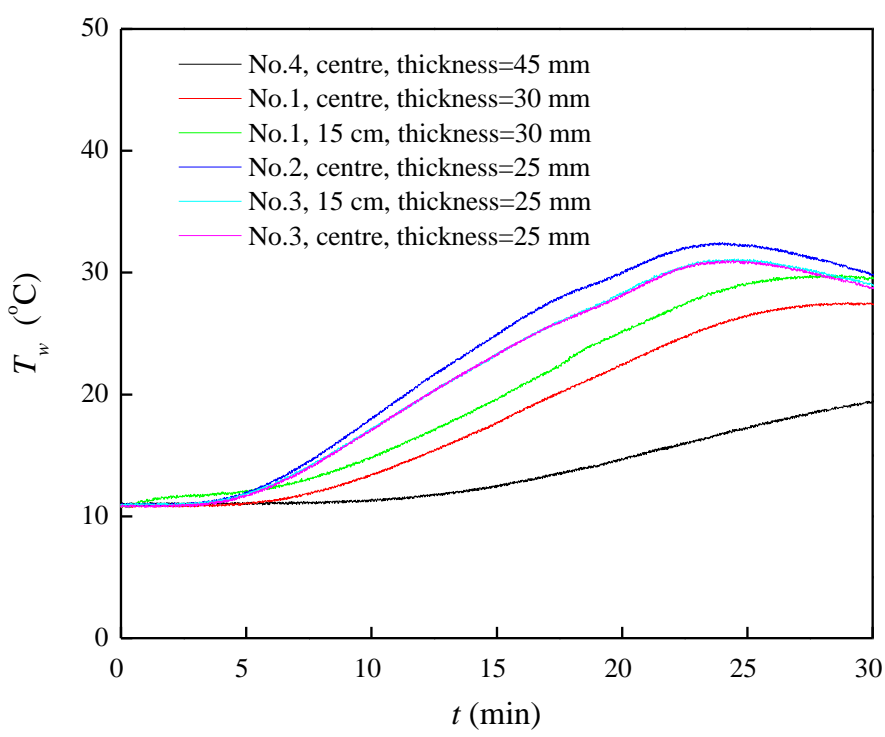

Figure A11 Back surface temperature of the Promatect T close to the fire, TO.

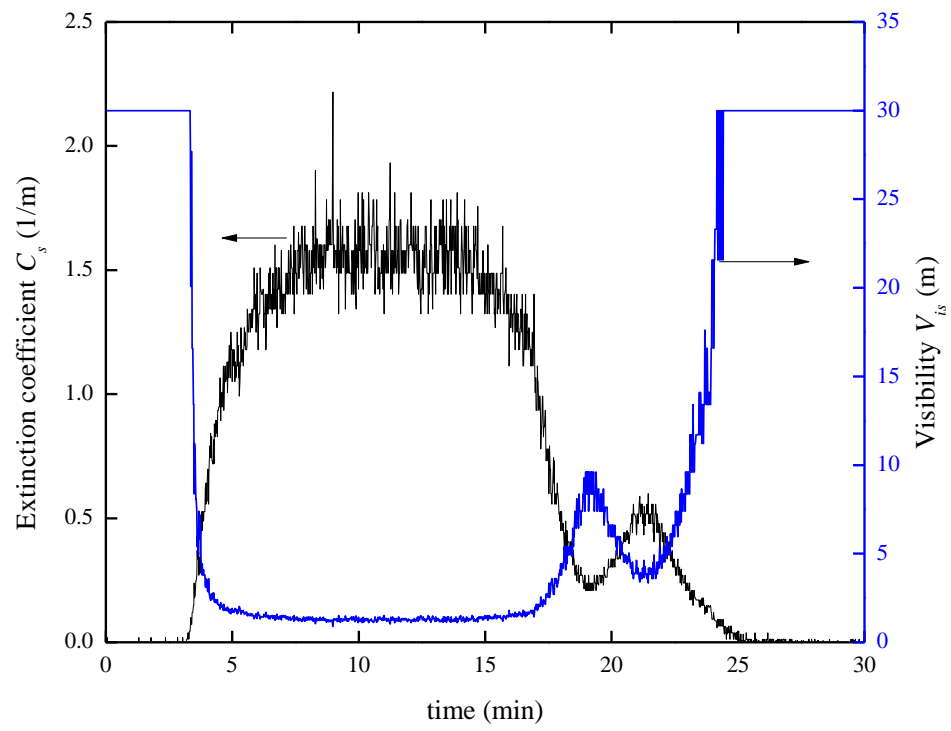

Figure A12 Measured extinction coefficient and estimated visibility at measurement station $+458 \mathrm{~m}, 2.9 \mathrm{~m}$ above floor, T0. 


\section{Appendix B Test Results - Runehamar test T1}

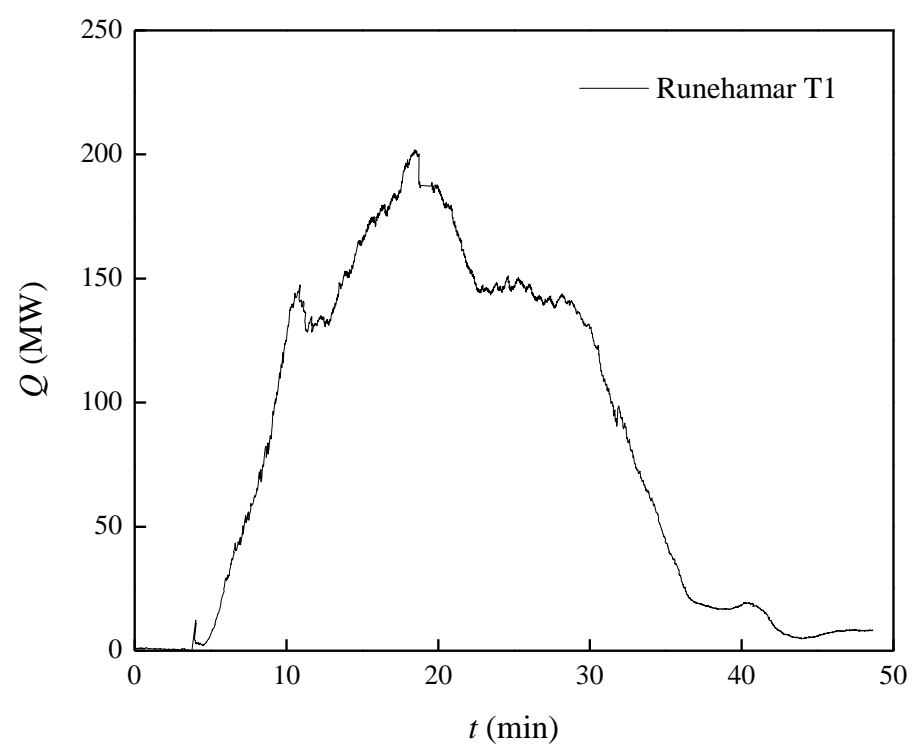

Figure B1 Measured heat release rate, $T 1$.

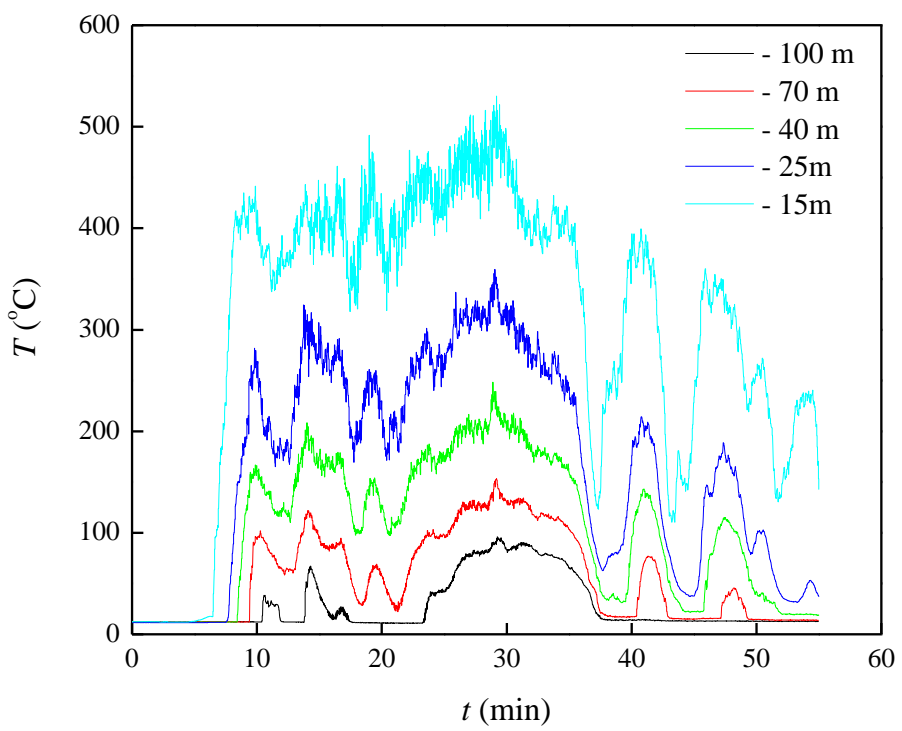

Figure B2 Ceiling temperature upstream of the fire, T1. 


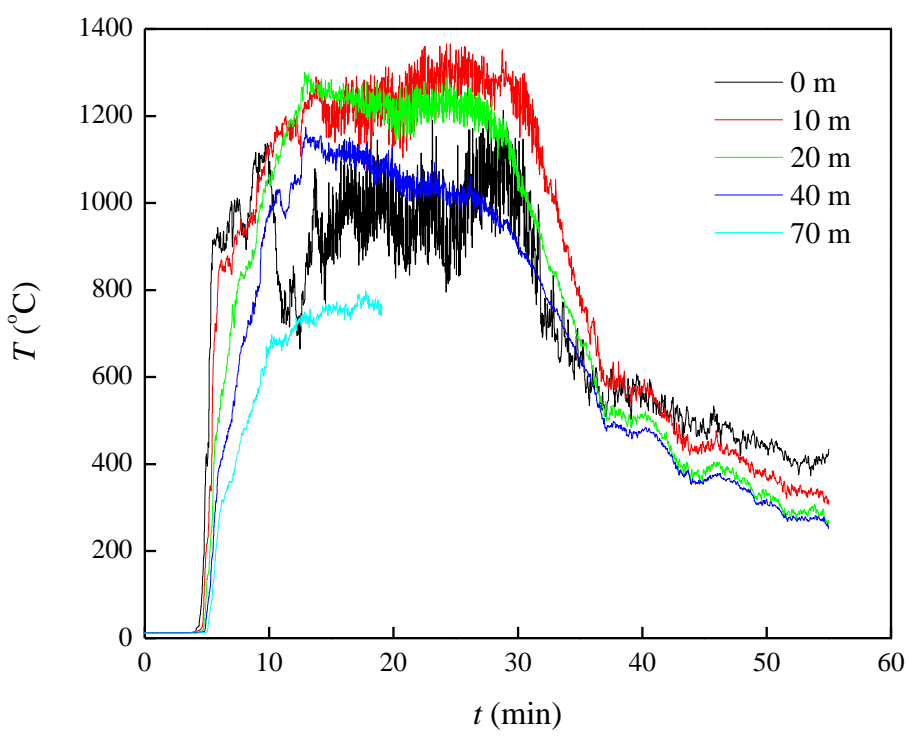

Figure B3 Ceiling temperature downstream of the fire, T1.

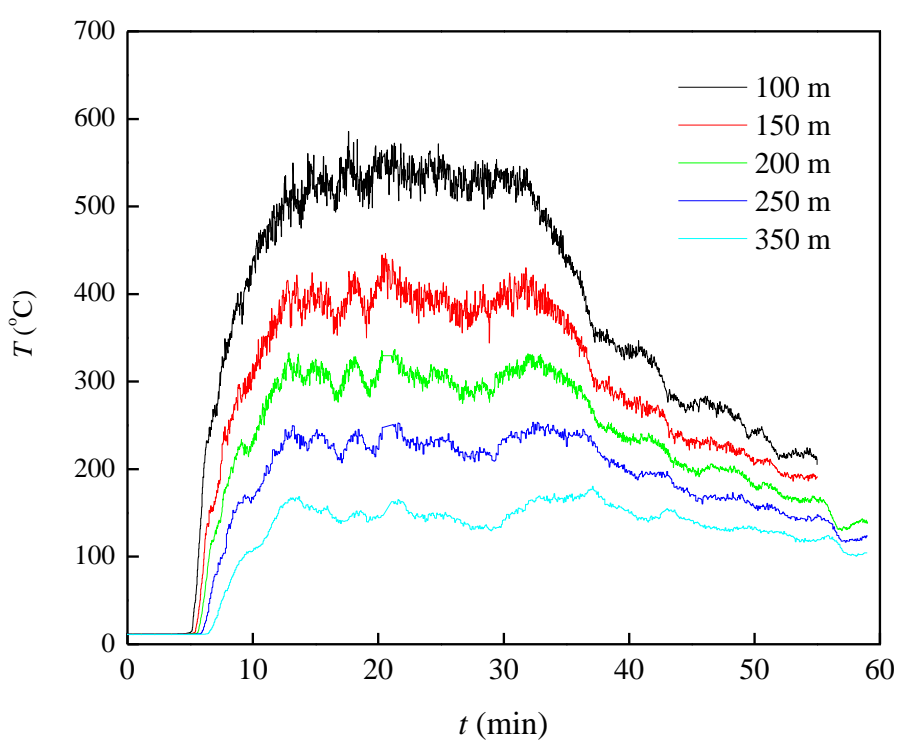

Figure B4 Ceiling temperature downstream of the fire, T1. 


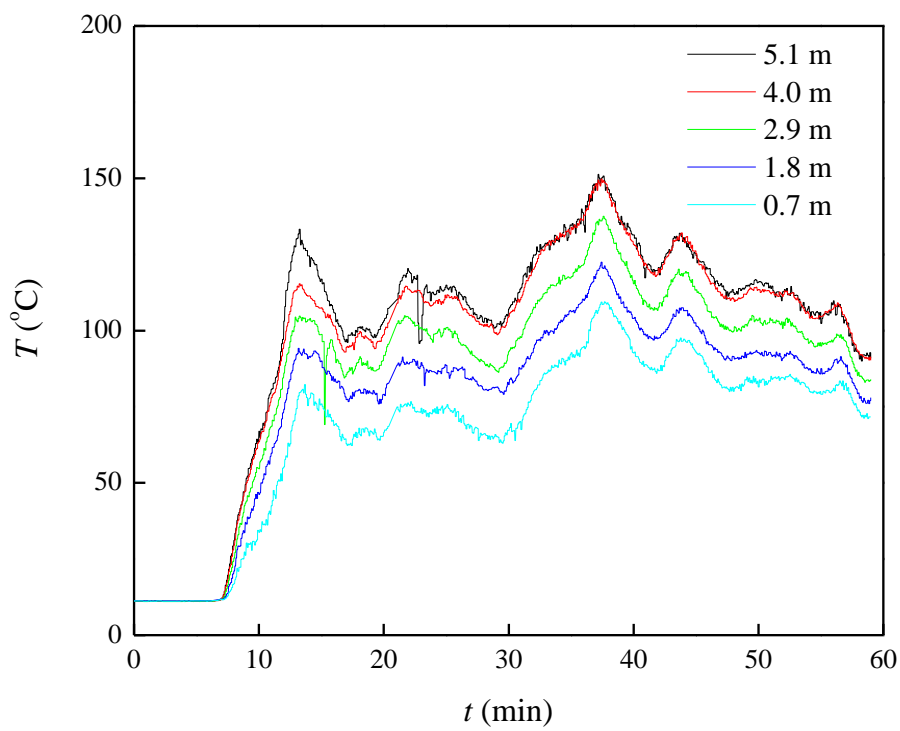

Figure B5 Vertical temperature distribution $458 \mathrm{~m}$ downstream of the fire, T1.

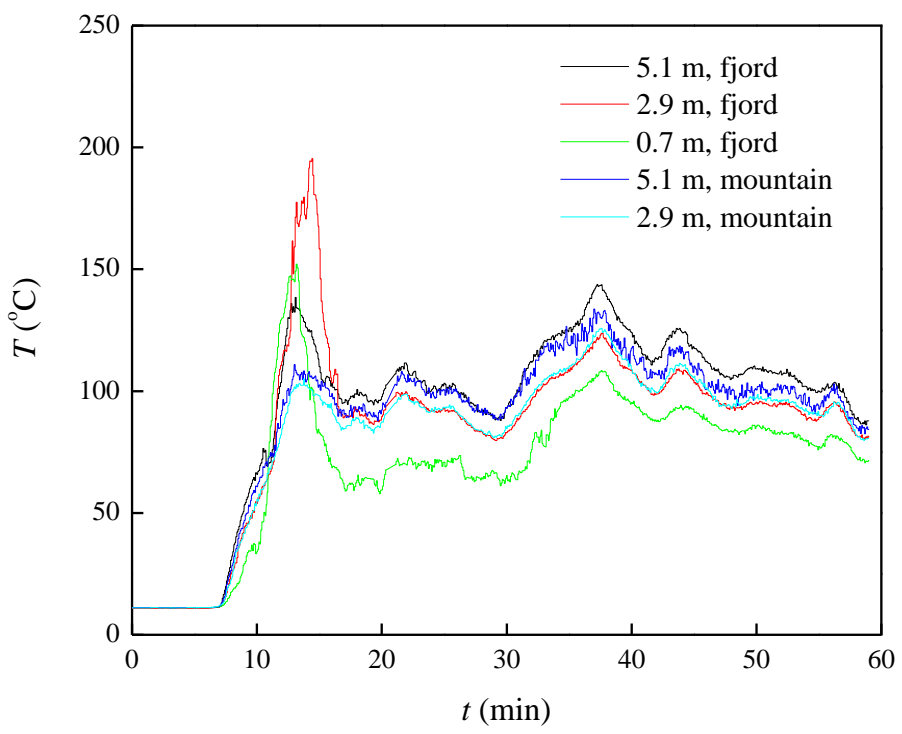

Figure B6 Lateral temperature $458 \mathrm{~m}$ downstream of the fire, $T 1$. 


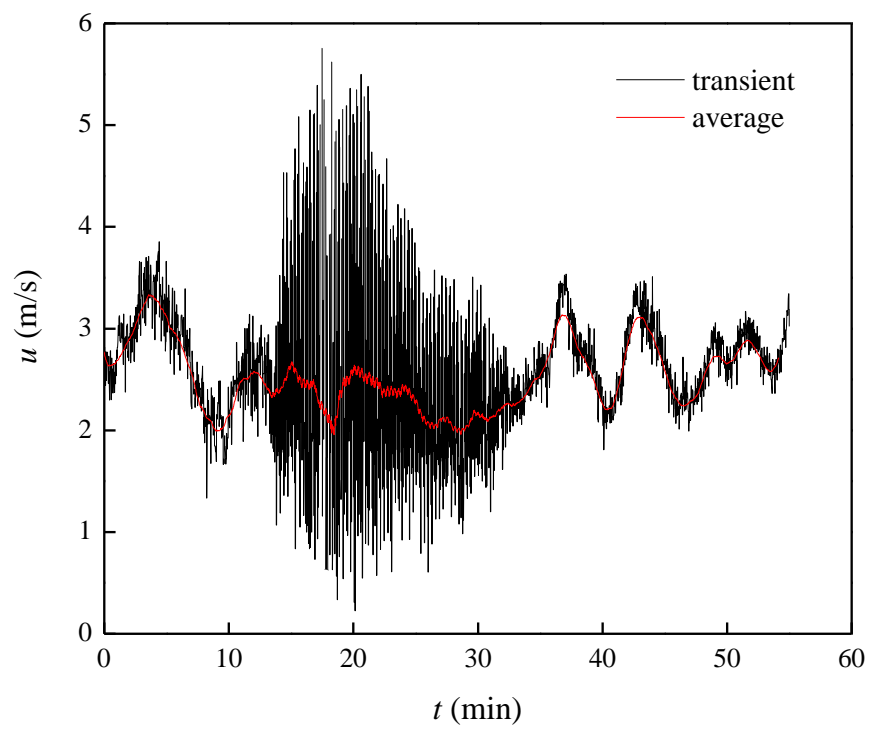

Figure B7 Measured central velocity $50 \mathrm{~m}$ upstream of the fire, $T 1$.

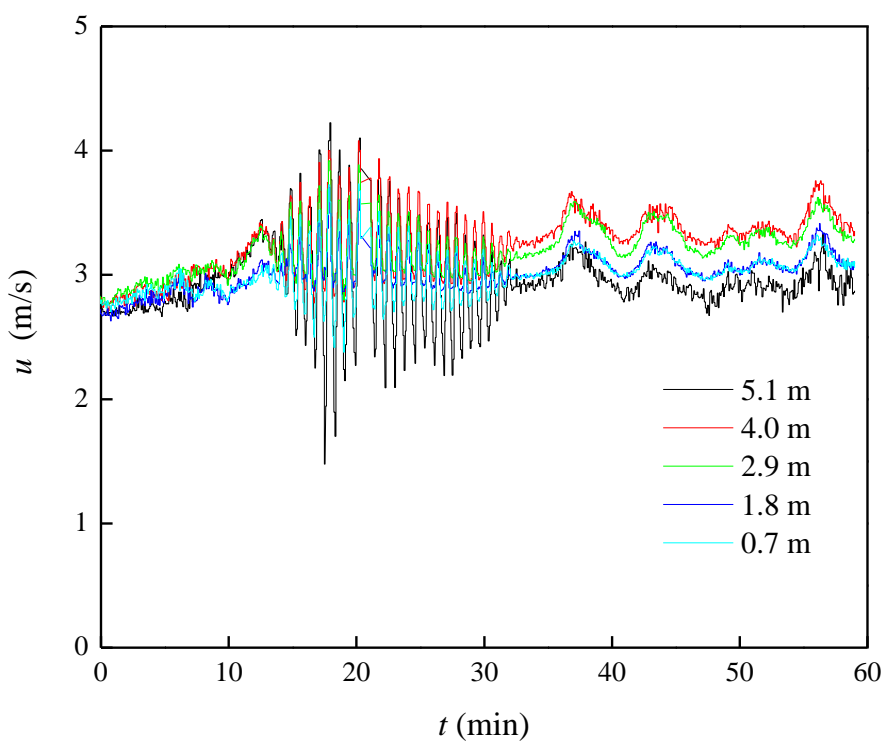

Figure B8 Measured central velocity $458 m$ downstream of the fire, T1. 


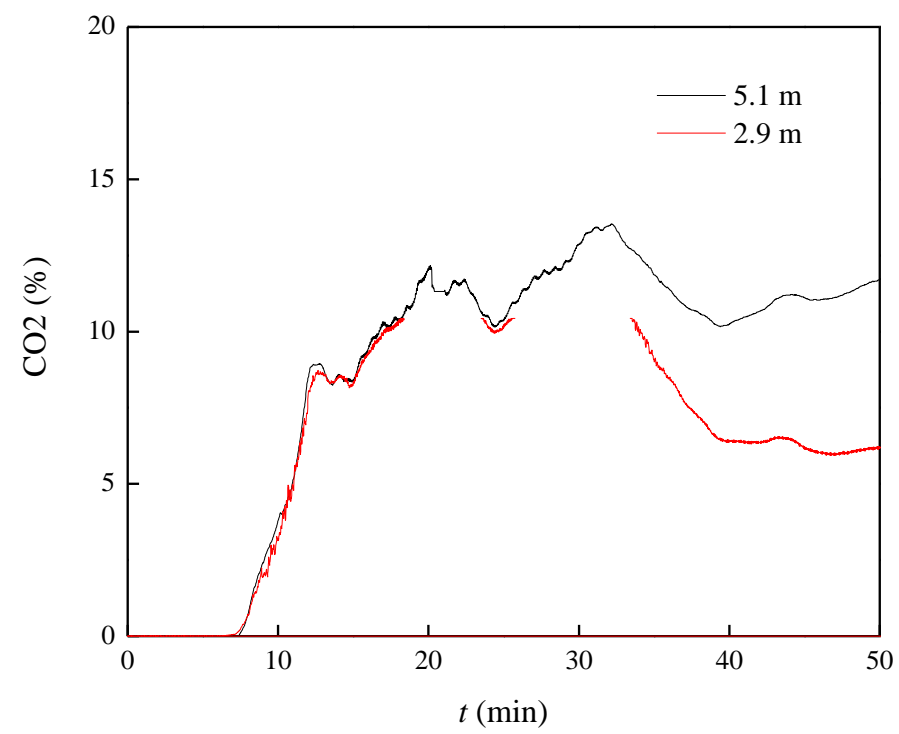

Figure B9 Measured $\mathrm{CO}_{2} 458 \mathrm{~m}$ downstream of the fire, $\mathrm{Tl}$.

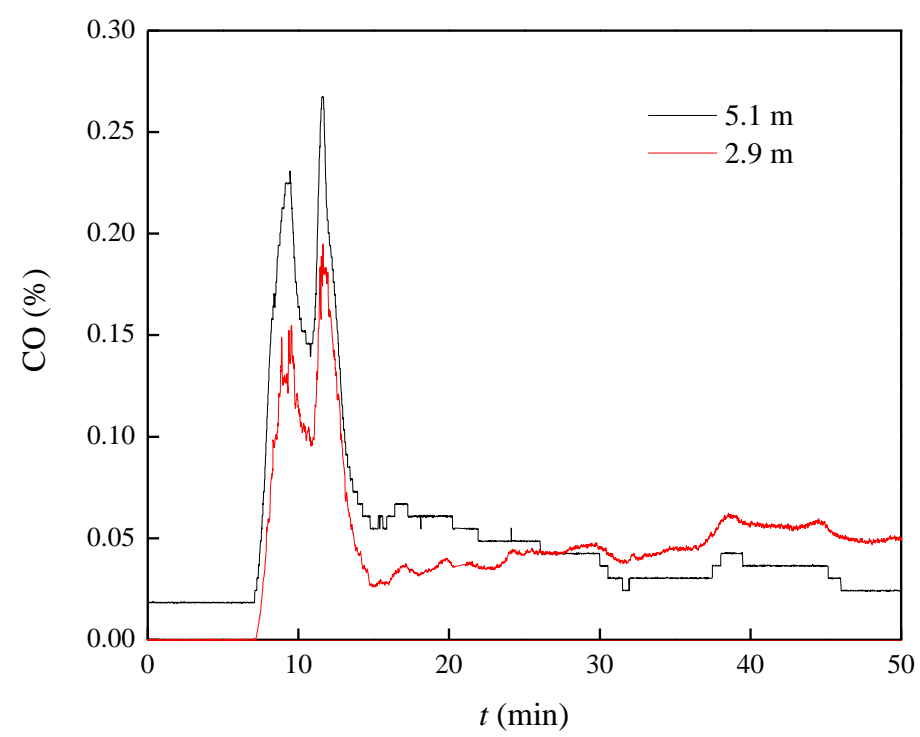

Figure B10 Measured CO $458 \mathrm{~m}$ downstream of the fire, T1. 


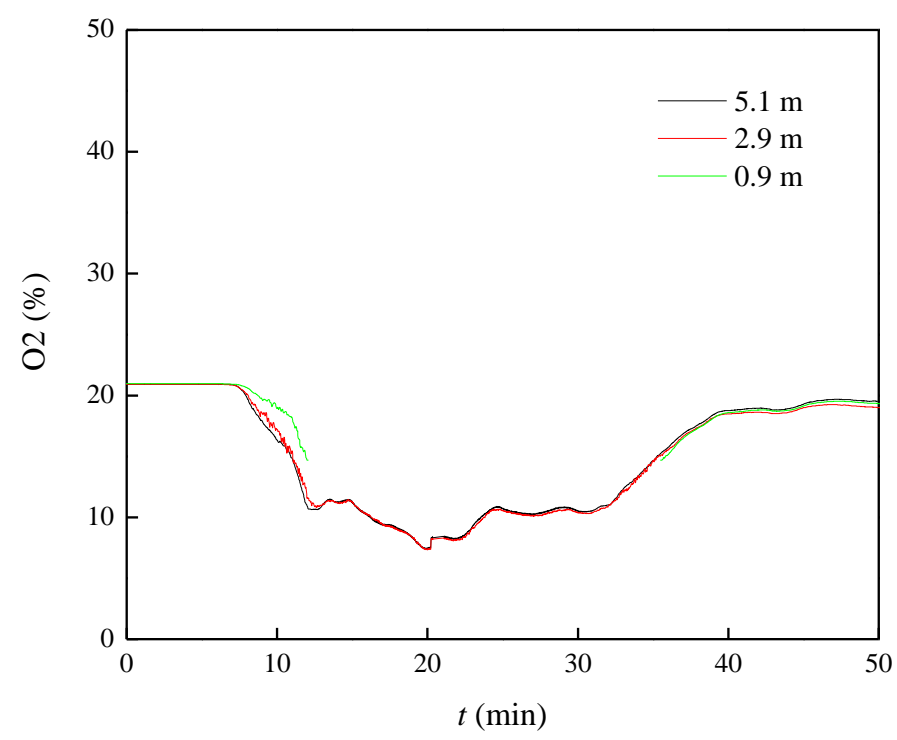

Figure B11 Measured $\mathrm{O}_{2} 458 \mathrm{~m}$ downstream of the fire, $\mathrm{Tl}$.

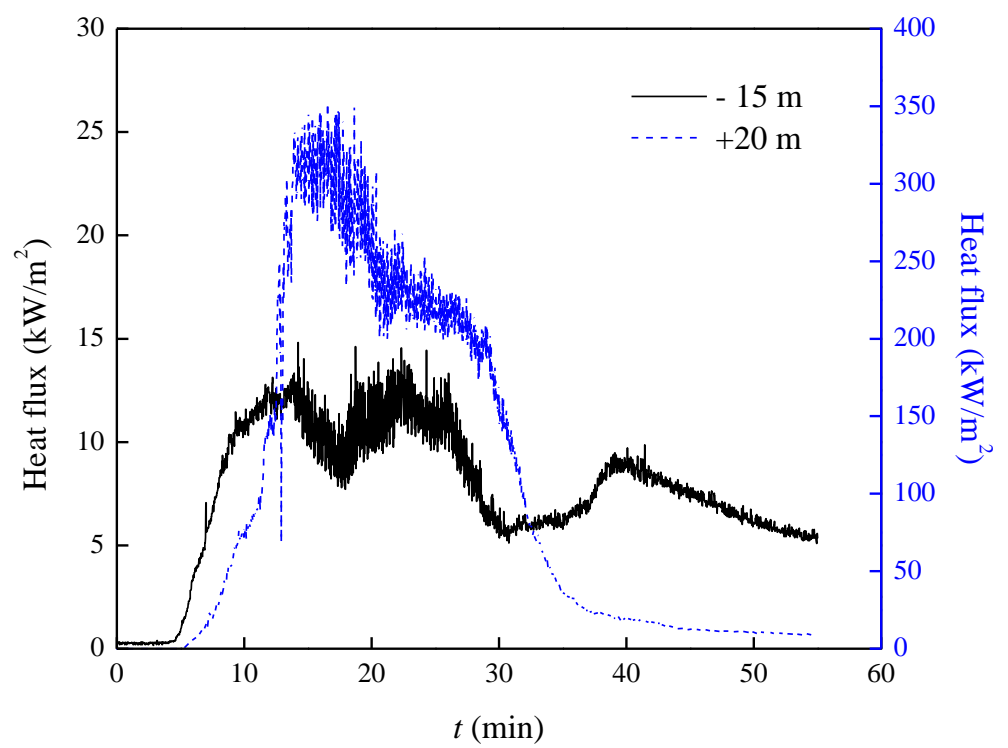

Figure B12 Heat flux measured by Schmidt-Boelter flux meter at two locations close to the fire, T1. The heat flux meter at $-15 \mathrm{~m}$ was towards the fire load and the heat flux meter at $+20 \mathrm{~m}$ was flush with the wall. Both were placed $1.6 \mathrm{~m}$ above the floor 


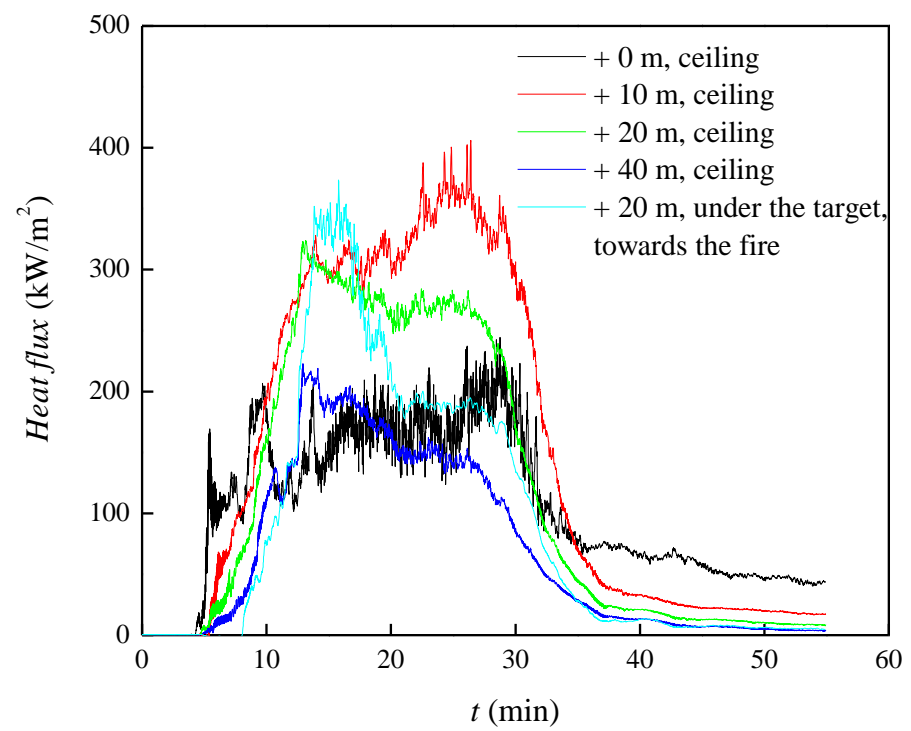

Figure B13 Heat flux measured by plate thermometer at the ceiling close to the fire, T1.

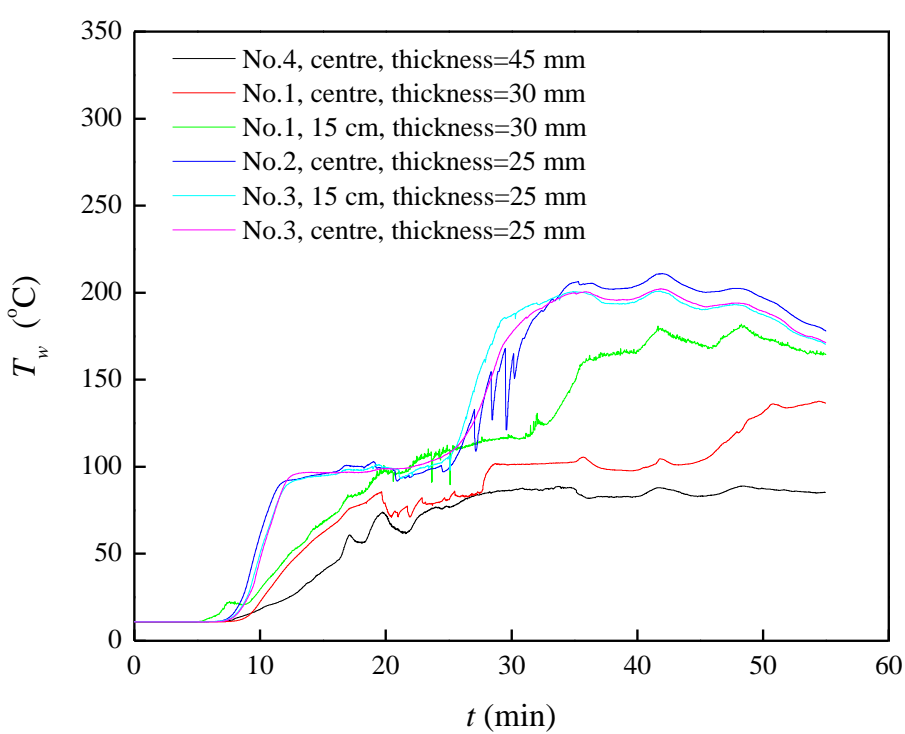

Figure B14 Back surface temperature of the Promatect T close to the fire, T1. 


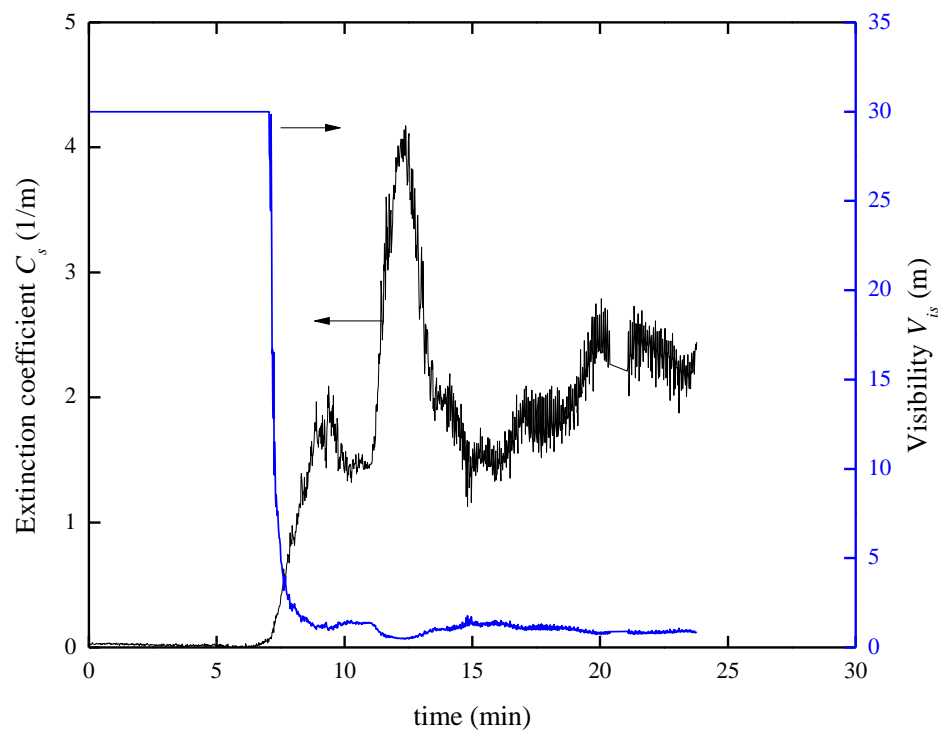

Figure B15 Measured extinction coefficient and estimated visibility at measurement station $+458 \mathrm{~m}, 2.9 \mathrm{~m}$ above floor, $\mathrm{Tl}$. 


\section{Appendix C Test Results - Runehamar test T2}

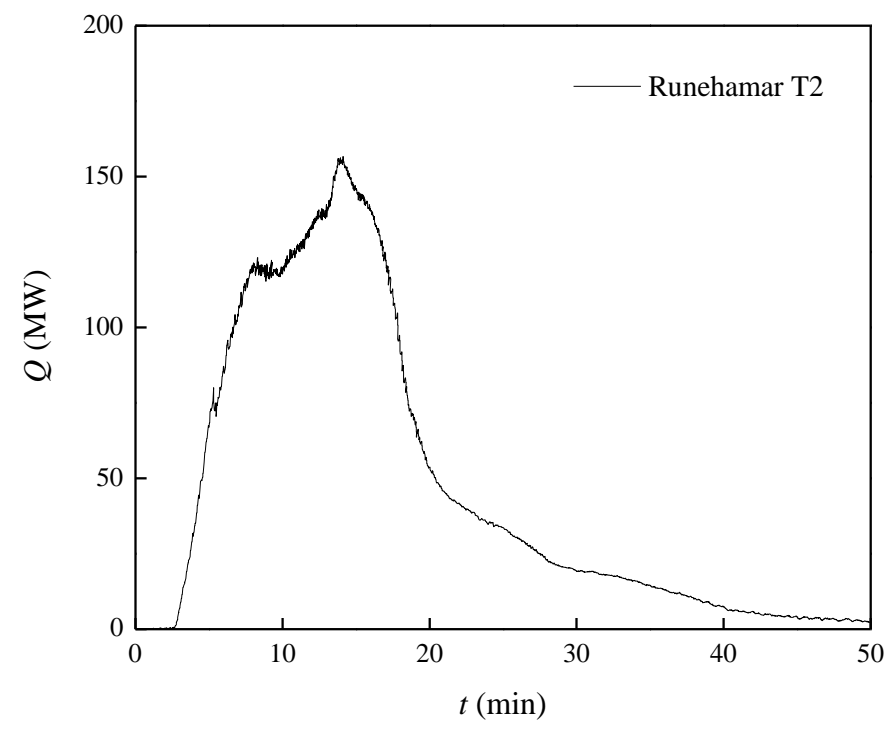

Figure C1 Measured heat release rate, T2.

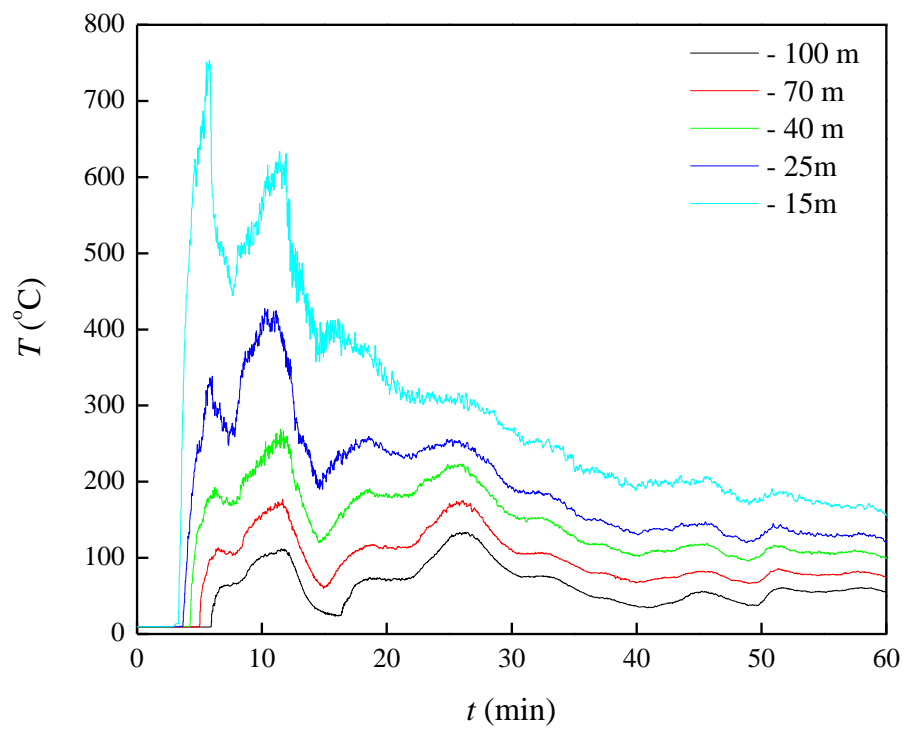

Figure C2 Ceiling temperature upstream of the fire, T2. 


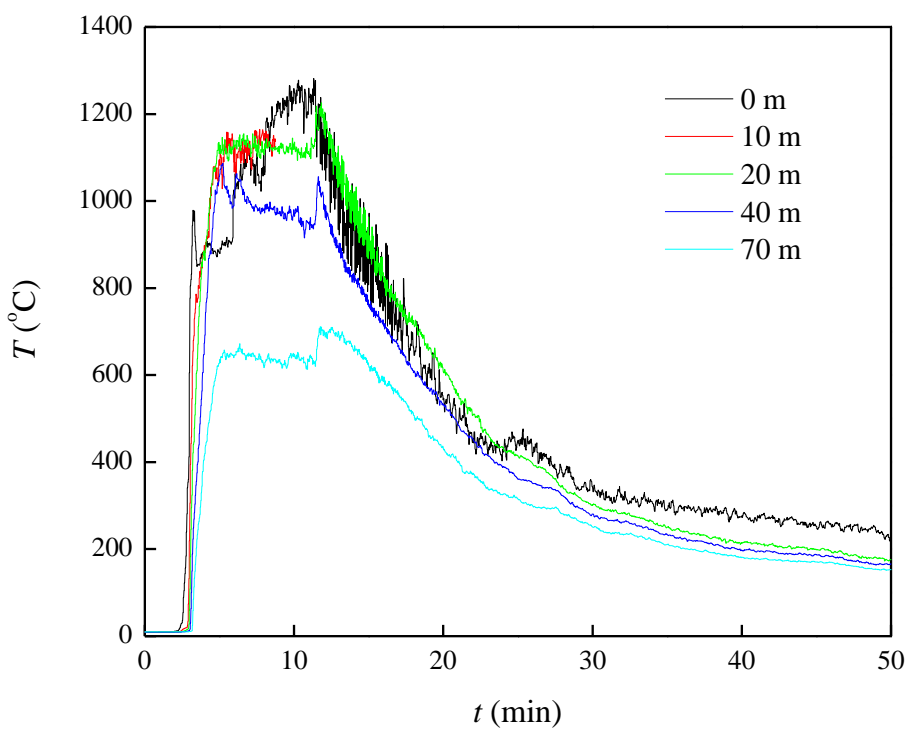

Figure C3 Ceiling temperature downstream of the fire, T2.

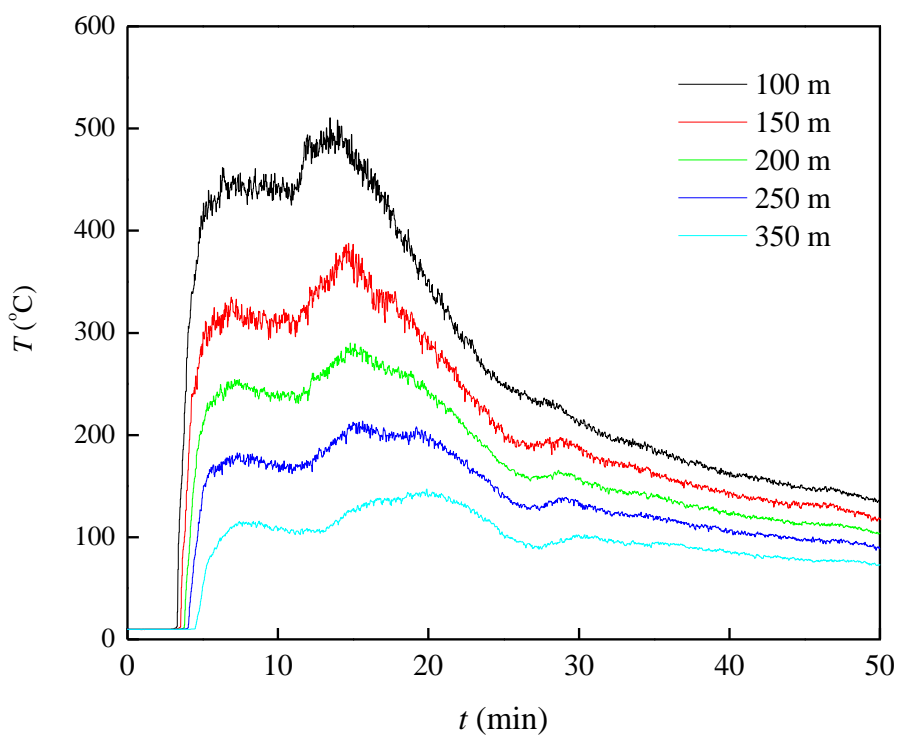

Figure C4 Ceiling temperature downstream of the fire, T2. 


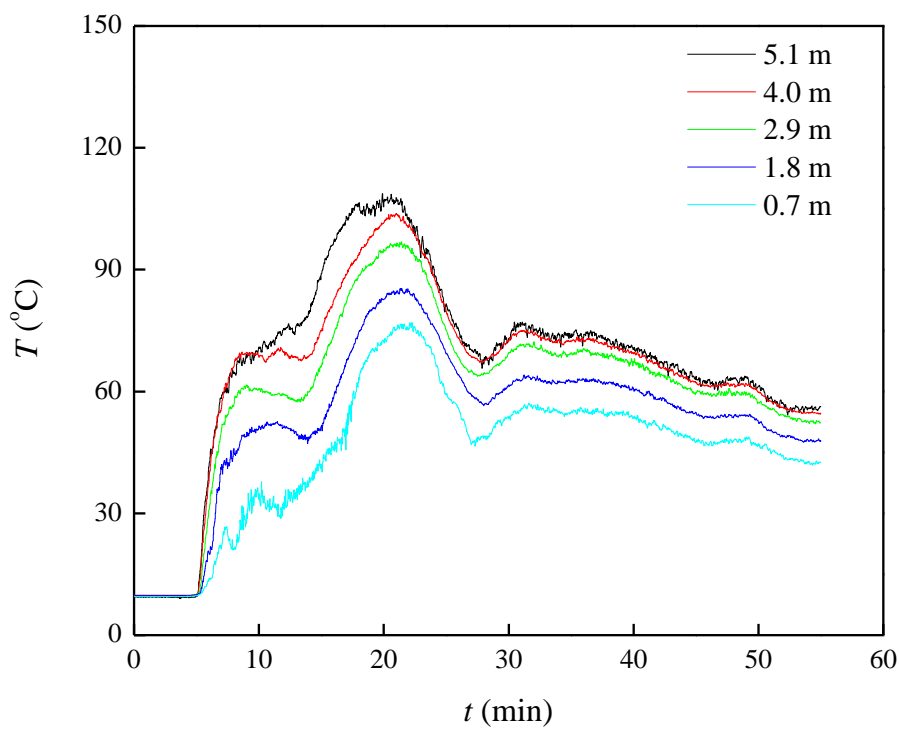

Figure C5 Vertical temperature distribution $458 m$ downstream of the fire, T2.

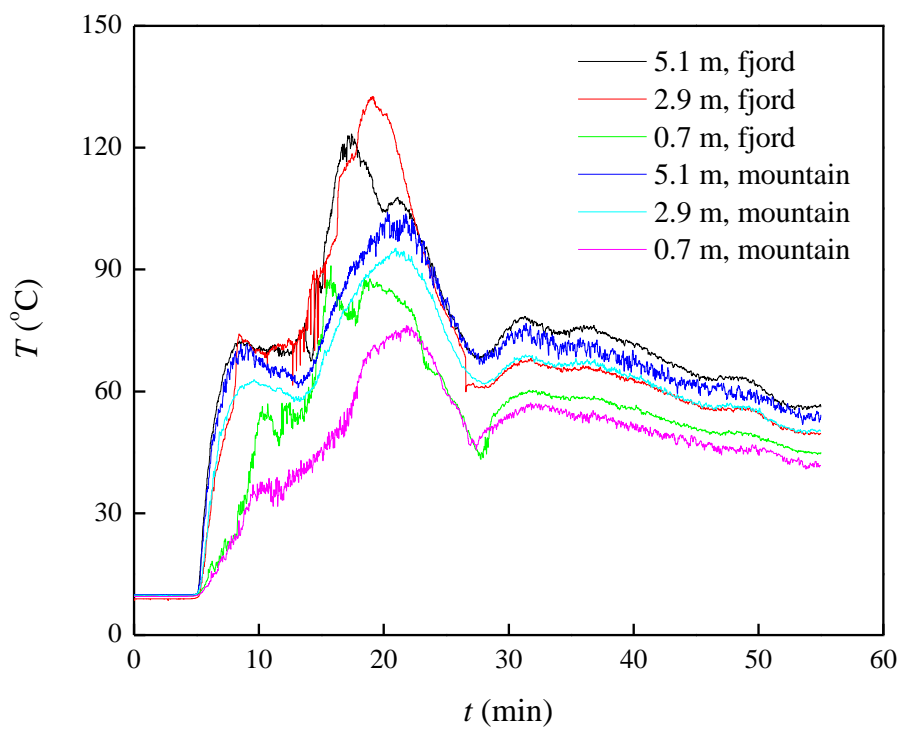

Figure C6 Lateral temperature $458 \mathrm{~m}$ downstream of the fire, T2. 


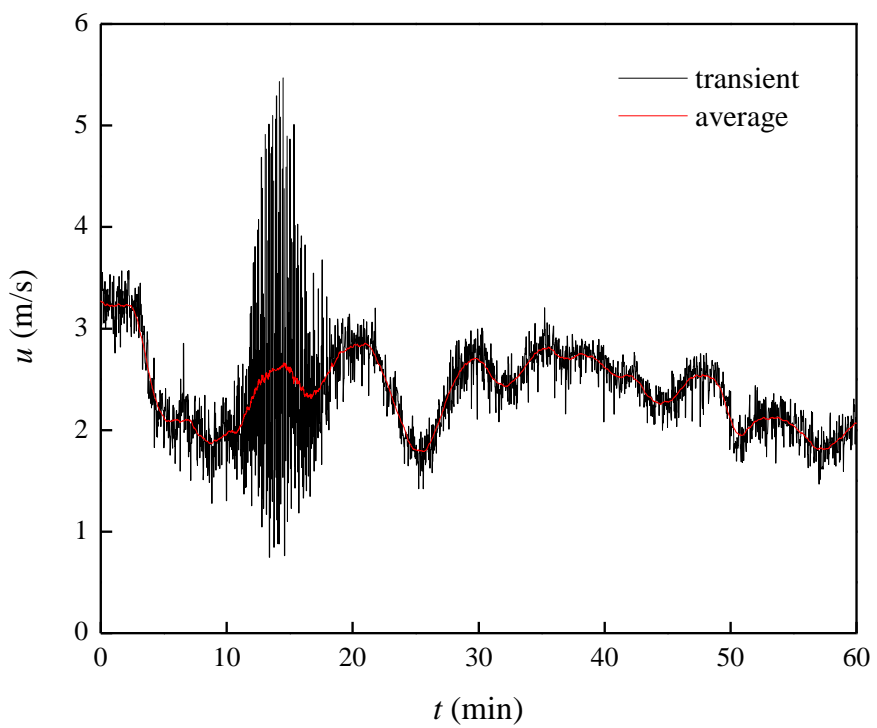

Figure C7 Measured central velocity $50 \mathrm{~m}$ upstream of the fire, T2.

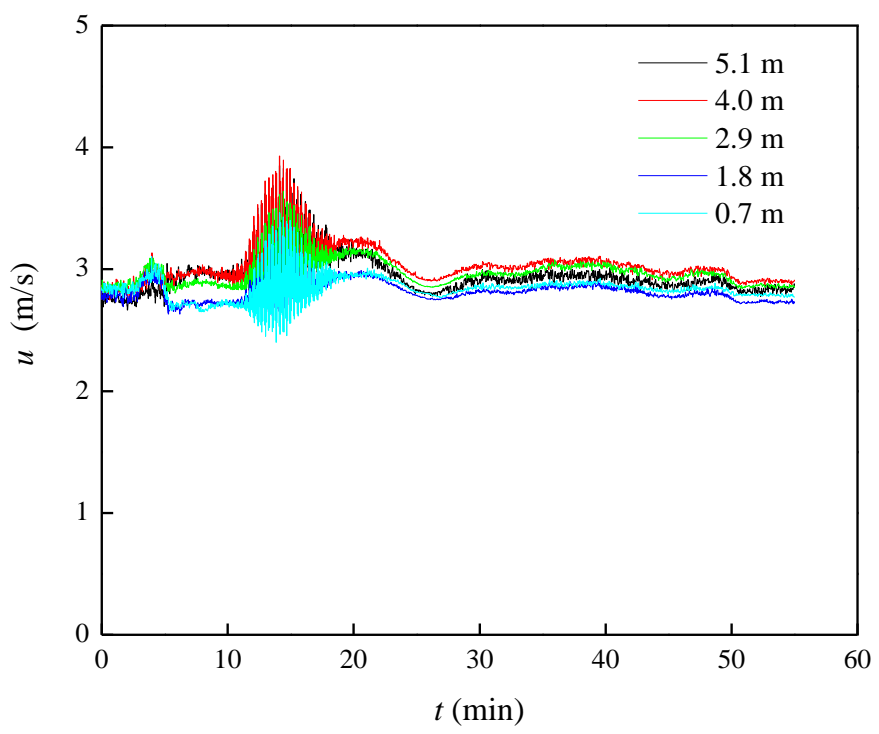

Figure C8 Measured central velocity $458 m$ downstream of the fire, T2. 


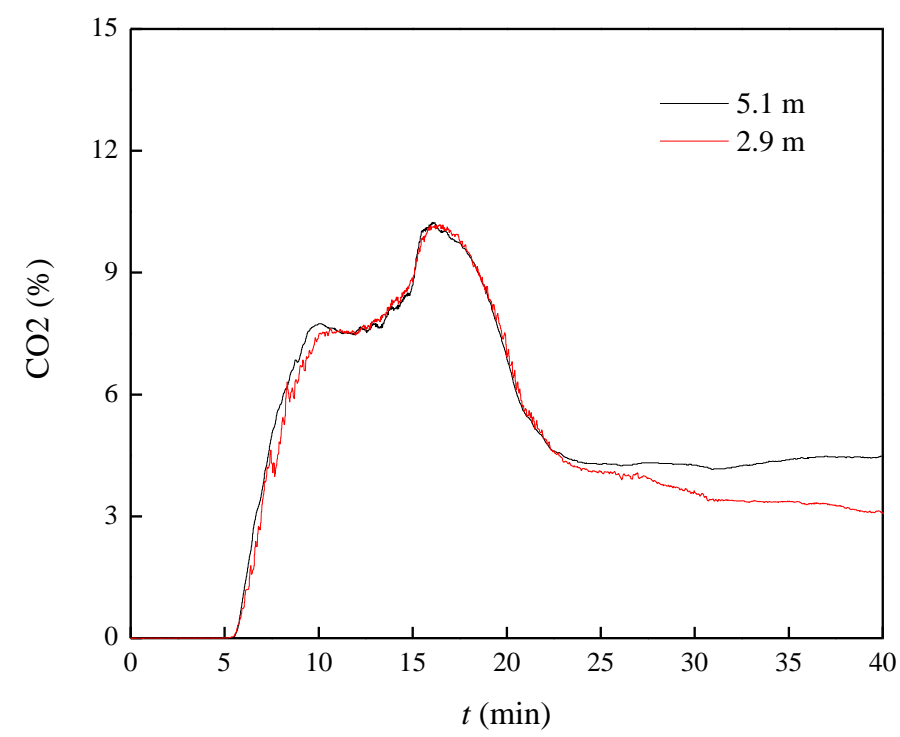

Figure $\mathrm{C} 9$ Measured $\mathrm{CO}_{2} 458 \mathrm{~m}$ downstream of the fire, $\mathrm{T} 2$.

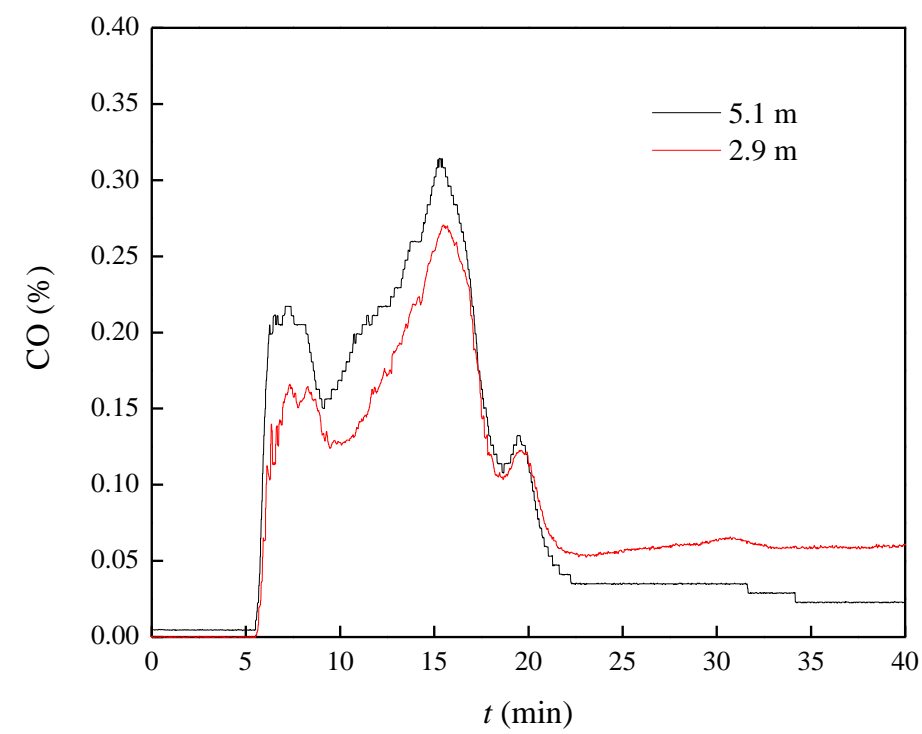

Figure C10 Measured CO $458 \mathrm{~m}$ downstream of the fire, T2. 


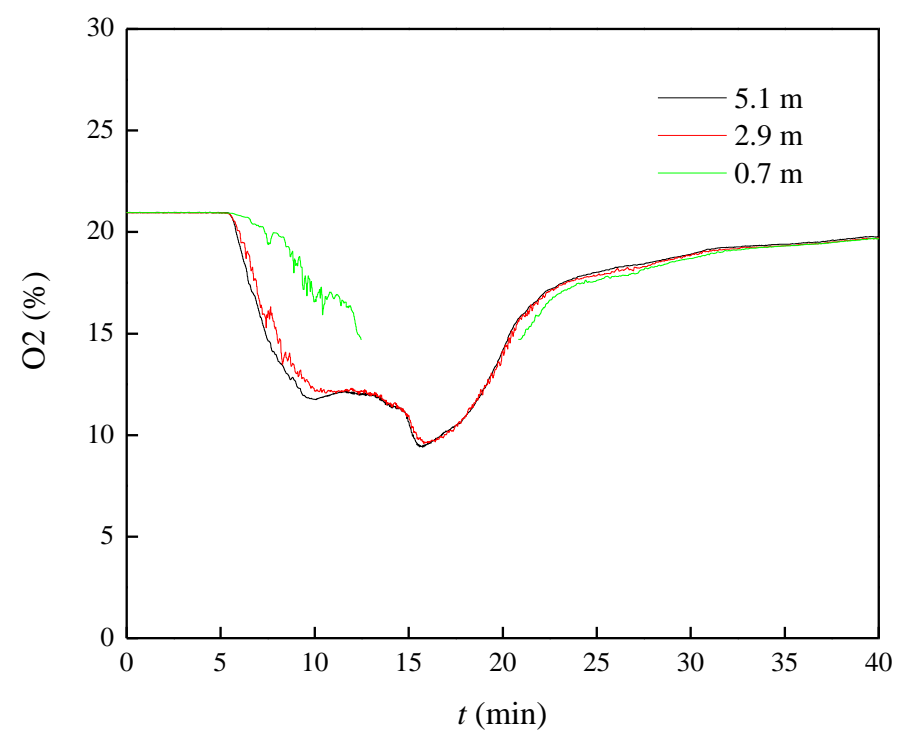

Figure C11 Measured $\mathrm{O}_{2} 458 \mathrm{~m}$ downstream of the fire, $T 2$.

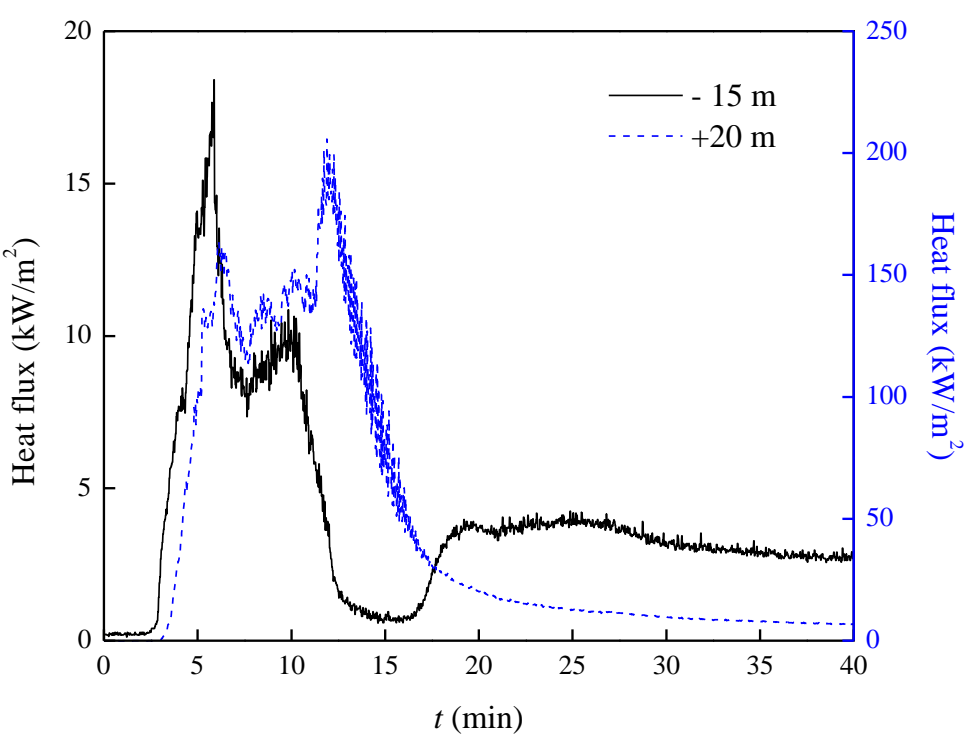

Figure C12 Heat flux measured by Schmidt-Boelter flux meter at two locations close to the fire, T2. The heat flux meter at $-15 \mathrm{~m}$ was towards the fire load and the heat flux meter at $+20 \mathrm{~m}$ was flush with the wall. Both were placed $1.6 \mathrm{~m}$ above the floor 


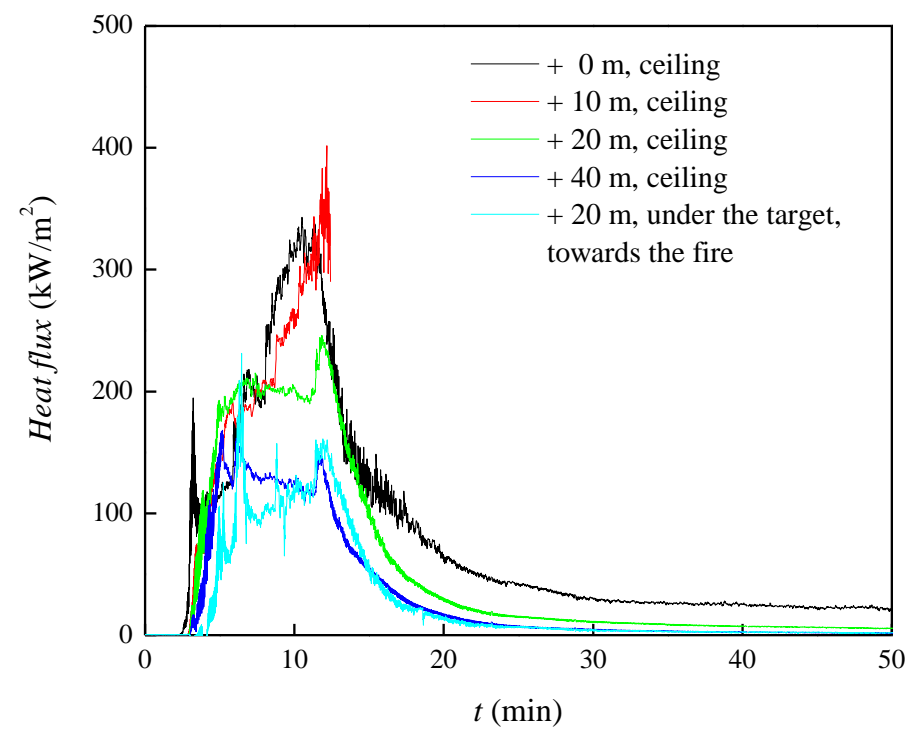

Figure C13 Heat flux measured by plate thermometer at the ceiling close to the fire, T2.

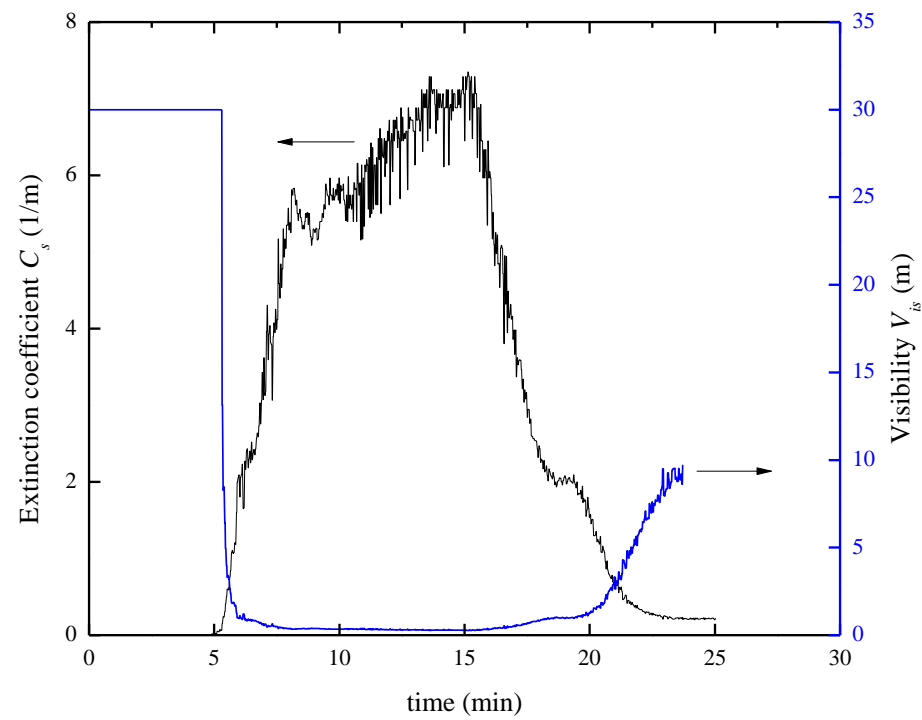

Figure C14 Measured extinction coefficient and estimated visibility at measurement station $+458 \mathrm{~m}, 2.9 \mathrm{~m}$ above floor, $T 2$. 


\section{Appendix D Test Results - Runehamar test T3}

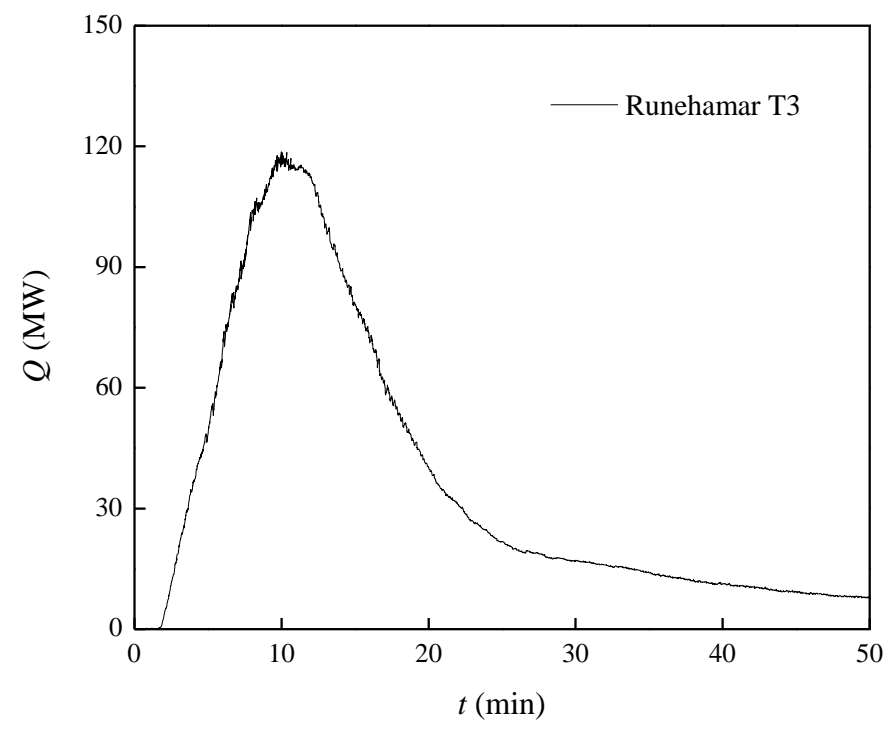

Figure D1 $\quad$ Measured heat release rate, T3.

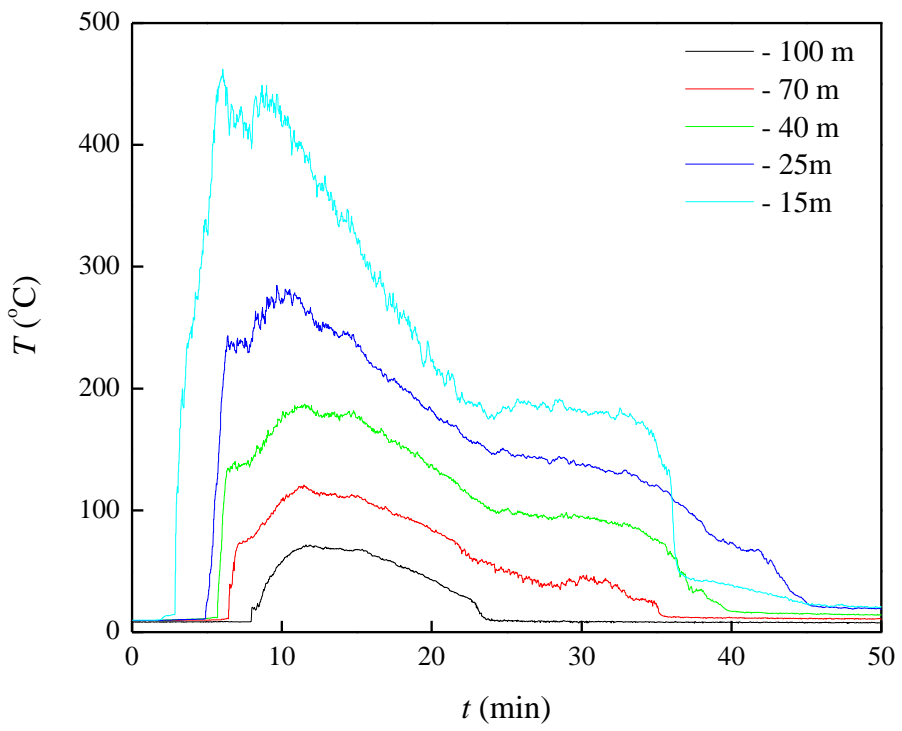

Figure D2 Ceiling temperature upstream of the fire, T3. 


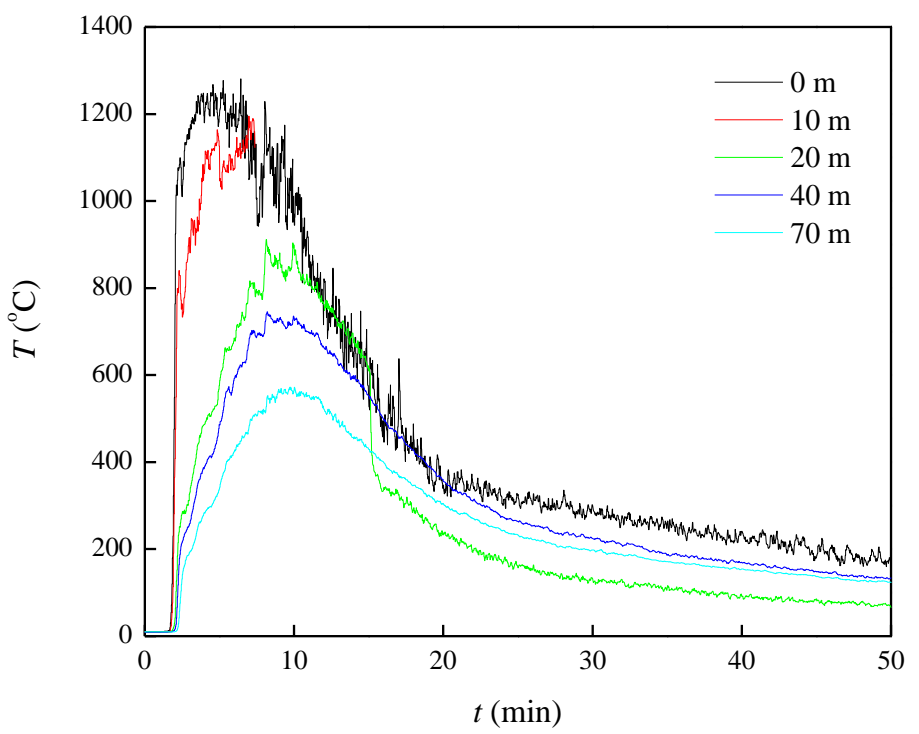

Figure D3 Ceiling temperature downstream of the fire, T3.

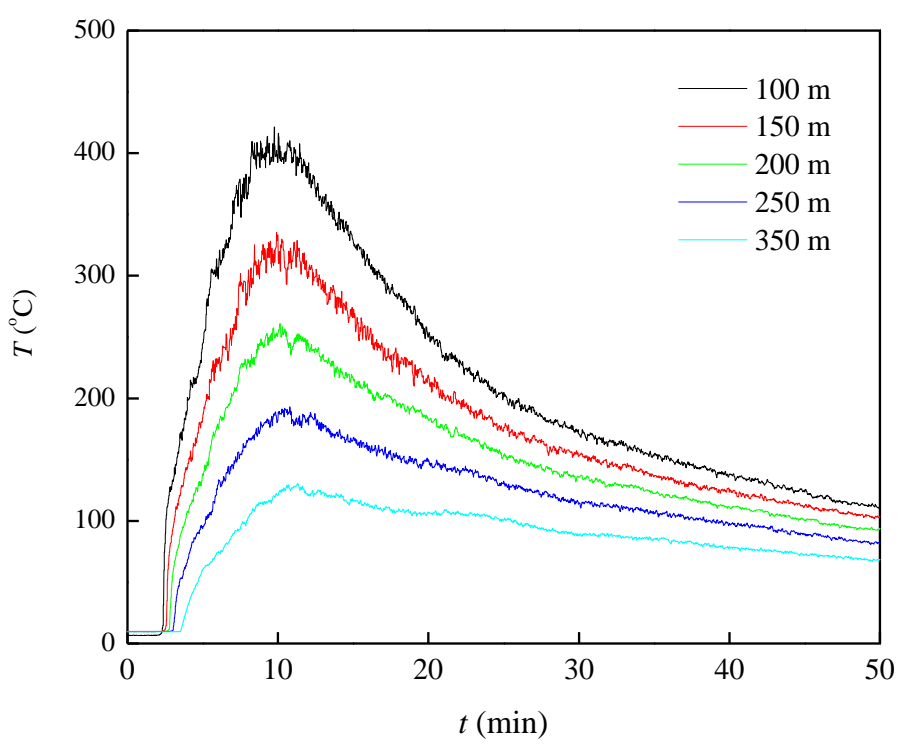

Figure D4 Ceiling temperature downstream of the fire, T3. 


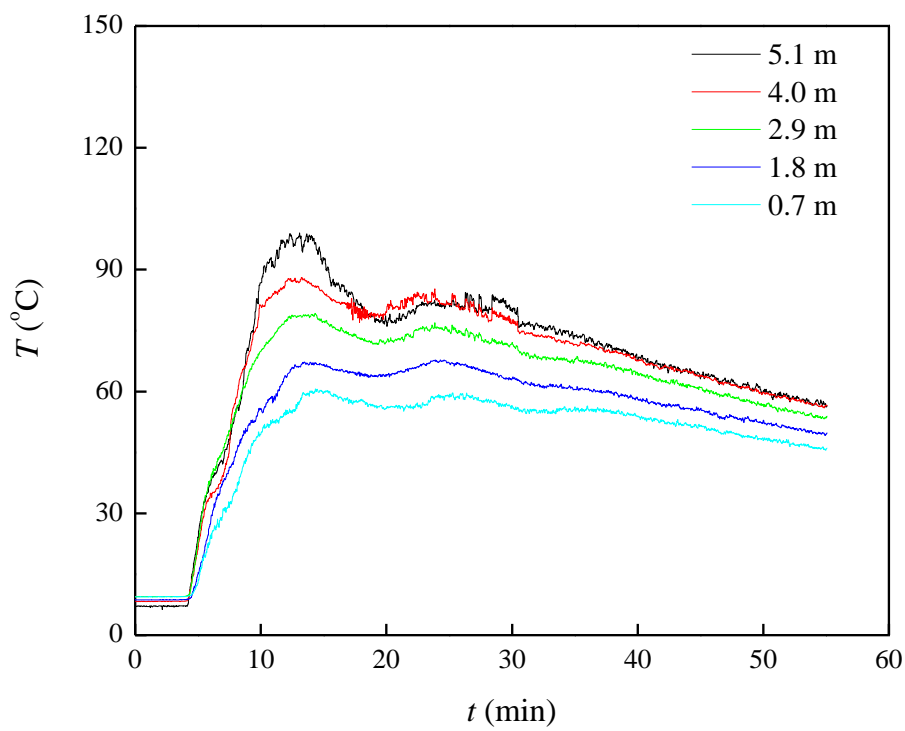

Figure D5 Vertical temperature distribution $458 \mathrm{~m}$ downstream of the fire, T3.

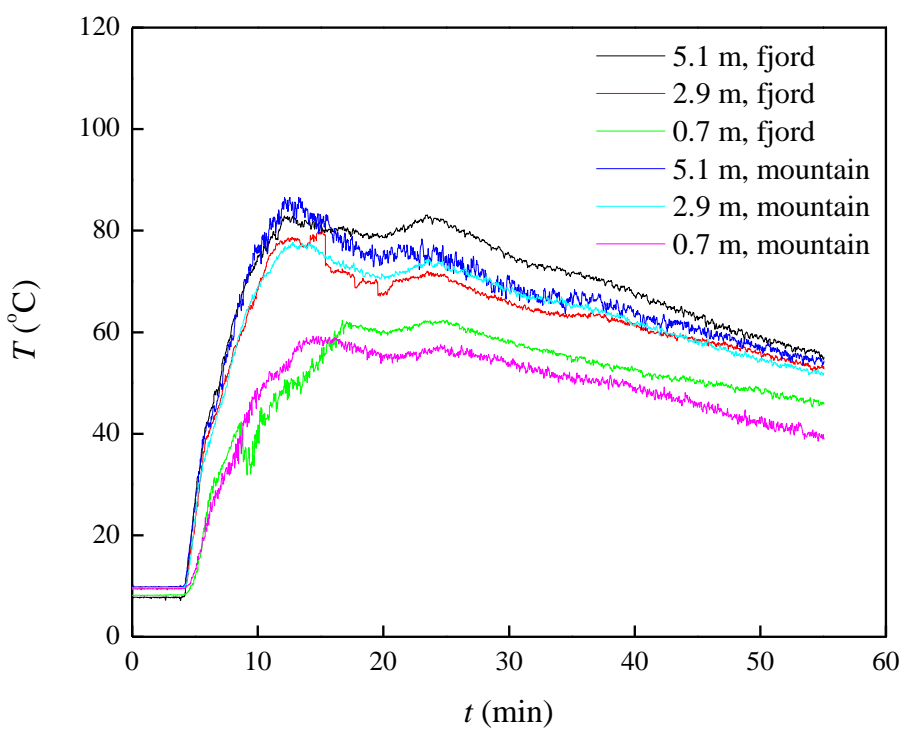

Figure D6 Lateral temperature $458 \mathrm{~m}$ downstream of the fire, T3. 


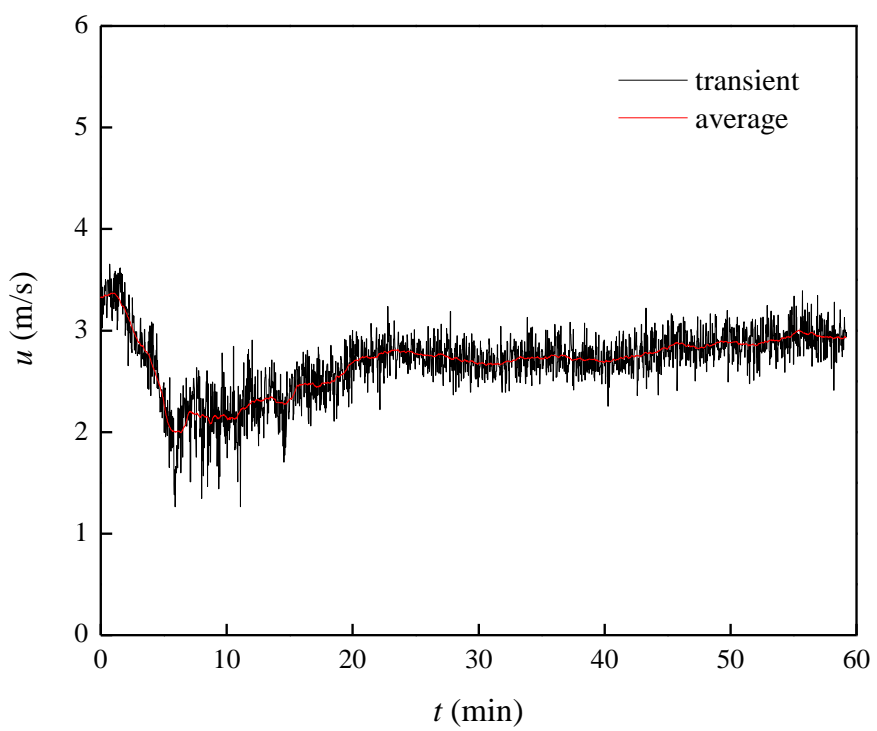

Figure D7 Measured central velocity $50 \mathrm{~m}$ upstream of the fire, T3.

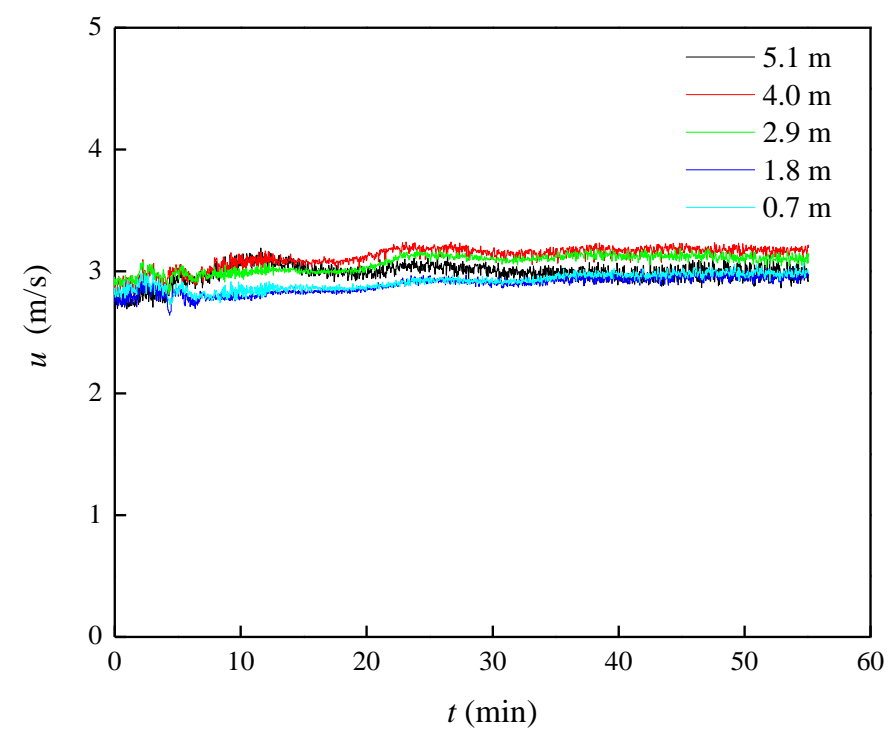

Figure D8 Measured central velocity $458 m$ downstream of the fire, T3. 


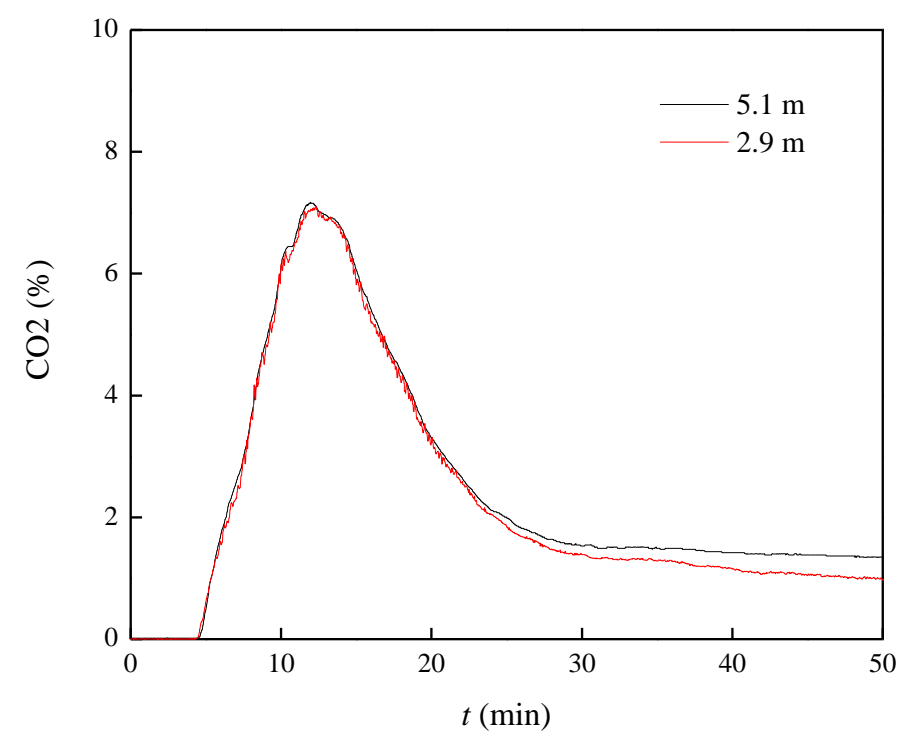

Figure D9 Measured $\mathrm{CO}_{2} 458 \mathrm{~m}$ downstream of the fire, T3.

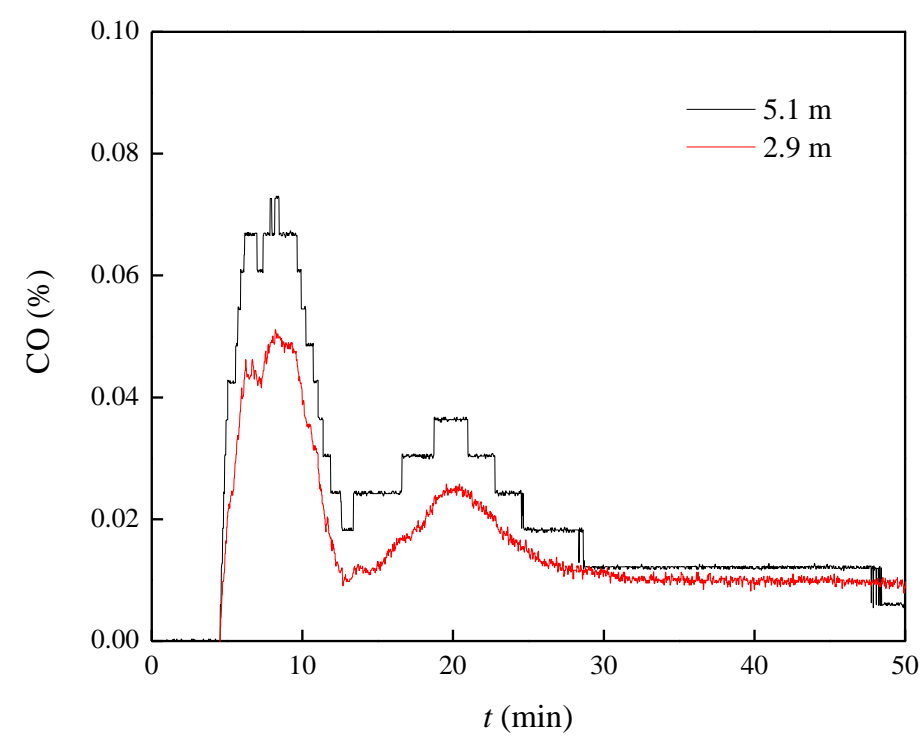

Figure D10 Measured CO $458 \mathrm{~m}$ downstream of the fire, T3. 


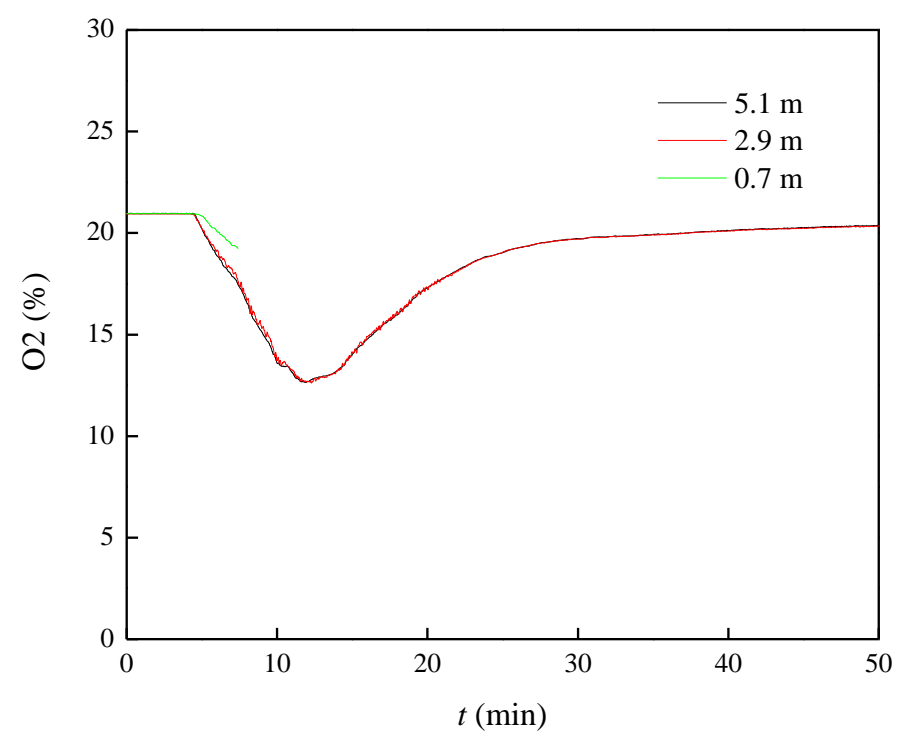

Figure D11 Measured $\mathrm{O}_{2} 458 \mathrm{~m}$ downstream of the fire, T3.

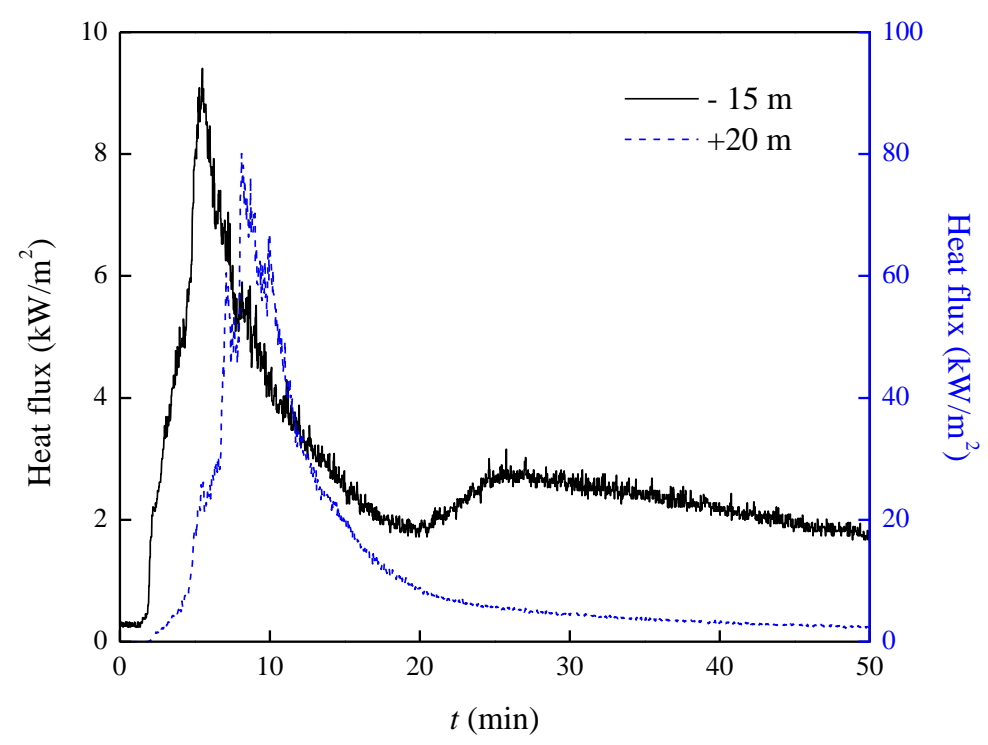

Figure D12 Heat flux measured by Schmidt-Boelter flux meter at two locations close to the fire, T3. The heat flux meter at $-15 \mathrm{~m}$ was towards the fire load and the heat flux meter at $+20 \mathrm{~m}$ was flush with the wall. Both were placed $1.6 \mathrm{~m}$ above the floor 


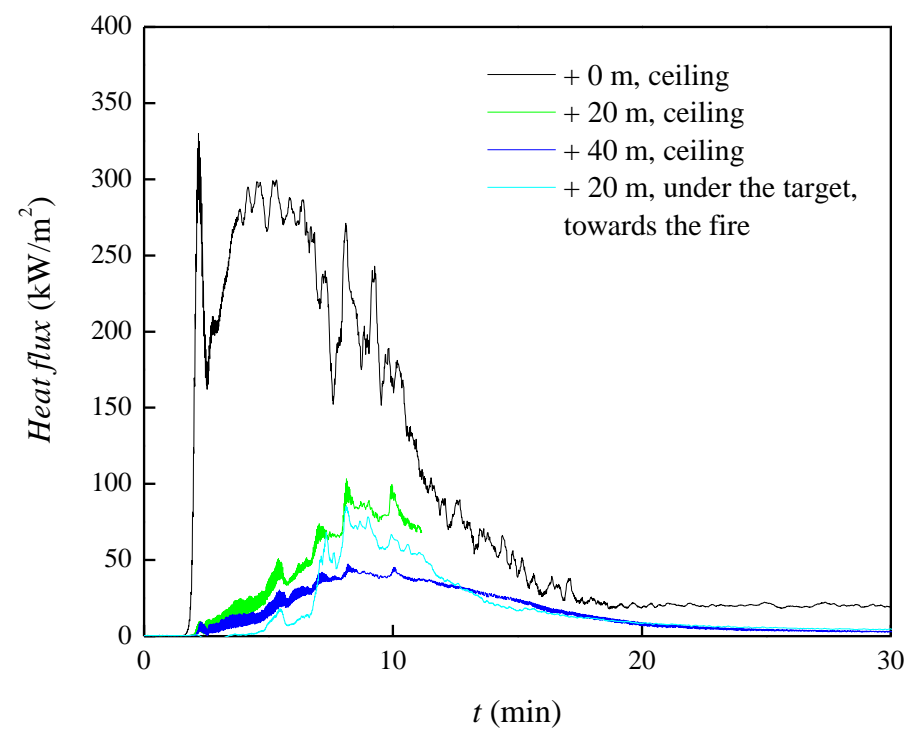

Figure D13 Heat flux measured by plate thermometer at the ceiling close to the fire, T3.

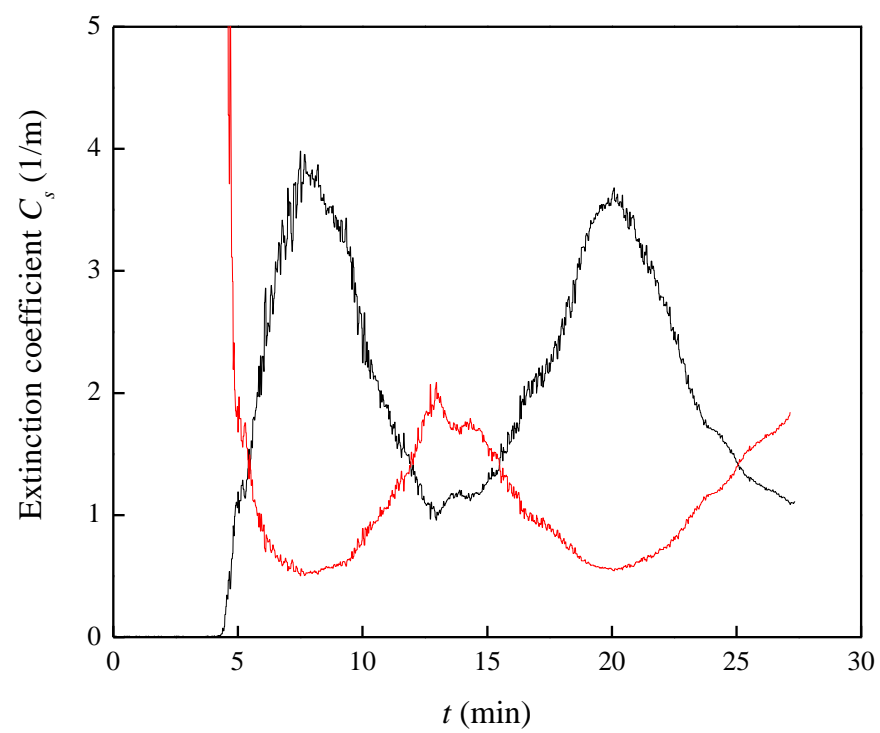




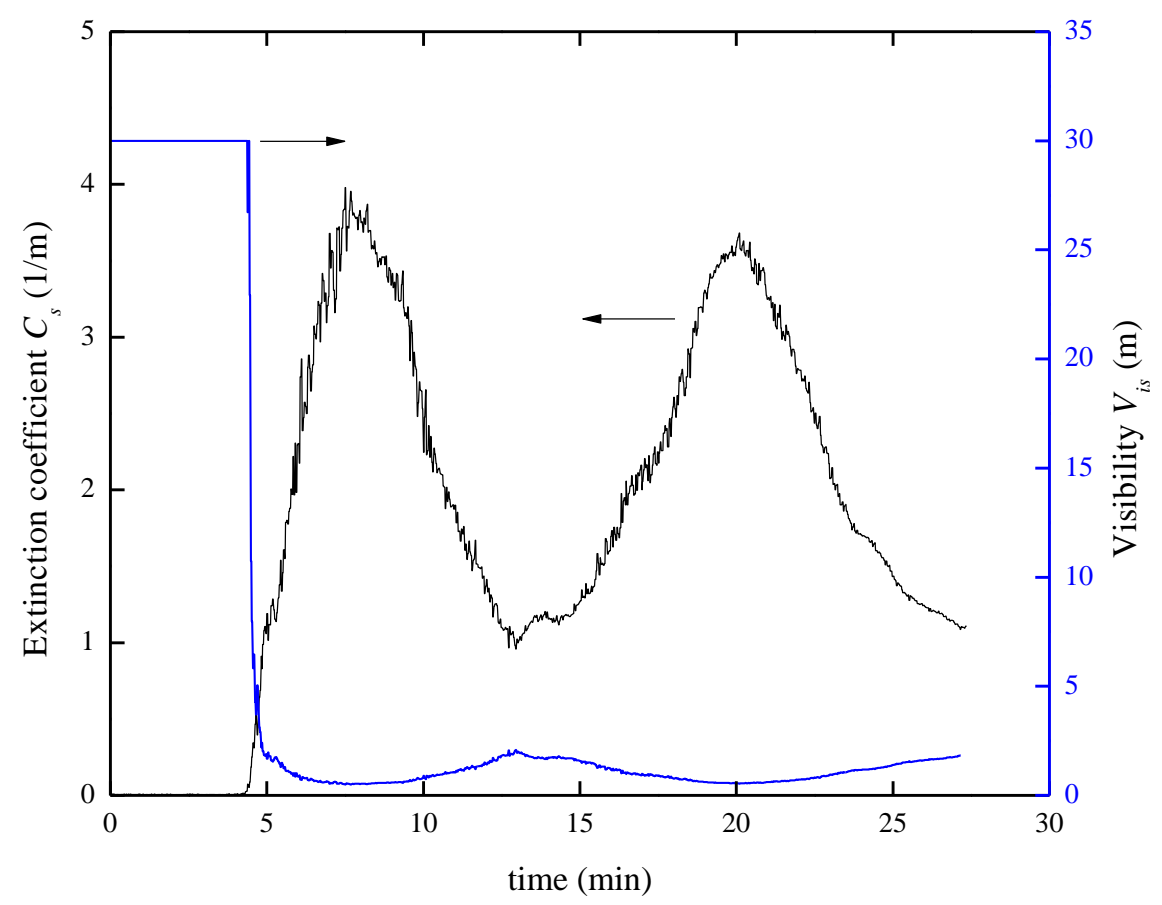

Figure D14 Measured extinction coefficient and estimated visibility at measurement station $+458 \mathrm{~m}, 2.9 \mathrm{~m}$ above floor, T3. 


\section{Appendix E Test Results - Runehamar test T4}

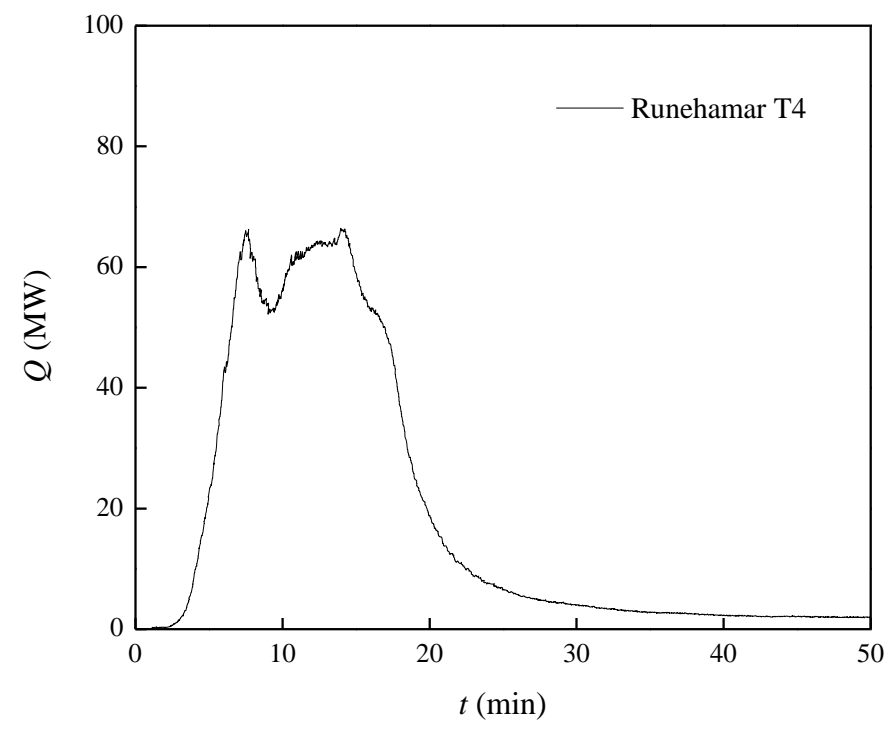

Figure E1 Measured heat release rate, T4.

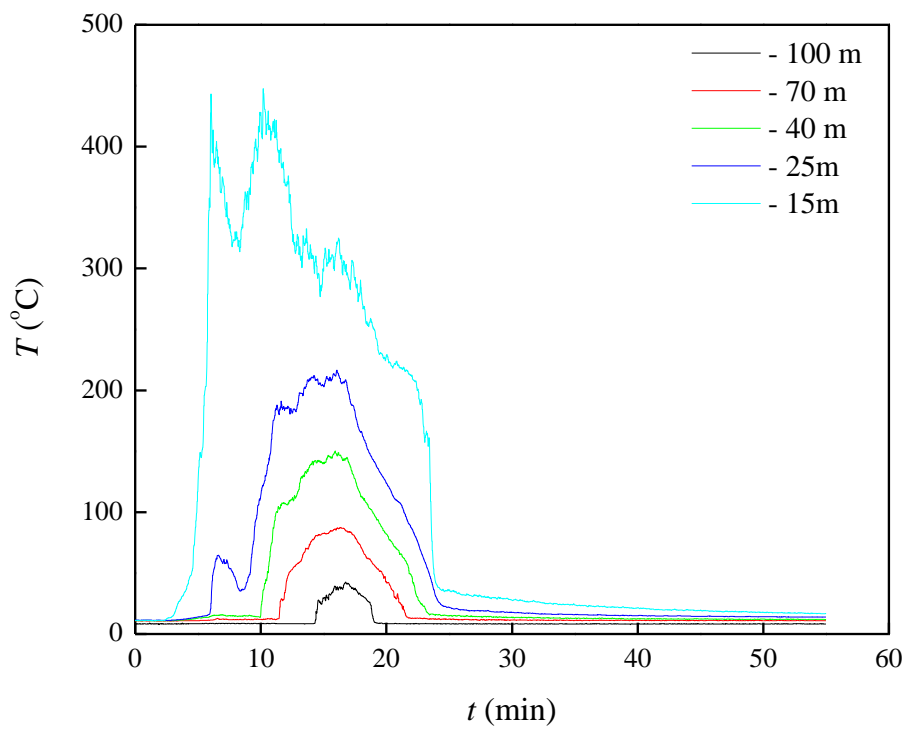

Figure E2 Ceiling temperature upstream of the fire, T4. 


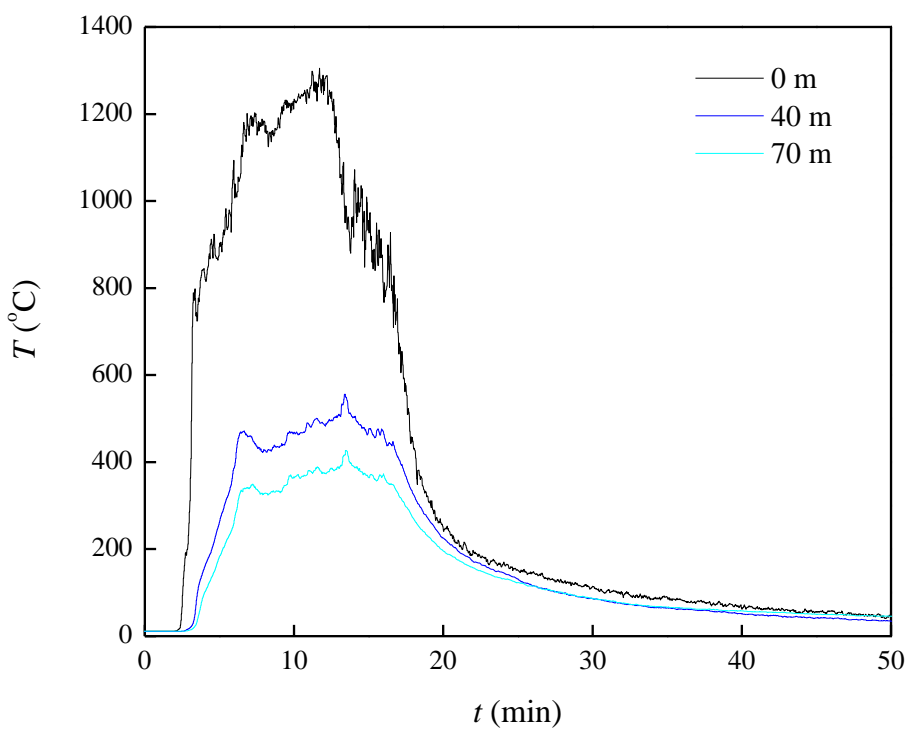

Figure E3 Ceiling temperature downstream of the fire, T4.

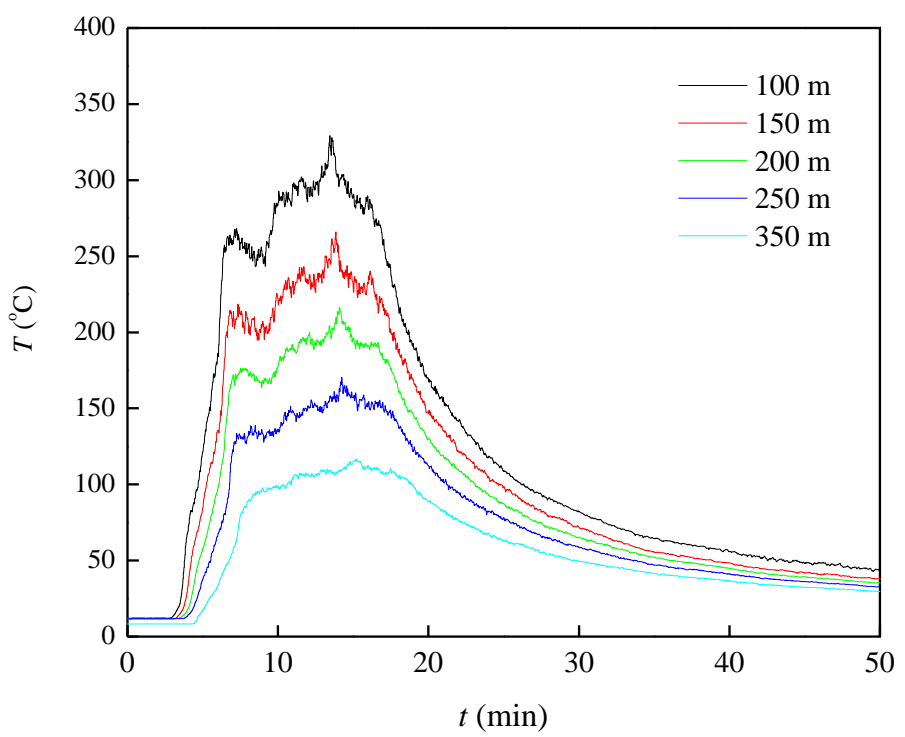

Figure E4 Ceiling temperature downstream of the fire, T4. 


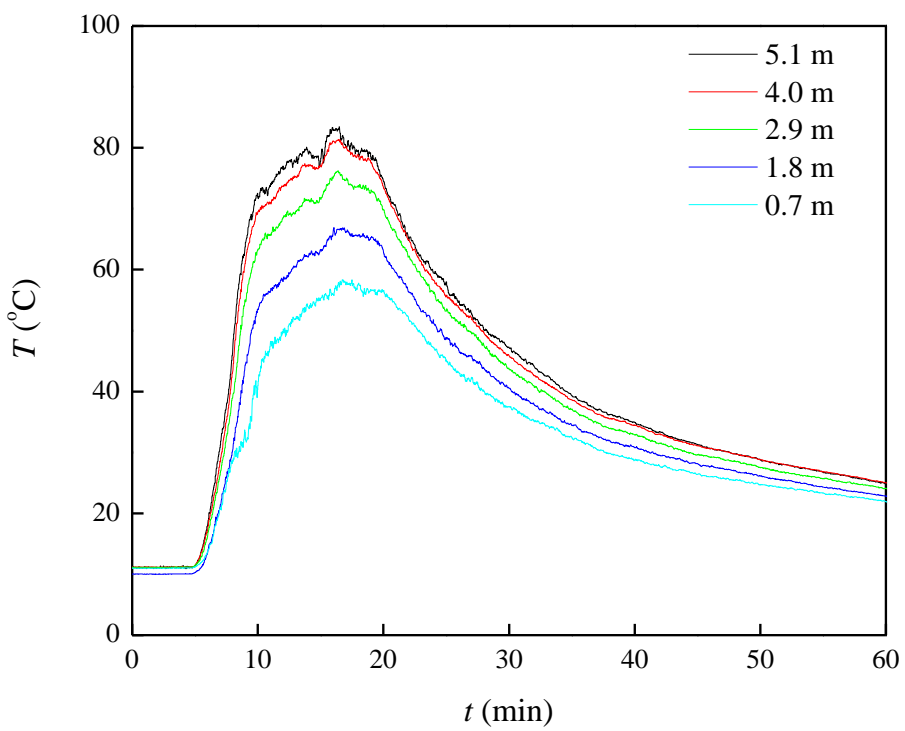

Figure E5 Vertical temperature distribution $458 \mathrm{~m}$ downstream of the fire, T4.

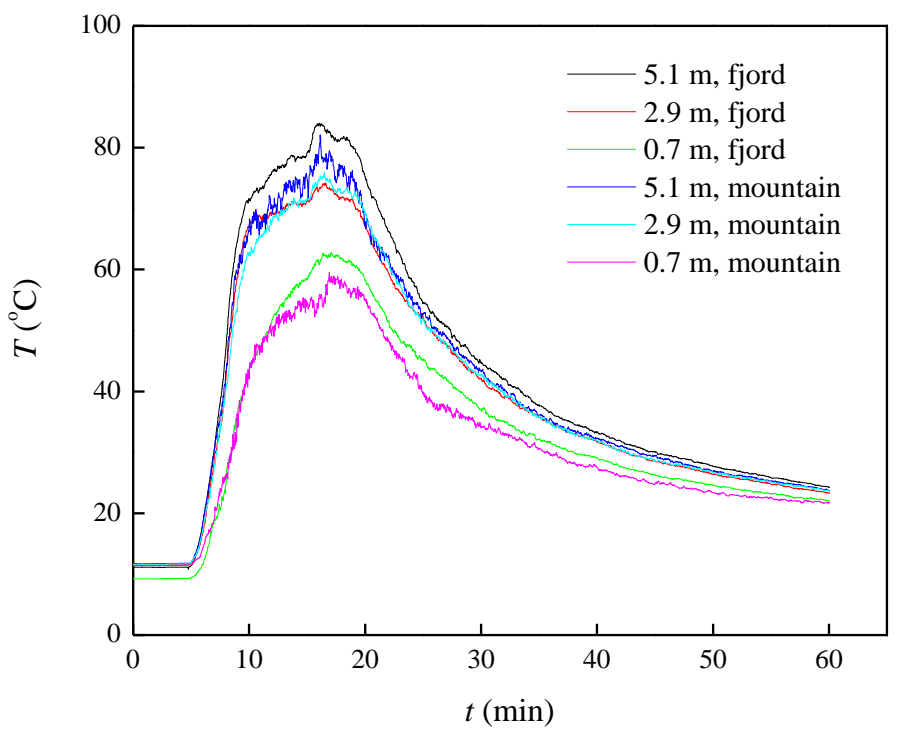

Figure E6 Lateral temperature $458 \mathrm{~m}$ downstream of the fire, T4. 


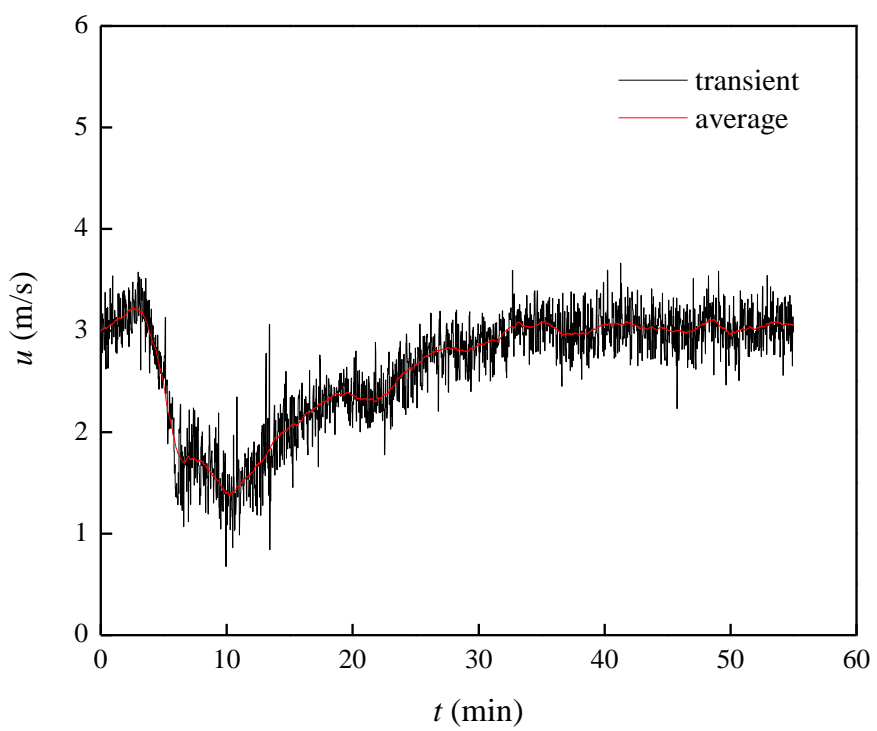

Figure E7 Measured central velocity $50 \mathrm{~m}$ upstream of the fire, T4.

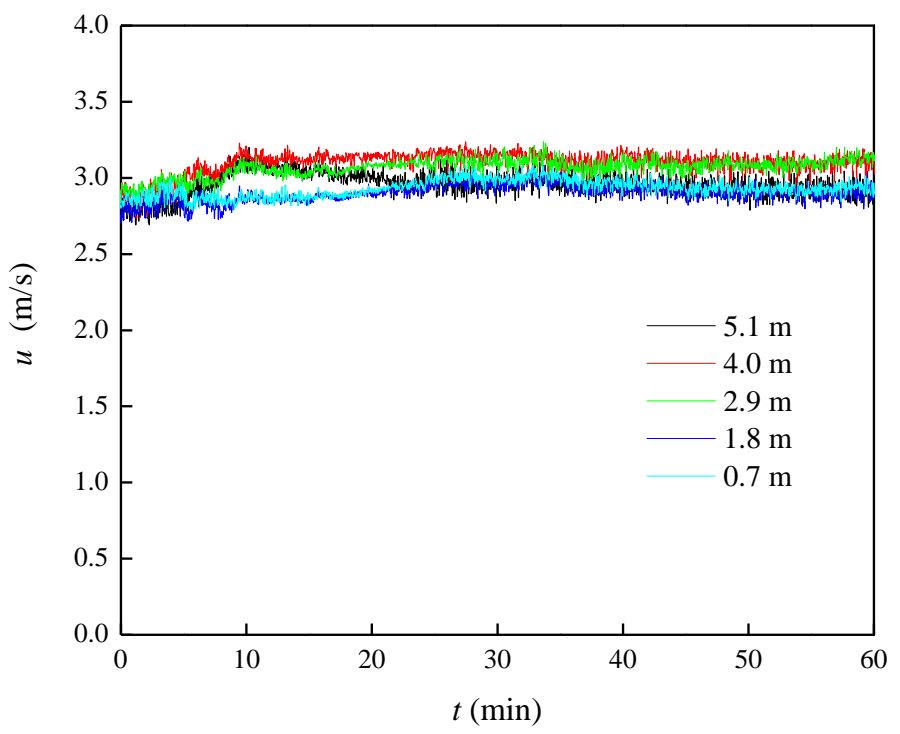

Figure E8 Measured central velocity $458 \mathrm{~m}$ downstream of the fire, T4. 


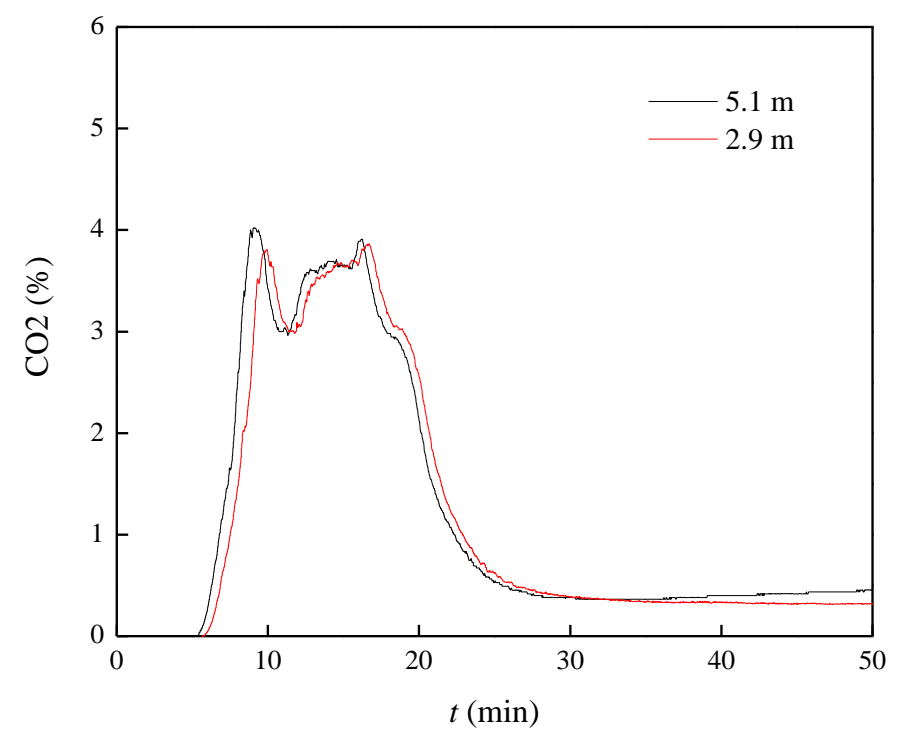

Figure E9 Measured $\mathrm{CO}_{2} 458 \mathrm{~m}$ downstream of the fire, T4.

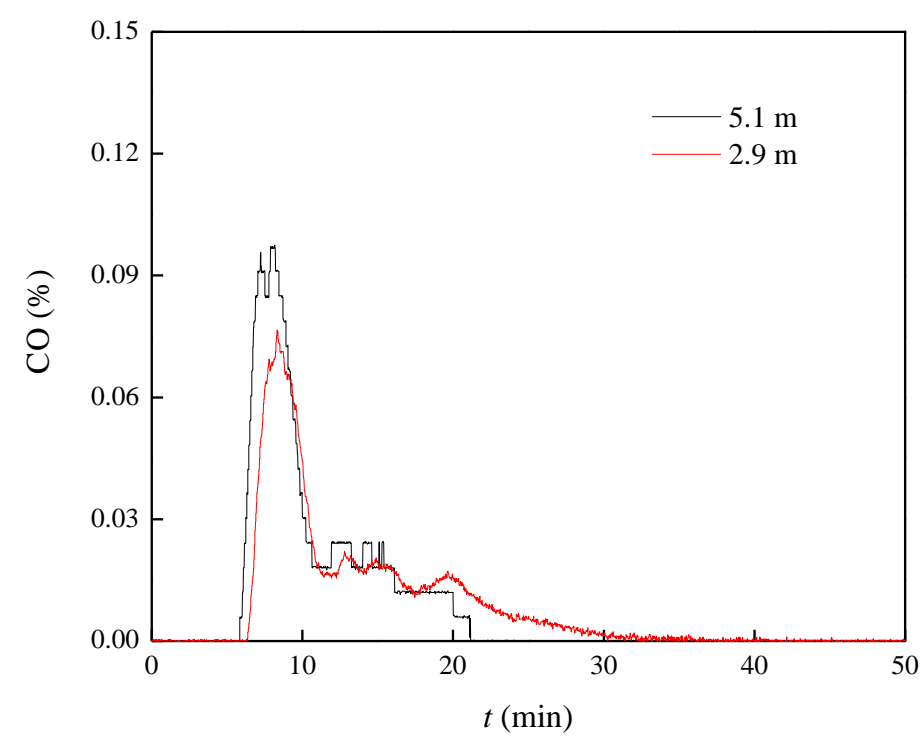

Figure E10 Measured CO $458 \mathrm{~m}$ downstream of the fire, T4. 


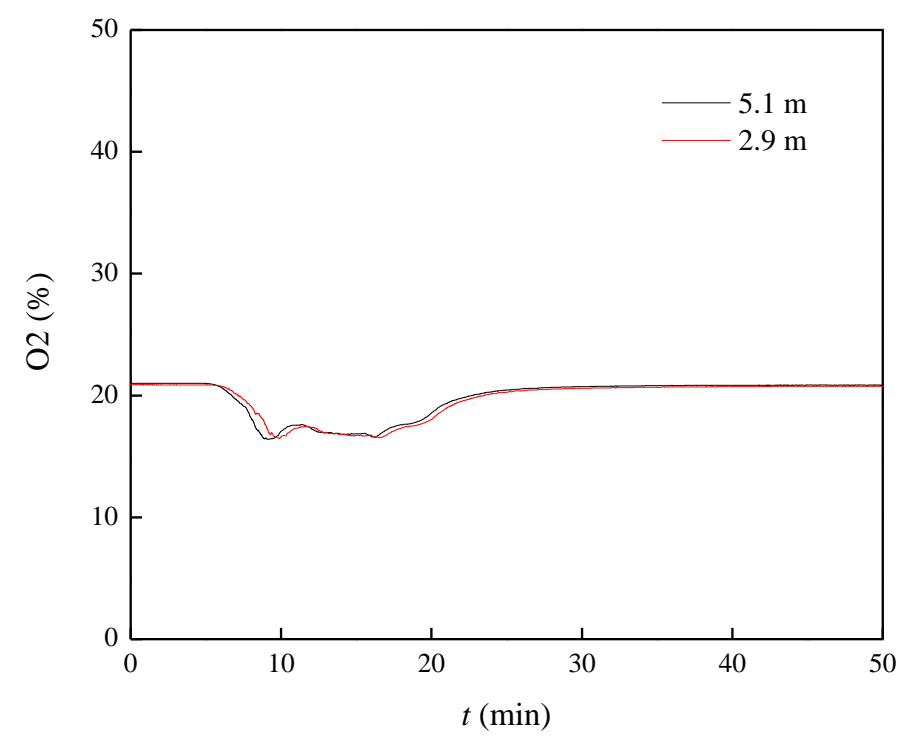

Figure E11 Measured $\mathrm{O}_{2} 458 \mathrm{~m}$ downstream of the fire, T4.

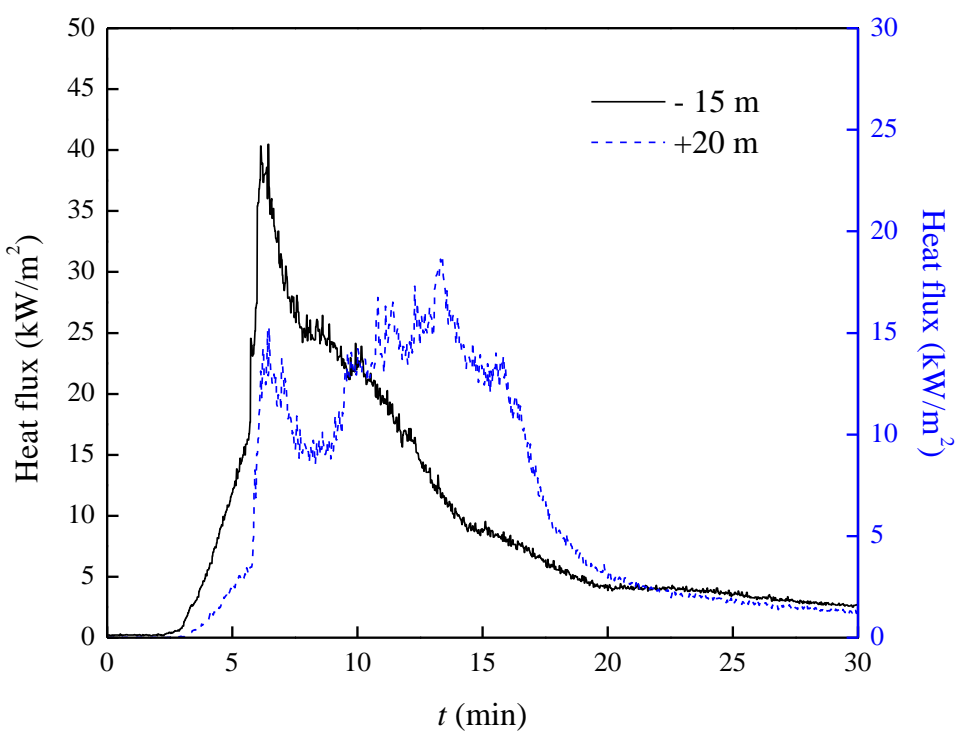

Figure E12 Heat flux measured by Schmidt-Boelter flux meter at two locations close to the fire, T4. The heat flux meter at $-15 \mathrm{~m}$ was towards the fire load and the heat flux meter at $+20 \mathrm{~m}$ was flush with the wall. Both were placed $1.6 \mathrm{~m}$ above the floor 


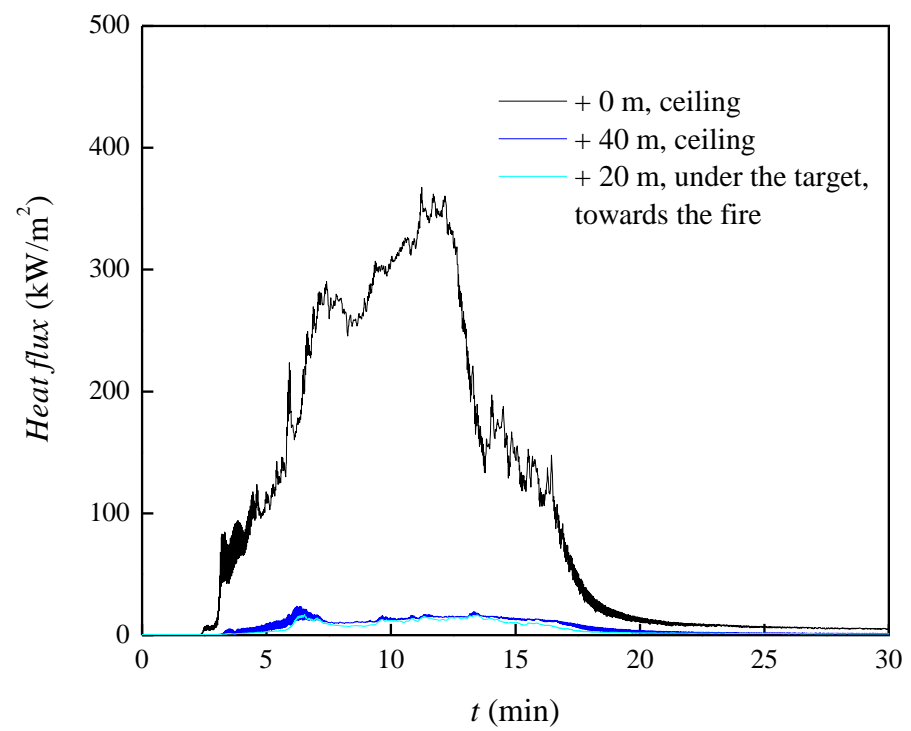

Figure E13 Heat flux measured by plate thermometer at the ceiling close to the fire, T4.

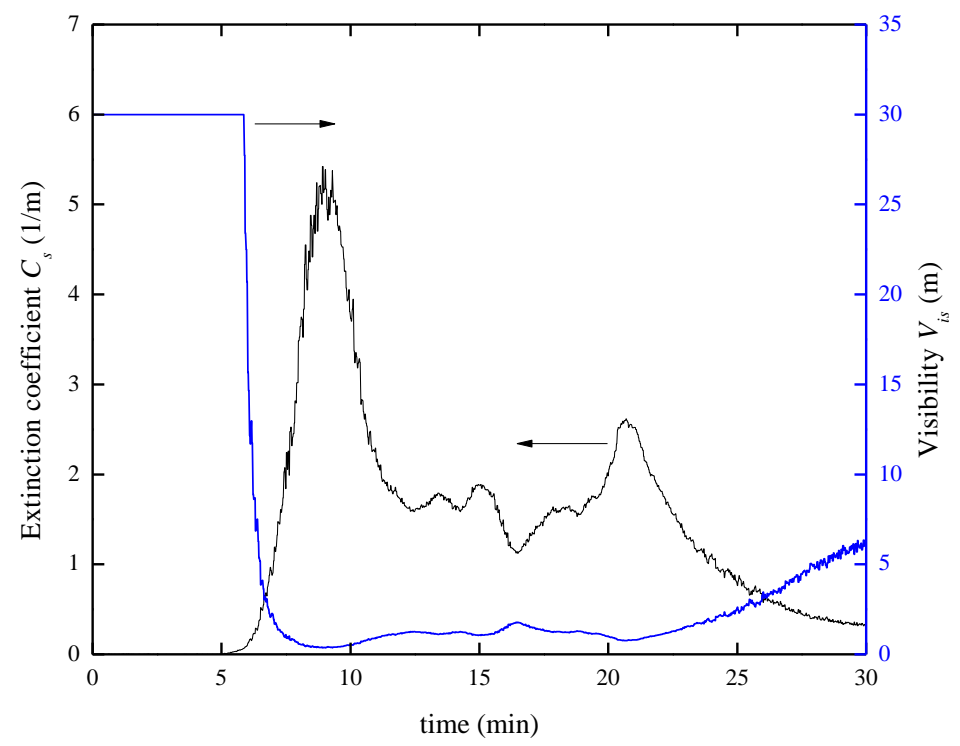

Figure E14 Measured extinction coefficient and estimated visibility at measurement station $+458 \mathrm{~m}, 2.9 \mathrm{~m}$ above floor, T4. 


\section{SP Technical Research Institute of Sweden}

Our work is concentrated on innovation and the development of value-adding technology. Using Sweden's most extensive and advanced resources for technical evaluation, measurement technology, research and development, we make an important contribution to the competitiveness and sustainable development of industry. Research is carried out in close conjunction with universities and institutes of technology, to the benefit of a customer base of about 9000 organisations, ranging from start-up companies developing new technologies or new ideas to international groups.

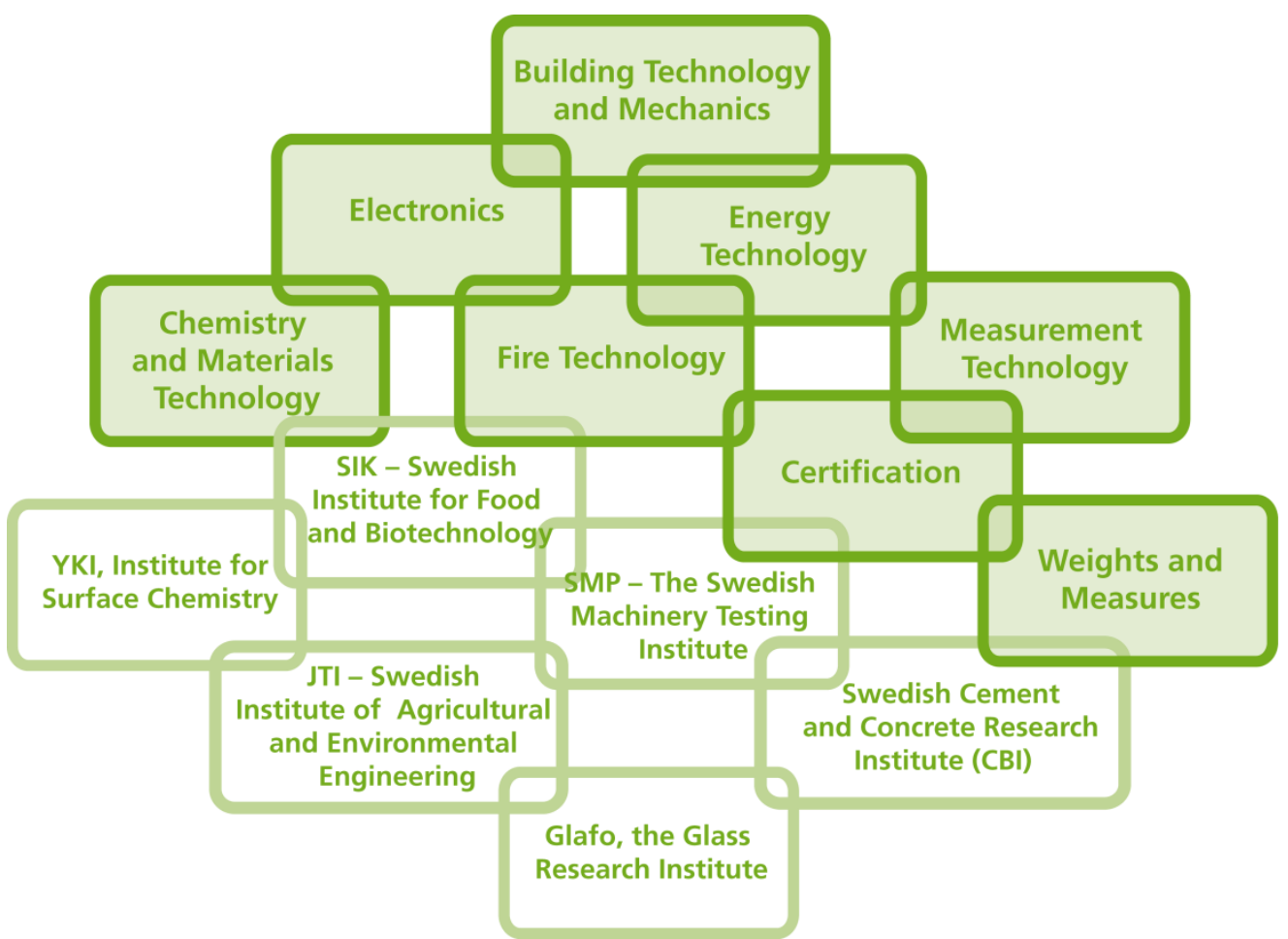

SP Technical Research Institute of Sweden Box 857, SE-501 15 BORÅS, SWEDEN

Telephone: +461051650 00, Telefax: +46 33135502

E-mail: info@sp.se, Internet: www.sp.se

www.sp.se
Fire Technology

SP Report 2011:55

ISBN 978-91-86622-85-5

ISSN 0284-5172

More information about publications published by SP: www.sp.se/publ 